$L B L--15180$

DE83 017678

\title{
METABOLIC CHANGES ASSOCIATED WITH SHOOT FORMATION IN TOBACCO CALLUS CULTURES
}

By

\author{
Karen Lee Grady \\ (Ph.D. Thesis) \\ Lawrence Berkeley Laboratory \\ University of California \\ Berkeley, California 94720
}

August 1982

This work was supported by the Assistant Secretary for Conservation and Renewable Energy, Office of Renewable Energy, Biomass Energy Technologies Division of the U.S. Department of Energy under Contract Number DE-AC03-76SF00098.

\section{MASTER}




\section{DISCLAIMER}

This report was prepared as an account of work sponsored by an agency of the United States Government. Neither the United States Government aor any agency thereof, nor any of their employees, makes any warranty, express or implied, or assumes any legal liability or respansibitity for the sccuracy, completeness, or usefulness of any information, apparatus, product, or process disclosed, or represents that its use would not infringe privately owned rights. Reference herein to any specific commercial product, process, or service by trade name, trademark, manufacturer, or otherwise does not necessarily constitute or imply its endorsement, resommendation, or favoring by the United States Government or any agency thereof. The views and epinions of authors expressed herein do not necessarily state or reflect those of the United States Government or any agency thereol. 
This report was done with support from the Department of Energy. Any conclusions or opinions expressed in this report represent solely those of the author(s) and not necessarily thase of The Regents of the University of California, the Lawrence Berkeley Laboratory or tite Depanment of Energy.

Reference to a company ol product mame does not imply epproval or recemmendation of the product by the University of Californiz or the "I.S. Department of Energy to the exclusion of others that may be suitable. 


\section{CARBOH METABOLISH OF SHOOT-FORMIMG AMD}

\section{MOH-SHOOT-FORAING TOBACCO CALLUS CULTURES}

Table of Contents

ACKNOWLEDGEMENTS .................. iv

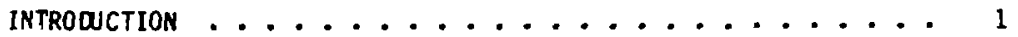
CHAPTER 1

LITERATURE SURVEY ................... 3

1. Hormonal Control of Shoot Formation ....... 4

2. Histology and UItrastructure of Shoot Formation ... 12

3. Physiological and Biochemical Changes Associated witn Shoot Fomation ......................... 15

a. Nucleic acids and proteins.......... 15

b. Carbohydrate metabolism ............. 19

c. Secondary products metabolism ........ 26

4. Molecular Mechanisms for Hormonal Regulation of

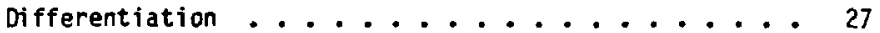

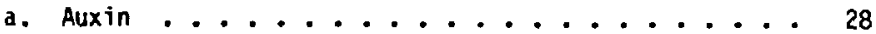

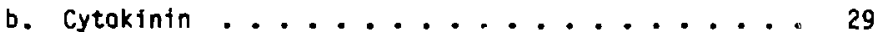

\section{CHAPTER 2}

GROHTH AND GEMERAL PHYSIOLOGY OF TOBACCO CALLUS CULTURES . . . 33

1. Methods for Growing Tobacco Plants ........ 33

2. Methods for Growing Tobacco Calius.......... 34 
3. Induction of Shoots from Tobacco Callus Cultures.... 35

4. General Phystology of Callus Cultures ....... 37

a. Growth rates of calli ............... 38

b. Chlorophyll contents of calli ........ 39

c. Starch contents of calli .......... 42

5. Chapter 2; Tables and Figures ......... 48

\section{CHAPTER 3}

SUCROSE METABOLISM IN NON-SHOOT-FORMING AND SHOOT-FORMING

TOBACCO CALlUS CULTURES ...................... 67

1. Methods for Studies of Sucrose Metabolism ...... 67

a. Assay for sucrose metatolism ........ 67

b. Extraction of callus tissues........ 69

c. Fractionation and chromatography of aqueous extracts 70

d. Fractionation of $\mathrm{MCH}$-insoluble macromolecules ... 73

2. Ethanol Interferes with Sucrose Metabolism ...... 74

3. Variability in Replicate Samples of Callus Tissue . . 75

4. Use of $0.3 *$ Sucrose for Metabolic Studies....... 79

5. Sucrose Metabol ism by NSF and SF Calli....... 89

a. Methous and general results ......... 90

b. Total incorporation of sucrose ........ 92

c. Hexose monophosphates synthesis ....... 94

d. Synthesis of malate and citrate, and release of $\mathrm{CO}_{2}, \quad 97$

e. Amino acid synthesis ............ 101

f. Lipid, protein, starch, and cell wall synthesis . . 112

g. Conclusions ...................... II5

6. Chapter 3: Tables and Figures ............ 117 


\section{CHAPTER 4}

METABOLITE CONCENTRATIONS IN MON-SHOOT-FORMING AND

SHOOT-FORMING TOBACCO CALLUS CULTURES . . . . . . . 141

1. Saturation of Metabolite Pools with Carbon-14 .... 142

2. Metabol ite Concentrations in NSF and SF Calli .... 147

a. Methods and general results ......... 147

b. Changes in carbon content and general metabolite

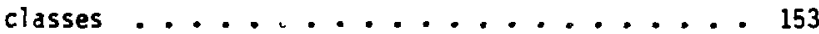

c. Sugar concentrations ............. 156

d. Malate and citrate concentrations ....... 158

e. Anino acid concentrations ......... 161

f. ACC concentrations .............. 170

g. Conclusions .........................

3. Chapter 4: Tables and Figures ......... 176

\section{CHAPTER 5}

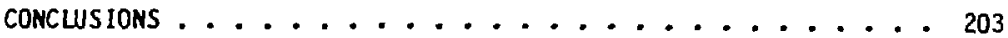

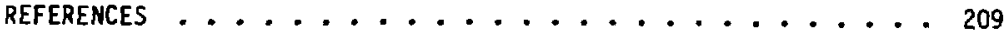




\section{ACXNONLEDGEMENTS}

I thank Al Bassham for the support and guidance which he has given me during the years that I worked at the Laboratory of Chenical Biodynamics. I also thank Lew Feldman for continued guidance and encouragement throughout my graduate research.

Without the friendship, assistance, conversation, and patience of many people in the this laboratory I might never have completed this project. I therefore express my appreciation to Chris Bayesdorfer, Karen Cornwell, Wally Erwin, Sherry Gee, Ben Gordon, Paul Hayes, Craig Hodges, Sheryi Krohne, Artie Lawyer, Andre Lazlo, Bruce Macler, Brad Peconon, and Steve Treon.

I tharik Russell Jones for his guidance, and for the fine example of a scientist which he provided; and espectally George Ellmore for awakening me to the wonders of the plant kingdom. I also thank many dear friends for their patience, support, and understanding during those difficult times inherent to biologica! ressach.

Special thanks go to Kenneth Gr..y, ky father, and Donna Grady, my mother, for their love and support whenever I needed it.

This work was supported by the issistant Secretary for Conservation and Renewable Energy, Office of Renewable Energy, Biomass Energy Technologies Division of the United States Department of Energy Contract No. DE-ACO3-76SF00098. 


\section{ABSTRACT}

Callus tissue derfied from Micotiana tabacum L. stem pith parenchyma cells was grown either on medium wich m: 'ntalns the callus In an undifferentisted state, or on mediu which induces the formation of shoots. Two complementary types of studtes were performed with the goal of establishing metabolic markers for the initiation of shoot fomation: one designed to characterize the flow of radioactive sucrose into varfous metabolic pools, and one which allowed measurement of Intermediary metabolite concentrations.

Many differences in rates and patterns of sucrose metabolism by non-shoot-forming (NSF) and shoot-forming (SF) calli were apparent within the first week after subeulture of undifferentiated callus tissue to NSF and SF media, respectively. Synthesis of hexose monophosphates was the primary rate-limiting reaction in sucrose metabolism of both types of calli. The increased rates of synthesis of hexose monophosphates by SF calli, relative to NSF calli, was reflected to varying degrees in all other intermediary metabolites. Differences between MSF and SF calli were most pronounced 7 days after subculture, and generally correlate with increased rates of cell division required for "meristemoid" formation in SF calli.

Greater rates of synthesis of many amino acids were observed in SF calli than in NSF calli. These differences are partially explained by increased amino acid concentrations in SF calli, al though there is also evidence for stimulation of secondary product formation during the development of shoots. Glutamine, glutamate, 
phenylalanine, and proline concentrations were greater in SF calli than in NSF calli one week after subculture.

Greater mounts of starch were al so abserved in SF cally than in NSF calli four days after subculture. This difference was maintained through 21 days, and was reflected in rates of starch synthesis in the two types of calli.

1-aminocyclopropane-1-carboxylic acid concentrations were greater in NSF cally than in SF calli. two days after subeulture. This difference was maintained during the first week of growth, and may reflect a mechanism whereby ethylene prevents organized development 


\section{INTRODUCTION}

The potential applications of plant tissue culture methods to the breeding of new varieties, and possibly new species, for agricultural use have received much attention in the past decads. In vitro techniques exist for the rapid propagation of cloned tissue. Through protoplast fusion, it is now possible to create samatic hybrids between species which are sexually incompatible. Selection schenes have been devised for the isolation of variant plant cells which show resistance to pathogenic toxins, herbicides, and high concentrations of salts. Research is rapidly progressing which may soon allow transfer of selected fragments of DKA from one genome to another. Yet fundamental to this research is the assumed ability to regenerate whole plants from the selected cells.

Though the totipotency of plant cells was demonstrated almost thirty years ago, regeneration of plants from in vitro cell cultures is not always possible. Many important crop species, especially cereals and grasses, remain resistant to attempts to regenerate whole plants from isolated cells. Even those species from which it is relatively easy to induce regeneration show considerable variability and loss of totipotency in culture, yet many selection programs incorporate extensive periods of manipulation in vitro. A thorough understanding of the biochenical events which dictate organogenesis in responsive species, such as tobacco, will elucidate causes for the lack of regenerative ability in other species and suggest remedies for the problem. 
The purpose of this research project was to study differences in carbon metabolism of Nicotiana tabacum L. (var. Wisconsin 38) callus tissues grown under conditions which either maintain the callus in an unorganized state, or which induce shoot formation. I sought to define biochenical characteristics of differentiation which could serve as early markers of shoot formation. These markers could be used to determine which changes in media fngredients elic,t biochenical changes in the callus tissue that are predictive of organogenesis.

Two complementary types of studies were performed: one designed to characterize the flow of radiaactive sucrose into various metabolic pools, and one which allowed measurenent of metabolite concentrations. In the former, callus tissue was incubated in $\left[\mathrm{U}-{ }^{14} \mathrm{C}\right]$ sucrose for periods up to one hour, and patterns of metabolite labelling in tissue grown on shoot-forming and non-shoot-forming media were compared. In the latter studies, tissue was grown for an entire subculture period on non-shoot-forming medium labelled with $\left[U-{ }^{4} C\right]$ sucrose, then subcultured to labelled non-shoot-forming or shoot-forming media, and sampled at intervals during the first week of growth. 


\section{CHAPTER 1}

\section{LITERATURE SURVEY}

This literature survey provides a general review of our current knowledge or cirose mechanisms controlling organ differentiation in vitro. A brief historical sketch is included for perspective. Homonal control of shoot formation from unorganized callus tissue is then discussed. A summary of histological and ultrastructural responses to shoot induction is presented to provide a frantework for reported alterations in tissue metabolism. The concluding section contains recent reports on the control of gene expression by auxins and cytokinins.

A complete survey of plant regeneration from tissue cultures is beyond the scope of this thesis. Elaboration of particular subjects can be found in recent review articles. Culture conditions used for the establishment of callus and subsequent regeneration of plants are reviewed by Gresshoff (19978), Hussey (1980), Murashige (1974), Narayanaswamy (1977), Reinert, et a1. (1977), and Yeoman and Macleod (1977); recent advances in the tissue culture of cereals and grasses are discussed by Vastl (1981); cytogenetic features of differentiation in callus tissues are reviewed by D'Amato (1977), Bayliss (1980), and Reinert, et al (1977); physiologicai and biochemical changes during callus differentiation are the subject of reviews by Aitchison, et al. (1977), Thcrpe (1980), and Tran Thanh Van (1981); and homonal regulation of RNA metabolism was reviewed by 
Jacobseri (1977).

\section{Homonal Control of Shoot Fomation.}

The ability of undifferentiated plant callus tissues cultured in vitro to regenerate shoots was first demonstrated by White in 1939 . Callus from proliferating procambial tissue of Nicotiana glauca $X$ Nicotiana langscorfii hybrids grew poorly when submerged in liquid medium. When subcsltured to semi-solid agar medium, vigorous growth was obtained, though there were no signs of argan differentiation. If this rapidiy growing callus was then refnoclilated in liquid mediam, shoot buds diffferentiated on the surface of the tissue. White proposed that the tnitiation of shoot buds was stimulated by the reduced oxygen supply in liquid medium.

Skoog (1944) confimed White's results using this hybrid tissue. His observations, however, suggested that oxygen gradients alone could not account for the induced shoot formation. For example, if large masses of tissue were present, he observed shoot formation in tissue exposed to air levels of oxygen. Skong (1944) also showed that addition of micromolar concentrations of auxins to the medium could inhib: shoot formation in this hybird callus under conditions wnich nomaliy permitted shoot formation.

Skoog and Tsui (1948) reported that adenine stimulated shoot romation in tobacco stem fragments and callus. They also showed that auxin would stimulate root formacion and inhibit shoot formation in the presence of adenine. Skoog and Tsui (1951), and Miller and Skoog (1953) extended these observations, and demonstrated an interaction based on the ratio, rather than the absolute amounts, of adenine and 
auxin. Relatively large quantities of adenine were required to counteract the inhibitory effects of auxin on shoot formation, (approximately 15,000 molecules of adenine/molecule of auxin), suggesting that adenine was a precursor to the actual caulogenic substance (Miller and Skoog, 1953).

Miller and coworkers (1955a,b, 1956) isolated a substance from autoclaved herring sperm DNA which stimulated cytokinesis when added in micromolar amounts to tobacco callus cultures. They naned this compound kinetin. In 1957 Skoog and Miller reported that organ formation from tobacco callus cultures is controlled by the qualitative interaction of kinetin and indole-3-acetic acid, or in more general terms, cytoktnins and auxins. Tobacco callus grown on media containing relatively high concentrations of auxin combined with Iow concentrations of cytokinin formed roots. Media containing low levels of auxin and high levels of cytokinin stimulated shoot formation. Amounts of these substances intermediate between those inducing roots and shoots favored the proliferation of unorganized callus tissue.

The ability of auxins and cytokinins to regulate organogenesis from plant tissues cultured in vitro has been demonstrated with many species. The absolute amounts of these hormones required for organ formation depend on the plant species, the length of time the tissue has been in culture, and unknown vartables peculiar to the different laboratories in which the research is conducted. Increased cytokinin / auxin ratios in the growth medium have induced shoot formation from callus tissues of the following dicotyledonous species; Anagillis arvensis (Bajaj and Mader, 1974), Arabidopsis thaliana 
(Negruti, et al., 1978), Calocasia esculenta (Abo El-Nil and Zettler, 1976), Calica papaya (Yte and Ltaw, 1977), Chrysanthemum "Bronze pride" (Hill, 1978), C1trus grandis (Chaturvedt, et al., 1974), Convovulus arvensis (Hill, 1967), Datura innoxia (Engvild, 1973), Gafllardta grandifolta (Binding, et al., 1981). Glyctne max (Oswald, et al., 1977), Lemna perpusilla (Chang and Hsing, 1978), Nicottana acuminata, ․․․ eluta, … glauca, N. langsdorffif, … longiflora, ‥ otophora, N. paniculata, N. plumbaginifolia, N. suaveolens, and N. sylvestris (Bourgin, et al., 1979), Medicago sativa (Oswald, et al., 1977), Pelargontum hortorum (Pillai and Hildebrandt, 1969), Petunia axillaris, P. hybrtda, P. inflata, P. parodif, and P. violaceae (Power, et al., 1976), pisum sativum (Gamborg, eć al., 1974), Populus tremuloides (Woiter, 1968), Senecto vulgarus (Binaing, et al., 1981), Sinapis alba (Bajaj and Bopp, 1372), Solanum dulcamara, S. luteum, and S. nigrum (Binding, et al., 1981), Solanum tuberosum (Shepard and Totteı:, 1977), Solanum xanchocarpum (Rao and Narayanaswami, 1968), Stylosani'es guyanesis (Meijer and Broughton, 1981), and Trifolium repens (0swald, et al., 1977).

With some dicots, shoot formation has been reported only after subculture from medium containing either auxin, or auxin plus cyiokinin, to hormone-free medium. Examples of this type include Coffee arabica (Sharp, et al., 1973), Medicago sativa (Saunders and Bingham, 1975), and Nigella sativa (Chand and Roy, 1981).

Medicago sativa callus displayed unique organogenic requirements. walker, et al. (1978) showed that wile transfer of callus tissue to a regeneration medium lacking growth regulators was necessary for the actual emergence of shoots and roots, an induction medium coniaining 
high levels of auxin and low levels of cytokinin favored shoot formation. Conversely, transfer of callus from an induction medium containing high concentrations of cytokinin and low concentrations of auxin promoted root formation. As mentioned above, raising the cytokinin / auxin ratto usually induces shoot formation from callus tissue, while lowering this ratio favors root formation. The apparent discrepency in the hormonal responses of alfalfa callus tissue is not easily reconciled. Posssibly other endogenous growth regulacors modify the auxin / cytokinin response. Complex interactions between different plant hormones are not uncommon.

Auxin appears to be the most important plant hormone regulating in vitro dedifferentiation and redifferentiation in many monocotyledonous species. The formation of callus tissue is often induced on medium containing high concentrations of the potent artificial auxin, 2,4-dichlorophenoxyacetic acid (2,4-D). Shoot formation is subsequently induced on medium either lacking hormones, or containing very low levels of auxin. Spectes for which this protocol has been effective include Avena sativa (Carter, et al., 1967). Haworthia turgida (Kaul and Sabharwal, 1972), Hordeum vulgare (Cheng and Smith, 1975), Oryza sativa (Nishi, et al,, 1968), Panicum miliaceum (Rangan, 197a), Pennisetum americanum (Vasil and Vasil, 1981), Saccharum hybrids (Barba and Nickell, 1969), Sorghum bicolor (Masteller and Holden, 1970), and Zea mays (Green and Phillips, 1975).

With some monocots, for example Allium cepa (Fridborg, 1971), Asparagus officinalis (Bui Dang $\mathrm{Ha}$, et al., 1975), and Panicm maximum mature enbryos (Lu and Vasil, 1982), low levels of cytokinin were used in conjunction with decreased auxin concentrations to induce shoot 
formation from callus.

Unfortunately, most attempts to regenerate plants from unorganized callus tissue of many cereals and grasses have been unsuccessful (Vasil, 1981). This is reflected in the relative numbers of monocotoledonous and dicotyledonous species listed above. Presumably cells from all plant species are potentially totipotent, and this will be demonstrated once the appropriate culture conditions for each species are defined.

It is most important to recognize that endogenous fhytohomone levels are responsible for the davelopmental events which culminate in organogenesis in vitro, and that these may change during culture of callus tissue (Gresshoff, 1978). The hormone balance of the explant used to initiate callus depends on the source organ and tissue (Goodwin, 1978). Murashige (1974) reported that stem explants nearer the shoot apex of tobacco planis produced more adventitious shoots and roots than explants from the basal region cultured on identical medium. Similarly, Lu and Vasil (1982) found differences in the homenal requirements for regeneration of plantlets from callus derived from immature and mature embryos of Panicum maximum. Regeneration from callus of irmature embryos was obtafned via somatic embryogenesis, and was induced by reducing the amount of exogenouslysupplied auxin. In callus tissue derived from mature embryos, regeneration occurred via shoot bud fomation, and required the addition of both a cytokinin and coconut milk to medium with reduced auxin levels.

Though callus is often referred to as undifferentiated tissue, biochemical studies show that calli initiated from different organs 
matntain features of the primary explant after several subcultures in vitro. Arnison and Boll (1974) reported characteristic differences in isoenzyme patterns for several enzymes isolated from Phaseolus vulgaris callt dertved from different organs on the sane seedling plant. These cultures had been maintained for three years prior to the study. Raff, et al. (1979) demonstrated that prunus aviun calli derived from different plant organs retain specific antigenic features through at least four subcultures.

Perhaps endogenous homone synthesis in callus is also a persistent feature which is difficult to modify in vitro. Supraoptlmal homone concentrations may possibly explain the reluctance of callus from sone species to form shoots.

Calli from many of the dicotyledonous and monocotyledonous species mentioned above wil! no longer regenerate plants after only a few subcultures. In some cases this may be attributed to a charige in endogenous homone levels, and can be corrected by modification of the regeneration medtum. For example, after 16 weeks in culture only 1 \%

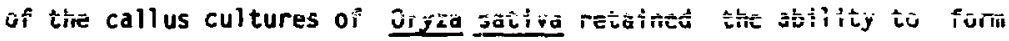
shoots on medium lacking hormones, though 50 \% had formed shoots on this medium $B$ weeks after explantation. Subculture to medium containing cytokinin resulted in shoot fomation in $15 \%$ of the 16 week-old calli (Henke, et al., 1978). Negrut1, et al. demonstrated the impact of the hormonal composition of previous culture media on the shoot-foming ability of Arabidopsis thaliana callus.

The accumulation of supra-optimal concentrations of gibberel]ins during culture may sometimes explain an observed decrease in 
regenerative ability. Murashige (1964) reported that shoot formation from N. tabacum callus tissue couid de compietely innidited by gibberellic acid $\left(10^{-6} M \quad G_{1,3-9}\right)$. Thorpe and Meier (1973) demonstrated that the repression of shoot fomation in tobacco callus by gibberellin was not reversed by increasing the concentration of auxin and cytokinin in the growth medium. Lance, et al.., (1976) showed that tobacco callus tissue contains endogenous gibberellns, and that. their concentration varies with culture conditions. An antagonistic role for gibberellins in shoot formation has diso been reported for cultures of Begonia rex (Schraudolf and Reinert, 1959), Bryophyilum tubiflorum (Marcelle, 1970), Cichorium intybus (Bessemer, et 21., 1969), Datura innoxia (Engvild, 1973), and Plumbago indica (Nitsch and Nitsch, 1967). On the other hand, gibberellins stimulate shoot formation in Arabidopsis thaliana (Negruti, et al., 1978), Cardamine pratensis (Paulet and Nitsch, 1959), and Chrysanthamum (Earle and Langhans, 1974).

The depressed morphogenic potential exhibited by tobacco callus tissues after prolonged culture has been correlated with an increased frequency of cells with an aneuploid chromosome number (Murashige and Nakano, 1967). Sinilar results were reported for Arabidopsis thaliana (Negruti, et al., 1978), Daucus carota (Muir, 1963), Pisum sativum (Torrey, 1967), and Saccharum sp. (Heinz, et al., 1969). Sacristan and Melchers (1969), however, reported regeneration of a wide spectrum of aneuploid tobacco plants from tumorous and nomal callus cultures which also exhibited aneupioid chromosome numbers. Cytogenetic abnomalities, including aneuploidy and chromosame breakage, were also reported for greater than $50 \%$ of the plants 
regenerated from Avena sativa tissue cultures (McCoy, et a1., 1982).

Though auxins and cytokinins are generally the most effective organic supplements for inducing organ differentiation in callus cultures, many other compounds also affect this process, often by modifying the metabolism of the natufal growth regulators. For example, Skoog and Miller (1957) reported that addition of L-tyrosine enhanced shoot formation from tobacco tissue cultures. Subsequently, Lee and Skoog (1965a) conducted a systematic survey of the effects of hydroxy- and methoxy-substituted phenol and benzoic acid derivatives an shoot formation from tobacco callus cultures. They found the monohydroxy derivatives, substituted in the ortho or para position, were best able to stimulate bud fomation in the presence of nomally inhibitory ratios of auxin / cytokinin. In a separate report, Lee and Skoog (1965b) demonstrated that the shoot-forming activity of many of these compounds paralleled their abslity to enhance the rate of in vitro inactivation of IAA. Though L-tyrosine did not promote IAAinactivation, it was suggested that a metabolic product of this amino acid might stimulate IAA oxidation in vivo.

Citrus tissue cultures required orange juice in the culture medium for growth (Murashige and Tucker, 1969), and this could not be replaced by IAA, 2,4-D, GA 3 , or xinetin. Erner, et al. (1975), partially purified the active component from orange jufice, and showed that it could be replaced by citric acid. The activity of this organic acid may be explained by its ability to promote IAA destruction via IAA-oxidase, as was demonstrated using tobacco callus cultures (Loewenherg, 1965).

Coconut milk has often been used interchangeably with kinetin to 
promote bud formation in various callus culture systems (Murashige, 1974). Many diverse substances with biological activity are present in coconut milk, including myo-inosital and 1,3-diphenylurea (Shantz and Steward 1955). Zeatin and zeatin riboside account for most of the cytokinin activity found in this natural complex (Letham, 1974, and van Staden and Drewes, 1975). Nevertheless, other unidentified compounds which stimulate bud formation must also be present, as attempts to replace coconut milk with cytokinins are not always successful.

There are many isolated examples of rather bizarre substances which promote shoot formation in tissue cultures. For example, tobacco smoke components, (benz(a)anthracene, benzo(a)pyre..e, benzo(e)pyrene, dibenz(a,h)anthracene, pyrene, and chrysene) all stimulate bud formation in the absence of auxins and cytokinins in tobacco callus cultures derived from haploid plants (Kochhar, et al., 1971). These compounds did not induce organogenesis from callus abtained from diploid tobacco plants.

\section{Histology and U? trastructure of Shoot Formation.}

Maeda and Thorpe (1979) reported no difference in the histology of tobacco callus grown for one week on shoot-forming medium and the original inoculum. However, by ten days noticeable changes had occurred. The initial inoculum was surrounded by relatively uniform cell files, apparently the result of repeated periclinal divisions in a recently-formed cambial layer followed by cell elongation. Tracheary elements were observed at the border between the inoculum and the cell files. Discrete clusters of meristematic tissue, 
"meristemoids", were also observed at the base of these cell files. ["Meristemold" cells are characterized by their small size, thin walls, densely-staining nuclet and cytoplasm, and apparent lack of vacuoles (Torrey, 1966)]. As these features are also characteristic of dividing cells found in meristenatic regions of whole plants, the term "meristemold" is used to distingutsh similar regions which arise de nova in cultured tissue). Cell division activity was initially more pronounced in the lower part of the tobacco callus, but soon became approximately equal throughout (Maeda and Thorpe, 1979). Broad files of cells which often contained large starch grains protruded from those regions of the callus which were in contact with the medium. Starch grains were also noted in centrally-located cells.

Two weeks after subculture the protrusions into the medium had advanced, and the cell strands observed within these were apparently derived from isodiametric cells located near the center of "meristemoids" (Maeda and Thorpe, 1979). Shoot-apex-like structurec had formed where the cell strands contacted surface cell layers. Starch grains were no longer observed in the strands. Though shoot meristems were initially ot served in the lower part of the callus, they were later distributed throughout the surface tissue. The actual emergence of visible shoots was not observed until approximately 28 days after subculture. This macroscoptc event was not synchronous in all calli, and was staggered over a period of about four days.

Similar patterns of de novo shoot development were reported for Convovulus (Earle and Torrey, 1965), corn (Springer, et al., 1979), endive (Vastl and Hilebrandt, 1966), and Panicum (Ranger, 1974) callus tissues. In these studies, snoot buds also formed at or near the 
surface of the tissue. Earle and Torrey (1965) noted the presence of starch-storing cells, crystal-storing cells, cellular filaments, and scattered tracheary elements, though the relationship of these specialized features to the shoot meristems was not reported.

In contrast to the organized patterns of cell division observed in shoot-forming callus, non-shoot-forming tobacco callus tissue proliferates by more random division of vacuolatec parenchymatous cells (Thorpe and Murashige, 1970). These divisions generally occur near exposed margins of the tissue (Aitchison, et al., 1977).

An ultrastructural study of shoot fomation in tobacco callus concentrated on features of the "meristemoid" ceills (Ross, et al., 1973). Eight days after subculture, these cells contained large accumulations of plastid starch and paracrystalline inclusions which were presumably proteinuceous. Numerous small vacuoles filled with membranous and cytoplasmic protrusions were observed in the periphery of the meristematic cells. The authors suggested that these prrterusions were involved in the reduction of vacuolar volume, and may have provided a means for dispensing storage products into the cytoplasm. None of these features were observed in "meristemoid" cells of callus grown on shoot-forming medium for two weeks. Plastid starch and paracrystalline inclusions were always observed in nomeristematic regions of shoot-forming tissue, as well as in nonshoot-forming tissue. 


\title{
3. Physiological and Biochemical Changes Associated with Shoot
}

\author{
Formation.
}

\section{a. Mucleic acids and proteins.}

Cytokinin-stimulated bua formation in the moss Funaria hygrometrica was accompanted by a 15-fold increase in the total RNA content of meristematic bud cells, compared to non-dividing protonematal cells (Schnetder, et al., 1969). Bud cell RNA also contained altered adenine:guanine ratios, suggesting specific changes in transcription. These measurements were taken two weeks after subculture, at which time buds were visible in the cell filanents. No differences in DNA content or composition were observer between the two cell types.

Using histochemical techniques, Thorpe and Murashige (1970) observed more dense staining for ONA and RNA in shoot-forming regions of tobacco callus after eight days of growth on shoot-forming medium. The apparent increase in DNA content was attributed to the higher cell density in differentiating zones, which cuincided with regions of preferential cell division. The increased staining for RNA was not attributed solely to the increased cell density, however, as this feature was also observed in large vacuolated cells located near the sttes of organ inftiation.

Sekiya and Yamada (1978) measured the activity of isolated DNAdependent RMA polymeiase If from three types of tobacco callus cultures. This enzyme is belfeved to catalyze the first step in transcription of messenger RilA. Undifierentiated callus, harvested three days after subculture to medium supplemented with $\angle, 4-D$, and 
callus with well-formed shoots possessed similar levels of enzyme activity. Relative to these two types of callus, the activity of the enzyme was reduced by approximately one-haif in callus harvested three days after subculture to medium containing kiretin at a concentration which inciuced shoot formation. The reduced activity of RNA polymerase was correlated with the decreased growth rate observed in callus recently transferred to shoot-forming medium. These results are not necessarily inconsistent with observations of increased RNA content in shoot-forming regions, as the measurements of polymerase activity were taken much earlier than the histuchenical changes noted by Thorpe and Murashige (1970).

Syono (1965) included chloramphenicol, an inhibitor of protein synthesis, in the shoot-forming medium for carrot callus tissues, and observed an inhibition of shoot formation. Cuncentrations of the inhibitor were use'j which did not decrease the growth rate of callus. Syono(1965) postulated an essential role for protein synthesis in the differentiation process.

A histoclemical comparison of protein content in shoot-forming and non-shoot-foming regions of tobacco callus revealed increased amounts of protein in "meristemoid" regions. This may have reflected the increased cell density in these areas, however, and not an increase in protein concent per cell (Thorpe and Murashige, 1970).

There was a sharp increase in the specific activity of protein extracted from shoot-iorming callus cultures during the first six days of growth on medium containing $\left[{ }^{14} \mathrm{C}\right]$ tyrosine (Hasegaiwa, et al., 1977). Though the incorporation of radioactivity into protein continued through fifteen days, the rate was less than that observed during the 
early phases of growth. These results suggested rapid protein synthesis following subculture to shoot-forming medium, but because the obvious comparison with non-shoot-forming tissue was not perfomed, the significance of these observations to the specific requitements of shoot formation remains unclear.

Aritigen analysis, using immunoelectrophoresis, showed that novei proteins are synthesized during the formation of callus tissue from pith parenchyma cells, and possibly during organogenesis from callus (Moisseva, et al., 1979 and Butenko, 1979). Ihese studies reported the production and isolation of antigens specific for tobacco shoot meristems, root meristems, pith parenchyma cells, and callus tissue. Initiation of callus rom pith sections resulted in the loss of two antigens specific for pith cells. At the same time several new antigens appeared, including one characteristic of shoot meristoratic tissue. Though precise culture conditions were not reported, shootdifferentiation was evidently induced prior to the detection of the meristem-speciftc antigen in callus.

Peroxidase enzymes are of interest in studies of tissue differentiation since they are apparently involved in IAA metabolism (Galston, et al., 1953). Lee and Skocg (1965) postulated that changes in IhA oxidase / peroxidase activity may reflect an internal mechanism for the regulation of auxin concentrations during shoot differentiation. However these enzjoms are probably also iavolved in many other diverse functions, including lignification, making reports on the appearance of new peroxidase iscenzymes difficult to interpret. Anodic peroxidases haye been assoclated with lignification (wolter and Gordon, 1975), while cathodic isoenzymes dre generally thought to be 
involved in auxin metabol ism (Thorpe, 1980).

Lee (1971) reported that low concentrations of cytokinin, in the presence of auxin, increased the production of two anodic IAA oxidase isoenzymes in tobacco callus cultures. These enzymes also possessed peroxidase activity.

Both callus and shoot formation from tobacco tissues are accompanied by increased percxidase activities (Mader, et al., 1975). The peroxidase isoeizyme patterns in tobacco stem tissue, nondifferentiating callus tissue, and shoot-forming callus tissue were all different. In shoot-forming tissue the isoenzyme pattern was characterized by decreased amounts of the fast-migrating anodic species, and a substantial increase in all of the cathodic species.

Thorpe and Gaspar (1978) also reported differences in peroxidase activity exhibited by shoot-forming and non-shoot-foming tobacco callus cultures. There was a steady increase in total peroxidase activity in shoot-forming calli during the first 17 days after subculture. Peroxidase activity also increased in non-shoot-forming calli, though the rate of increase was only half that observed in the differentiating tissue. These workers reported that most anodic isoenzymes exhibited lower activity in the shoot-forming cultures. On the cathodic side of the zymogram, one band in particular showed dramatically increased activity in the caulogenic tissue.

Seent and Gnanam (1981) detected approximately 3-fold greater peroxidase activity in shoot-forming regions, compared to undifferentiated regions, of tobacco leaf discs cultured in vitro for 12 days. Two additional peroxidase isoenzymes were $:=0$ reported in the differentiating cells. 


\section{b. Carbohydrate Metabolism.}

Thorpe and Murashige $(1968,1970)$ reported preferential accumulation of starch in loci of shoot-forming tobacco callus cultures which ultimately developed shoot primordia. Starch accumulation was evident four days after transfer to shoot-forming medium, prior to any observable change in tissue histology, and was the most conspicuous histochemical difference noted between shootforming and non-shoot-forming calli. Callus grown on non-shootforming medium contained iow levels of starch throughout the 18 day culture period.

Thorpe and Meier (1972a) extended these observations, and showed that starch concentrations increased during the first 12 days after subculture to shoot-foming medium, then decreased rapidly through day 21. A correlation was observed between the number of shoots formed after 28 days on individual pieces of callus grown on media containing a variety of different sugars, and the starch content of identical calli after 12 days of growth.

Ross and Thorpe (1973) dissected shoot-forming calli into upper and lower halves, and reported that starch concentrations in the lower half of the tissue reached a peak at six days after subculture, then decreased steadily through 18 days. The upper half of the tissue revealed a similar pattern of starch accumulation, though the peak concentration was not reached until nine days. This was correlated with the observation that the first visible shoot primordia emerge from the lower portion of the callus. The stored starch was hypothesized to serve as a source of readily-available energy during 
organ development.

Palmer (1976) observed no significant differences in the activities of ADP-glucose pyrophosphorylase and UDP-glucose pyrophosphorylase from shoot-forming and non-shoot-forming tobacco calli. The activities of both enzymes increased steadily in both types of callus during the first eight days after subculture, then remained approximately constant through day 14. Measurements of the UDP-glucose concentrations also revealed no significant differences between the two types of callus. AdP-glucose levels were below the limits of detection. It was concluded that starch accumulation during shoot formation was not regulated at the level of sugar nucleotide synthesis, and was therefore possibly controlled by differential activities of starch-hydrolyzing enzymes.

Thorpe (1974) studied the effect on shoot formation in tobacco callus tissue of transfer from medium containing sucrose to media containing either no carbohydrate, or containing sorbitol. The reverse transfers were al so examined. Sorbitol was unable to support tissue growth or organ differentiation when supplied as the sole carbohydrate source. When callus was transferred at five or ten days after subculture from sucrose medium to either of the media lacking sucrose, no shoots were formed. When similar manipulations were perfomed after 15 days, shoot primordia which had already emerged did not undergo any further development. If tissue was transferred at five or ten days from carbohydrate-deficient media to medium containing sucrose, nomal shoot development occurred, though events were delayed by approximately five and ten days. Transfer from carbohydrate-deficient medium at 15 days resulted in fewer and smaller 
shoots. Measurements of sucrose and starch revealed that callus tissue utflized stored reserves in the absence of exogenous sucrose. Thorpe (1974) concluded that no organogentc development occurred in the absence of exogencusly-suppl fed sucrose.

Tobacco callus tissie grown on shoot-forming medium containing $3.0 \%$ sucrose $(w / v)$ produced more shoots than callus grown on media containing lower or higher sucrose levels (Brown, et al., 1979). Though mannitol alone did not support callus growth, callus grown on shoot-forming medium containing $2.0 \mathrm{w}(\mathrm{w} / \mathrm{v})$ sucrose plus mannitol, to give a final molar sugar equivalent of $3.0 \%$ sucrose, produced the same number of shoots as callus grown on 3.0 \% sucrose. Growth, as measured by increase in fresh weight, was slightly inhibited in the sucrose plus mannitol cultures. Attempts to supplement $2.0 \%$ sucrose with varying amounts of agar, pyruvate, alanine, citrate, aspartate, or glutanate did not increase the number of shoots formed over that found with $2.0 \%$ sucrose alone. Rather, many of these treatments inhibited shoot formation, presumably by altering necessary metabolic processes through feedback inhibition of enzymes. The authors concluded that sucrose served a dual role in organogenesis: as an energy source and as an osmoregulatory agent.

Plumb-Dhindsa, et al. (1979) measured sle activities of enzymes associated with non-autotropic $\mathrm{CO}_{2}$ fixation in shoot-forming and nonshoot-forming tobacco calli. Phosphoeneolpyruvate carboxylase (PEPC) activity was slightly greater in shoot-forming tissue than in nonshoot-forming tissue 4 , and 9 - 21 days after subculture. Following a temporary decline at 7 days, the activity of PEPc from shoot-forming calli increased steadily through 20 days. In non-shoot-forming callus 
there was a small continuous increase in PEPC activity between days 0 and 12, followed by a sharp decrease between days 12 and 20. Malate dehydrogenase, NAD-malic enzyme, and glutamic-oxalacetic transaminase activities were always slightly greater in shoot-forming calli than in non-shoot-forming calli. The activfty of each enzyme varied throughout the three week study, and each showed a somewhat different activity profile in the two types of tissue.

The rate of non-autotropic incorporation of ${ }^{14} \mathrm{CO}_{2}$ into organic acids decreased approximately 4-fold in shoot-forming callus tissue between 0 and 9 days after subculture, then remained constant between days 9 and 16 (P7umu-Chindsa, et al., 1979). In non-shoot-forming callus, the rate of organic acid labelling decreased 3-fold during the first week, then increased between days 7 and 16 to approximately the same rate as that observed on day 0 . Between days 9 and 16,1 abelling of organic acids in non-shoot-forming calli was approxmately 3-fold greater than in shoot-forming calli.

The malate content of shoot-forming callus increased dramatically between 0 and 4 days after subculture, then declined b! day 9 to levels lower than those observed in the non-shoot-forming callus, and remained constant between $g$ and 20 days ( $P l$ umb-Dhindsa, et al., 1979). Malate concentrations in non-shoot-forming calli increased continuously during the three-week study. Though rates of nonautotropic ${ }^{14} \mathrm{CO}_{2}$ incorporation into organic acids did not reflect malate concentrations, the authors suggested this could be reconciled by postulating increased malate decarboxylation in shoot-forming tissue. They hypothesized that malate functions as an osmoregulatory agent in undifferentiated callus tissue, and primarily as a source of 
reducing power in shoot-foming callus, via NALP-malic enzyme mediated malate decarboxylation and MADPH formation.

Scott and coworkers (1964) demonstrated decreased activity of pentose phosphate pathway enzymes (glucose-6-phosphate dehydrogenase, 6-phosphogluconate dehydrogenase, and transketolase) in Micotiana glauca callus cultures grom on media supplemented with IAA or kinetin, compared to callus grown on medium lacking these homones. Callus tissue grew faster on media containing hormones, and the authors suggested that activities of enzymes of the pentose phosphate pathway may be related to the growth rate of the tissue.

Thorpe and Laishey (1973) reported increased activity of glucokinase, glucose-6-phosphate dehydrogenase, 6-phosphogluconate dehydrogenase, and aldolase in shoot-forming tobacco callus tissue, compared to non-shoot-forming callus tissue. Between 6 and 18 days after subculture, glucokinase activity was approximately 4-fold greater in shoot-forming tissue than in non-shoot-forming tissue. The activity of glucose-6-phosphate dehydrogenase was 2-, 3-, and 5-fold greater in shoot-forming calli than in non-shoot-forming calli at 6 , 12, and 18 days after subculture, respectively. By 9 days after subculture, 6-phosphogluconate dehydrogenase activity was approximately 3-fold greater in shoot-forming calli, compared to nonshoot-forming calli. Aldulase activity remained approximately constant during the 18-day sampling period, and was only slightly greater in shoot-forming calli than in non-shoot-forming calli. Between the two types of callus, the differences in actiyities were greater for enzymes of the pentose phosphate pathway than for those of glycolysis. Growth measurements were not reported, so these results 
neither support nor refute the hypothesis of Scott, et al. (1964). Comparison of ${ }^{14} \mathrm{CO}_{2}$ released from shoot-forming and non-shootforming calli following incubation with glucose specifically labelled in the $C-1$ or C-6 position also suggested relatively greater activity of the pentose phosphate pathway in shoot-forming callus (Thorpe and Lafshey, 1973). The authors hypothesized that although both the glycolytic and pentose phosphate pathways of glucose oxidation were utilized during organogenesis, the preferential stimulation of the latter probably reflected an increased requirement for reducing power by the shoot-forming tissue.

Seeni and Gnanam (1981) also reported greater activity of glucose-6-phosphate dehydrogenase in shoot-forming regions of tobacco leaf discs cultured in vitro for 12 days. This was accompanied by the appearance of two additional isoenzymes in the shoot-forming cells that were not observed in the non-shoot-forming regions of tissue.

Brown and Thorpe (1980) measured concentrations of nicotinamide adenine dinucleotides in shoot-forming and non-shoot-forming callus tissues, and found relatively higher levels of $\mathrm{NAD}^{+}$and $\mathrm{NAOP}^{+}$in shoot-forming tissue from day 6 until 15 days after subculture. This was accompanied by approximately equal levels of $\mathrm{NAOH}$ in the two types of callus tissue. NALPH levels were consistently greater in the nonshoot-forming tissue. The $\mathrm{NADP}^{+} / \mathrm{NADPH}$ ratio increased 10-fold in shoot-forming tissue during the first 6 days, but increased only marginally in the non-shoot-forming tissue. These results supported the hypothesis proposed by Thorpe and Laishey (1973) that shootinittation is accompanied by greater requirements for reducing power for use in reductive biosyntheses. 
During the first nine days after subculture, non-shrot-forming callus cultures consumed oxygen at a greater rate than shoot-forming tissues (Thorpe and Meier, 1972a). This was observan in cultures grown both in the dark and under continuous light, and reflects the greater fresh weight increase in non-shoot-foming callus. From days 12 through 21 respiration was greater in the shoot-forming calli cultured in the light but not those grown in the dark, relative to the respective types of non-differentiating tissues. It was proposed that the increase observed in light-grown shoot-forming tissue reflected increased metabolic activity during the fomation and growth of shoot primordia. The reported difference between light- and dark-grown tissues was not explained.

Tabata, et al. (1971) reported differences in individual amino acid concentrattons of eight-week-old tobacco calli grown on medium containing no auxin and high kinetin, and calli grown on media containing increasing esncentrations of 2,4-D in the presence of high kinetin. The tissues cultured without auxin had formed numerous shoot buds, while only undifferentiated callus was formed in the presence of 2,4-0. of special interest was the observation that low concentrations of 2,4-D stimulated the accumulation of all amino acids. Most were approximately two-fold greater in callus from the medium with low 2,4-D, though alanine, glutamine, glycine, and threonine accumulation increased ten-fold relative to calli grown on medium lacking auxin. Callus grown on medis containing moderate and high levels of 2,4-D, however, contained lesser amounts of most amino acids than callus from media with low auxin or lacking auxin. Proline was detected only at the moderate and high auxin concentrations. 
A recent report by Huxter, et al. (1981) demonstrated increased ethylene evolution fram non-shoot-forming tobacco callus cultures, relative to shoot-forming cultures. This olfference was evident within three days after subculture, and was observed in both lightand dark-grown cultures. Addition of exogenous ethylene to shootforming cultures inhibtted shoot formation in light-grown callus, though no effect was observed for cultures maintained in darkness.

\section{c. Secondary products metabol ism.}

Tyron (1955) reported that a shoot-forming strain of Nicotiana affinis callus tissue contäinad approximately 18 times more scopoletin than a non-differentiating strain of similar age. A substrain of the shoot-forming strain, which had reverted to the original nondifferentiating condition, contained only one-sixth as much scopoletin compared to the organ-forming cultures.

Sargent and Skoog (1960), and Skoog and Montaldi (1961) demonstrated that the relative amounts of auxin and cytokinin added to the growth medium regulate the inter-conversion of scopoletin and its glycoside, scopolin in tobacco callus cultures. High, toxic concentrations of IAA coupled with low kinetin concentrations stimulated both the accumulation of scopcletin, and the release of this campound to the culture medium. Injury promoted by high temperatures also induced ain increase in scopoletin levels. Low auxin and high cytokinin, conditions which favored shoot fomation, resuled in increased levels of scopolin. This was accompanied by uptake of scopoletin from the growth medium, which may explain the relatively high concentrations of this compound in the shoot-forming strain 
studied by Tyron (1955). Moderate amounts of IAA and kinetin supported the growth of healthy callus tissue, and prenoted the conversion of scopoletin to an unknown substance which the authors suggested was used in lignin biosynthesis.

A more recent study using tobacco callus cultures demonstrated that about $90 \%$ of the extractable scopoletin moieties were strongly bound to unknown structures by acid-hydrolyzable linkages (Anderson, et a1., 1981). The precise role of scopoletin remained unclear, though its incorporation into iignin was considered quite probable.

Nicotine production in tobacco tissue cultures was greatly increased by the addition of kinetin is the growth medium (Tabata, et a)., 1971). The time course for nicotine production closely paralleled the fomation of shoot buds, and those occasional pieces of callus tissue which did not form shoots contained an average of about 50\% less nicotine than was found in shoot-forming calli. Both shoot fomation and nicotine biosynthesis were strongly inhibited by $2,4 \ldots \mathrm{D}$ in the presence of optimum levels of kinetin. A specific rale for nicotine in the induction of shoots is unknown. Eecause many other species which form shoots in vitro do not synthesize this alkaloid, it seems much more likely that the synthesis of this secondary product coincides with differentiation, but does not control the process.

\section{Molecular Mechanisms for Hormonal Regulation of Differentiation}

Little is known about the specific molecular mechanisns whereby auxin and cytokinin regulate the differentiation of plant tissues. However, it is reasonable to infer that differential gene expisssion is involved. Goldberg (1980) showed that although the messenger Rrin 
populations of tobacco leaf, stem, root, and flower tissues show many similarities, there are also numerous tissue-specific sequences.

\section{a. Auxin.}

IAA induced chaiges in the pattern of protein synthesis in etiolated peas epicotyl sections (Pattersori and Trewavas, 1967). Zurfluh and Guilfoyle (1980) demonstrated that incubation with 2,4-0 altered the pattern of protein synthesis in both elongating and basal soybean hypocotyl segments. These changes were noted five hours after wxin treatment was initiated, and were tissue-specific.

Chen and coworkers (1975) reported that nuclei isolated from soybean hypocotyl tissue that had been sprayed with 2,4-D contained about twice as much RNA and protein after 24 hours as nuclei of untreated tissue. Nucleoli of auxin-treated tissue were greatly enlarged, suggesting that the increased RNA lavels reflected increased ribosonal RNA synthesis. RNA polymerase I activity was al so about two times greater in nuclei of auxin-troated hypocotyls.

Baulcombe, et al. (1980) demonstrated that synthesis of an abundant class of polyadenylated RNA is markedly decreased in soybean hypocotyl sections in response to auxin. Baulcombe and Key (1980) were able to resolve 40 auxin-regulated sequences, using translation analysis of RNA complementary to cloned radiozctive probes. These were divided approximately equally between sequences increased and sequences decreased in relative concentration. Thz wu:in cffocts wer: detectable within four hours of treatment, before auxin-stimulated elongation was observed.

Zurfluh and Guilfoyle $(1982 a, b)$ detected auxin-induced changes in 
translatable messenger RNA in elongating and basal hypocotyl sections, as well as intact soybean hypocotyls. They demonstrated that the concentrations of at least ten in vitro translation products are increased within 15 minutes after auxin treatment. The responses to IAA and 2,4-D were identical, and were observed in alt three tissues. Bevan and Northcote (1981b) also reported auxin-induced synthesis of specific translatable nessenger RNAs. Within two hours after subculture of auxin-starved soybean cell suspensions to medium containing 2,4-D, an increase in the translatable levels of at least three RNA species was observed. Transfer to medium containing naphthalene acetic acid (NAA) also resulted in increased production of at least three in vitro translation products, though these were not identical to those observed in response to 2,4-D. No increase in any of these bands was detected after subculture to auxin-free medium.

These studies using seedling stem tissue and tissue culture cells suggest that one way auxins regulate differentiation in plant tissues is via modification of DNA transcription. Jacobsen (1977) has reviewed much of the early evidence which supports this conclusion.

\section{b. Cytokinin.}

Fosket, et al. (1977) observed qualitative changes in protein synthesis 24 hours after transfer of stationary-phase soybean suspenition cells to mediun which contained cytokinin. Cytokinin induced the synthesis of at least four poiypeptides, and repressed the synthesis of at least one polypeptide. Similar changes were not found when cells were transferred to medium lacking this homone.

Zurfluh and Guilfoyle (1980) showed that add iion of cytokinin 
caused a decrease in total polypeptide labelling in both auxin-treated and untreated elongating soybean hypocotyl sections. Specific changes in the patterns of protein synthesis were also reported in this study. Maass and $\mathrm{Klambt}(1977$ ) reported a $35 \%$ increase in total protein synthesis 20 minutes after the addition of cytokinin to tobacco cell cultures. These cells had been inoculated to hormone-free medium 12 hours prior to the addition of cytokinin. Addition of actinomycin-D did not inhibit this response, implying that RNA synthesis was not involved.

Earlier studies reported that cytokinin treatment can promote or inhibit total RNA synthesis in peanut cotyledons depending on the concentration supplied (Carpenter and Cherry, 1966). Selective increase in the production of certain transfer RNA species has also been observed in response to cytakinins. Bick, et al.: (1970) reported enhancement of two leucyl transfer RNA species following treatment of soybean cotyledons with cytokinins.

Short and coworkers (1974) reported increased polyribosome aggregation within 15 minutes after subculture of cytokinin-starved soybean cells to cytokinin-containing medium. They observer no similar changes in the rate of either total RNA or polyadenylated RNA synthesis. Fosket, et al. (1977) later showed that subculture of cells to cytokinin-free medium also stimulated polyribosome formation. They reported, however, that direct addition of cytokinin to cells whict had been deprived of this homone for 24 hours led to increased formation of polysomes from monosomes. Studies on the incorporation of ritiated-leucine into nascent polypeptides associated with poly omes supported the assumption that polyribosome formation 
represented an increased rate of protein synthesis (Tepler and Fosket, 1978).

Tepler and Fosket (1978) were not able to demonstrate any specific effects of cytokinin-treatment on average polyribosone size, or on the rate of polypeptide chain initiation, elungation or temination. However, they did find a redistributicn of labelled RNA after cytokinin-treatment that was not seen in the absence of the homone. The specific activity of polysamal polyadenylated RNA increased almost $80 \%$, while that of nonpolysomal polyadenylated RNe decreased $40 \%$. The specific activity of nonpolyadenylated RNA was not affected by cytokinin. Based on these results, Fosket and Tepler (1978) concluded that cytokinin regulates protein synthesis at the ievel of translaticin through activation of messenger RNAs.

These conclusions have recently been challenged by the results of similar studies by Bevan and Northcote (1981a). They reported that subculture of soybean and Phaseolus vulgaris suspension cultures from either cytokinin-containing or cytokinin-free medium to cytakinin-iree medium stimulated polysome formation within 30 minutes. This was accompanied by an increase in the translatable messenger RNA $f:$ a small group of polypeptides. Subculture to cytokinin-containing medium resulted in an additional slight increase in polysome formation, but had no detectable qualitative or quantitative effects on translatable messenger RNA. These workers did not observe any changes in polysome iormation after cytokinin addition to cytokiainstarved cells which were not subcultured. These results suggested that cytokinin regulates protein synthesis through modification of transcription. 
The synthesis of novel proteins in response to cytokinins supports the hypothesis that this class of plant homones regulates differentiation through modification of gene expression. Whether this is controlled by modification of gene transcription, or translation of messenger RNA, or both, remains a controversial issue. 


\section{CHAPTER 2}

\section{GROLTH AMO GENERAL PHYSIOLOGY OF TOBACCO FALLUS CULTURES}

\section{Methods for Erowing Tobacco Plants.}

Nicotiana tabacum L. (cv Wisconsin 38) seeds were kindly provided by or. Toshio Murashige; the stock was maintained by collecting seeds from the pods of mature plants. Seeds were germinated under greenhouse conditions in clay pots containing vermiculite. The seedlings were watered daily with distilled water. Approximately two months after gemination, individual seedlings were wrapped in nonabsorbent cotton, placed in single-hole (1 on diameter) polyettiylene stoppers, and transferred to 5-gallon containers with covers which supported the stoppers. Three seedlings were transferred to each container, which was filled to one inch from the top with one-haifstrength modified Hoagland's nutrient solution (Table 1). The plants were grown under greenhouse conditions, and the nutrient solution was aerated continuousiy and replenished daily. When plants had actained a height of approximately two feet, they were harvested by severing the shoot portion from the roots and used to initiate callus cultures. Only non-flowering plants were used.

\section{Methods for growing tobacco callus.}

Callus cultures were derived from pith tissue of stem segments taken from between the fourth and sixth pairs of expanded leaves of tobacco plants. Leaves were removed, and the segments were divided at 
the node. The stem pieces were surface sterilized for $10 \mathrm{~min}$ in distilled water containing $10 \%\left(v^{\prime} v\right\rangle$ commercial bleach solution, (bleach contains $5.25 \%(v / v)$ sodium hypochlorite), and approximately $5 \mathrm{ml}$ Tween 20 detergent per $500 \mathrm{ml} 10 \%$ bleach solution. Approximately $500 \mathrm{ml}$ of this solution were used to sterilize 10 segments, which were agitated continuously by swirling. The segments were then washed four times with approximately $500 \mathrm{ml}$ sterile distilled water. Subsequent manipulations were performed in a sterile transfer hood.

A size No. 1 sterile cork borer (4 mm diameter) was used to remove pith tissue from the center of stem segments. Approximately 1 cm of tissue was discarded from both ends of the cylinder. The remairing tissue was sliced with a scalpel to give many small discs (4 mn diameter $\times 2 \mathrm{~mm}$ height). Five discs of pith tissue were placed in each Petri dish $(100 \times 15 \mathrm{~cm})$, which contained $25 \mathrm{ml}$ solidified nutrient medium. The Petri dishes were then sealed with strips of Parafilm "M" (American Can Company, Greenwich, CT).

The nutrient solution used was a modification of that described by Linsmaier and Skoog (1965). It contained inorganic salts in the concentrations prescribed by Murashige and Skoog (1962) ("Murashige and Skoog Plant Salt Mixture", Flow Laboratories, Inglewood, (A), and the following concentrations of organic nutrients: $87.6 \mathrm{mM}$ sucrose, $0.56 \mathrm{mM}$ myo-inositol, and $11.9 \mathrm{uM}$ thiamine-HCl (Table 2). This medium al so contained 16.1 uM a-naphthalene acetic acid (NAA), an auxin, and 1.5 UM $6(\gamma, \gamma$-dimethylallylamino)-purine (OMAAP), a cytokinin. The complete medium was adjusted to $\mathrm{pH} 5.8$ using $0.1 \mathrm{~N} \mathrm{KOH}$. TC agar (KC Biological, Inc., Lenexa, KS) was then added, $10 \mathrm{~g} / 1$, and the mixture was sterilized by autoclaving for $20 \mathrm{~min}$ at $121{ }^{\circ} \mathrm{C}, 19 \mathrm{p.s.j}$. 
Medium of the composition described above was used to induce callus tissue formation from stem pith explants, and also for the subsequent growth of unorganized callus tissue. Tissue continuously subcultured to this medium remained unorganized for as long as three years, so the medium will be referred to as non-shoot-forming (NSF) medium.

Primary explants and established callus cultures were grown at 24 ${ }^{\circ} \mathrm{C}$, in continuous light $\left(100-120 \mathrm{uE} \mathrm{m}^{-2} \mathrm{sec}^{-1}\right)$. Callus tissue was subcultured every three weeks, and the average inoculum size was 2 $\mathrm{mm}^{3}$. Only green, friable tissue from the exposed surfaces of calli was subcultured.

3. Induction of Shoots from Tobacco Callus Cultures.

Callus cultures of $\underline{N}$ tabacum were induced to form shoots by subculture to medium which contained identical concentrations of inorganic nutrients, sucrose, myo-inositol, and thiamine-HCl to those described above for NSF aediun (Table 2). The shoot-foming mediun, however, lacked NAA and contained 4.92 UM DMAAP. This concentration of cytokinin is approximately 3-fold greater than that used in NSF medium. Growth conditions were the same as those described above for NSF callus. Unless otherwise stated, callus used for experiments described in the following chapters was maintained on NSF medium for between three and six months prior to inoculation on SF medium.

Before choosing the SF medium described above, media containing different concentrations of NAA and DMAAP were screened for their ablifty to induce shoot formation. The results are summarized in 
Table 3. Though medta containing $1 \mathrm{mg} / \mathrm{l}$ DMAAP and either no NAA, or $0.01 \mathrm{mg} / 1$ NAA both induced all of the calli to form shoots, calli grown on the medium lacking auxin generally formed greater numbers of shoots. A survey of 5 different pieces of $\mathrm{SF}$ callus grown on this medium yielded an average of approximately 100 shoot primordia / $\mathrm{cm}^{3}$ of callus tissue. Shoot primordia were macroscopically visible by about 21 days after subculture to SF medium. Thts event was not synchronous in all cultures, but was staggered over approximately 4 days. As was also noted by Ross and Thorpe (1973), shoots initially formed on the lower surface of calli and grew in a negativeiy geotropic manner into the medium. Within one week after the first shoot primordia were visible, shoots were observed on all surfaces of the callus tissues.

A preliminary experiment revealed that callus tissue taken from the outer edges of NSF calli more consistently formed shoots on SF medium than tissue taken from the interior regions of the calli (Table 4). Calli which did not form shoots in this experiment, derived from the center of the tissue, showed no evidence of growth and were apparently dead by 3 weeks after subculture. This may be attributed to the observation that NSF cultures grow preferentially fran the edges of the tissue (Aitchison, et al., 1977). Tissue in the center of the callus is slightly older, and is less likely to be active in cell division.

It was not always possible to induce SF in large percentages of calli. The number of calli which formed shoots was a function not only of the medium und the region of tissue fram which callus was obtained, but also of unidentified factors. Occasionally cultures formed io 
shoots on the SF medium: they fomed efther unorganized tissue, or died. This might be related to changes in endogenous homone biosynthesis during culturs. Furthermore, same pleces of callus were extremely pro'ific in their ability to form shoots, while others which were derived from what appeared to be identical tissue formed very few shoots on the same medium. This was sometimes observed in callus pieces grown in the same Petri dish, suggesting possible genetic hetr rogeneity.

Each line of callus used for the various experiments described below was screened for shoot-forming ability six weeks prior to the experiment. Only cultures which had previ_usly demonstrated a reasonably uniform (greater than $75 \%$ of the calli forming similar numbers of shoots) shoot-forming response were designated for experimental use.

Photographs of NSF and SF tobacco calli a presented in Figures la and $1 \mathrm{~b}$ respectively.

4. General Physiology of Callus Cultures.

Metabolite labelling patterns and concentrations in shoot-forming and non-shoot-forming calli will be presented in the Chapters 3 and 4. Knowledge of gross physiological changes in callus tissues will be helpful in interpreting these results. Two very apparent differences between NSF and SF callus tissue are quantified in the following section: texture and color. Starch concentrations in the two types of callus tissue are al so included in thi: chapter. 


\section{a. Growth rates of calli.}

Methods. Calli were subcultured in day 0 to NSF or SF medium. Four replicate samples of eacii type of callus were collected after 1 , 5, 10, and 15 days of growth. Each sample contained the combined call from 5 petri dishes, each of which contained 5 pieces of callus tissue. The samples were placed in separate $10 \mathrm{ml}$ weighing bottles, and fresh weights determined. Dry weight measurements were obtained after heating the samples at $100^{\circ} \mathrm{C}$ for 24 hours. Types $\mathrm{A}, \mathrm{B}, \mathrm{C}$, and $D$ were initiated from plants harvested on different dates; all formed shoots after culture for \& weeks on SF medium.

Results and Discusston. Growth of the four independent types of callus, as measured by increase in fresh weight, is presenced in Figure 2. Though results were similar for the four types, they were all included to illustrate the sort of variability which was often encountered. Fresh wetght changes in SF calli were not appreciably different from those observed in NSF cultures during the first 10 days after subculture. However, excluding type $A$, the growth rate of NSF callus increased markedly between days 10 and 15 , while that of SF cultures remained relatively constant. Lag and $\log$ (exponential) phases of growth are quite common in unorganized salius tissue. This subject is thoroughly discussed in the review article by Aitchison, et al. (1977). Unlike NSF cultures of callus types B, C, and D, the growth rate of Nar callus type $A$ did not increase significantly between days 10 and 15 after subculture. This result is not readily explained, and might have resulted from an error in sampling on day 15. 
Dry weight accumulation reflected changes in fresh weights in these cultures (Table 5). The dry weight / fresh wetght ratio is more informative: differences in this ratio for NSF and SF cultures were evident by the first day after subculture for callus types $B, C$, and D; it was consistently greater for SF cissue by 10 days after subculture. The dry weight: / iresh weight ratio for MSF callus decreased approximately 15 \% between 1 and 15 days after subculture. This suggests both an increase in vacuolation of NSF callus during the 2 week study, and al so a decrease in the average thickness of cell wall's in the NSF calli. Results presented in Chapter 3 show that the decrease in cell wall thickness is significant factor in the decrease in dry weight / fresh weight ratio in NSF calli. For SF cultures, the ratio increased $38 \%, 15 \%, 15 \%$, and $40 \%$ for callus types $A, B, C$, ano $\bar{J}$ respectively during the two week study. Thorpe and Murashige (1970) reported a decrease in average cell size and vacuolation during growth of SF calli. Maeda and T.10rpe (1979) observed extensive tracheary element formation i.s SF calli beginning approximately 1 week after subculture. It is likely that the increase in dry weight / fresh weight ratio reported here for SF calli reflerts an increase in the cell wall / cyioplasm ratio of these calli, and also a decrease in vacuolation of the tissues.

\section{b. Chlorsphyll contents of calli.}

Methods. Chlorophyll content of NSF and SF tobacco callus cultures was detemined according to the methods of Bruinsma (1963). Each sample of callus tissue, $1 \mathrm{~g}$ fresh weight, was grolind in a $35 \mathrm{ml}$ Xontes glass homogenizing tube (Kontes Glass Co., Vineland, MJ), or, 
ice, in $1.7 \mathrm{ml}$ cold acetone. Samples were then 1 ransferred to individual $15 \mathrm{ml}$ glass conical centrifuge tubes wich an additional 1 ml cold acetone. Both the hamogenizing tubes and centrifuge tubes were covered with aluminum foil, and room lights were turned-off to prevent chlorophyll degradation. The tissues were extracted for one hour, on ice, then centrifuged for $20 \mathrm{~min}, 200 \times \mathrm{g}, 4^{\circ} \mathrm{C}$ (IEC centrifuge). Supernatants were removed with transfer pipettes, and transferred to cold, covered $10 \mathrm{ml}$ glass vials. Assuming $1 \mathrm{ml}$ water / $g$ fresh weight, the acetone concentration of the supernatants was $80 \%$ $(v / v)$. Pellets were resuspended in $1 \mathrm{ml} 80 \%(v / v)$ cold acetone, and centrifuged for $20 \mathrm{mtn}, 200 \times \mathrm{g}, 4^{\circ} \mathrm{C}$. Combined supernatants of each sample were brought to room temperature, and absorption at $645 \mathrm{~nm}$ and $663 \mathrm{~mm}$ determined (Cary spectrophotoneter, Model 118). Chlorophyli concentrations were calculated using tha equation of Arnon (1949):

$$
\operatorname{cn}]_{a+b}=20.2 A_{645}+8.0 A_{663} .
$$

Duplicate samples were obtained for SF and NSF tissues at $3,5,7,10$, and 12 days after subculture to the respective media.

Results and Discussion. Shoot-forming tobacco callus tissue contained more chlorophyll / g fresh weight than non-shoot-forming tissue (Figure 3 ). Though the magnitude of the difference between SF and NSF tissue decreases when expressed on a dry weight basis, the chloropyll content of SF tissue remained greater than that of NSF rissue at all time points (data not shown). Thus the apparent increase tn chloropyll concentration of SF tissues cannot be explained solely on the basis of increased tissue density, and represents an actual increase in chlorophyll synthesis in this tissue. 
SF medium contains approximately 3 times more cytokinin, DMAAP, than NSF medium. Stetler and Laetsch (1965) reported that the addition of kinetin to culture medium is required for the maturation of proplastids to chloroplasts in toba: co callus tissue transferred from darkness to continuous light. No grana were formed in plastids of callus grown on medium lacking the cytokintn. Kaul and Sabharwal (1971) reported that kinetin is required for chloropyll synthesis in non-green tobacco tissue cultures. However, in contrast to the data presented in Figure 3, these workers reported that increased xinetin concentrations inhibited chloropyll synthesis in green callus cultures. This apparent discrepency may be explained by the fact that SF medium used in the study reported here not only contains significantly greater amounts of cytokinin, but also contains no auxin, wile NSF medium contains appreciable amounts of NAA. NAA inhibited chlorophyll synthesis in oxalis dispar callus cultures (Sunderland and Wells, 1968). Bandiera and Morpugo (1970) reported that increased kinetin concentrations stimulate greening of carrot tissue cultures, while increased auxin levels in the culture wedium decreasej this response to kinetin. The increased amounts of chloropyll in SF calli reported here are probably a result of the combined influence of changes in the exogenous supplies of both hormones.

Increased chlorophyil synthesis is not required for the formation of shoots, as tobacco tissue cultures will form shoots when grown in complete darkness. However, shoot foimation from dark grown tobacco callus cultures requires not oniy increaseci cytokinin / auxin ratios, but also the addition of adentne, tyrosine, and increased 
concentrations of inorganic phosphate (Murashige, 1974). Inorganic phosphate concentrations may regulate starch synthesis and degradation in green leaves (Preiss and Levi, 1980). The additional requirement for this nutrient in SF medium of dark-grown calli could possibly be related to effects on starch levels in amyloplasts.

Many changes in chloroplast metabolism are probably concommitant with increased rates of chlorophyll synthesis in SF tobacco calli, and the possiblility that these organelles synthesize substances which modulate the development of shoots should not be discounted. The role of accumulated starch in shoot formation will be discussed below.

\section{c. Starch contents of calli.}

Methods. Starch content of shoot-forming and non-shoot-forming tobacco callus tissues was determined using a modification of the method of Hassig and Dickson (1979). Tissue was sampled at intervals after subculture to either SF or NSF medium, and fresh weights determined. The fresh wight of individual samples ranged from $0.2 \mathrm{~g}$ to $1.0 \mathrm{~g}$, depending on the number of days since subculture. Samples were ground on ice in $35 \mathrm{ml}$ Kontes glass homogenizing tubes (Kontes Glass Co,, Vineland, NJ) with $1 \mathrm{ml}$ methanol:chloroform:water (ACW) (12:5:'s then transferred to $15 \mathrm{ml}$ glass conical centrifuge tubes with an, Sitional $1 \mathrm{ml}$ MCW. Soluble metaboiltes were extracted were extracted vernigist at $4^{\circ} \mathrm{C}$. The tissue homogenates were then centrifuge, 4 times, $180 \times g$, at room temperature, the pellets being resuspended $\mathrm{n} 2 \mathrm{ml}$ MCW each time, Control experiments revealed that less than 0.5 \& of the $\mathrm{MCW}$-soluble metabolites was recovered in the fourth extraction. The MCW-insoluble pellets were then incubated with 
Protease (Signa Chemical Co.) to digest protein. (See Chapter 3 for complete detafls of protein extraction). Solubilized protein was removed by centrifugation followed by two water washes.

Starch gelatinization was accomplished after addition of $2 \mathrm{ml}$ water and $0.2 \mathrm{ml} 50 \%(\mathrm{v} / \mathrm{v})$ ethanol to each sample. Tubes were covered with aluminum foil and placed in a boiling water bath for 1 hour. After gelatinization, samples were cooled on $i c e$, and $1 \mathrm{ml} 1 \%(\mathrm{w} / \mathrm{v})$ $\mathrm{Cl}$ arase 900 (M-les Laboratories, Elkhart, IN) in $0.2 \mathrm{M}$ Na-acetate buffer, $\mathrm{pH} 4.45$, was added to each tube. (Clarase 900 contains mostly -amylase of Aspergillus oryze, and has significant maltase activity). Sample blanks contained $2 \mathrm{ml}$ water, $0.2 \mathrm{ml} 50 \%$ ethanol $(\mathrm{v} / \mathrm{v})$, and $1 \mathrm{ml}$ enzyme solution. Tubes were covered with aluminum foil, and incubated for 24 hours in a water bath shaker, $50^{\circ} \mathrm{C}$, with continuous agitation at $100 \mathrm{rpm}$. Following enzymatic digestion of starch, simples were centrifuged 3 times, $180 \times \mathrm{g}$, at room temperature, the pellet being resuspended in $2 \mathrm{ml}$ water each $i$ ime. Supernatants of each sample were conbined, and the total volune was brought to $7 \mathrm{ml}$ with water.

Glucose concentrations in the starch digests were determined colorimetrically in aliquot samples, (50 - $500 \mathrm{ul})$, following addition of $5 \mathrm{ml}$ peroxidase-glucose oxidase-o-dianisidine dihydrochloride reagent (Signa Chemical Co., Technical Bull. 510). Samples were incubated at $37{ }^{\circ} \mathrm{C}$ for $30 \mathrm{~min}$, and absorbance was measured at $450 \mathrm{~m}$ (Cary spectrophotometer, Model 118). Standard curves were obtained using 25, 50, and $100 \mathrm{ug}$ glucose $/ \mathrm{ml}$ water, and were repeated with each experiment to ensure accuracy of glucose deteminations.

Sfgnificance tests were performed using Student's t-test for differences between mean value determinations. The hypothesis of 
significantly different mean values was routinely accepted if the probability of error in this decision was less than 0.05 .

Results and Discussion. The above procedure for starch determination was verified using controls which contained $1,5,10$, and $20 \mathrm{mg}$ potato starch (Sigma chemical Co.). These results are presented in Table 6. The slight deviations from expected values, especially for the $1 \mathrm{mg}$ sample, were atiributed to error associated wit weigining such small amounts of starch.

By 4 days after subculture, the starch content of tobacco callus tissue subcultured to SF medium was almost 6-fold greater than that of tissue grown on NSF medium (Figure 4). This difference was sigr ficant 4 dàys after subculture, and was maintained through 21 days, (Calli used for starchmeasurements on days $\vec{i}$ - 21 were subc vided into top and bottom halves for use in a metabolite labe.ling experiment to be discussed in Chapter 3. Starch data presented in Figure 4 represent the average of 3 samples of each type of $t$ ssue at 1 and 4 days after subculture; for days 7 - 213 samples each of top and botton halves of NSF and SF calli were included in mean value calculations. Starch levels in top and bottom halves were not jignificantly different.)

The mean starch content of NSF tissue did not change significant?y during the duration of the experiment. The differences in roan values obtained for SF tissues on days 4, and $10-21$ were not stat stically significant. However, the low mean starch concentration

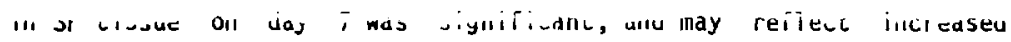
energy consumption in SF tissue at this time. This hypothesis is supported by results of metabolite labelling experiments presented in 
Chapter 3. "Mertstemoids" were abserved 10 days after subculture of tobacco calius tissue to shoot-foming medium (Maeda and Thorpe, 1979). Fomation of these localized centers of cell diviston may explain the transient decrease in starch reserves in SF calli at 7 days.

The results of several experiments in which starch content of SF and NSF tisstes was determined during the first week after subculture are presented in Table 7. Large amounts of starch were always observed in SF cultures, relative to NSF cultures. The absolute amount of starch present on a given day varied in both NSF and SF calli, depending on the particular line of callus used in each experiment. The ratio of starch stored in SF and NSF calli is constant for simflar sampling cimes in all experiments (Table 7), and may be diagnostic of the shoot-forming response in tobacco callus cultures. For example, this ratio ranged from 1.9 to 2.6 for sampies taken 3 days after subculture; it ranged from 4.2 to 6.5 for samples taken at one week. Similar starch - sncentrations in dark-grown NSF and SF calli during the first week after subculture were reported by Thorpe and Meier (1972), who measured starch by the anthrone reagent procedure. This consistency supporis the validity of the methods used here.

There is, however, one mportant difference between the results of starch deteminations reported here, and those reported by Thorpe and Meier (1972), and Ross and Thorpe (1973). No sustained decrease

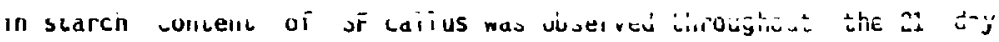
study reported in Figure 4. In contrast, Thorpe and Meier (19/2) observed a significant decrease in starch content of dark-grown SF 
tissue starting on day 12 and continuing through day 21 . Ross and Thorpe (1973) reported a similar decrease in dark-grown SF tissue starting on day 6 . They interpreted this as evidence for increased energy consumption during organ initiation and subsequent emergence of primordia. This situation is somewhat analogous to the utilization of carbohydrate reserves in seeds during germination.

Certainly shoot formation in the studies reported here also required considerable amounts of energy, yet starch levels showed only a transient de:rease at 7 days. It is important to recall that these callus cultures are heterotrophic. Increased rates of metabolism of sucrose supplied in the medium could provide an alternative to utilization of stored starch during periods of accelerated cell division and carbohydrate utilization. Evidence that this does occur will be presented in Chapter 3.

To reconcile the apparent discrepency between the results of Thorpe and coworkers, and those reported here, one could also postulate that greater numbers of shoots were formed per unit area of callus tissue loder the culture conditions used in Thorpe's laboratory. It is generaliy agreed that only a small fraction of the total number of calls in SF calli directly participate in shoot fomation. The histochemical studies reported by Maeda and Thorpe (1979) showed that starch accumulates in many regions of SF cultures, including those which do not divide to form shoot meristems. Starch reserves which accumulate in one region of the tissue may be degraded to simple sugars an t transported to actively-dividing loci in the tissue where the demand for carbon skeletons is greater. When a larger proportion of the total number of cells in an individual piece 
of callus tissue is directly involved in "meristemoid" formation, depletion of starch reserves should be more apparent.

Thorpe and coworkers studied shoot fomation in dark-grown tobacco calli, while calli used in the studies reported here were grown in continuous light. The increase in chlorophyll content during growth and differentiation of SF calli suggests an increase in photosynthetic carbon fixation (see Section 4b of this chapter). This additional supply of sugars for light-grown calli may also explain the differences between patterns of starch accumulation in light-grown and dark-grown SF cultures.

Thorpe and coworkers used kinetin, IAA, tyrosine, adenine, and increased concentrations of inorgainic phosphate to induce shoot formation in dark-grown tobacco callus tissue. The SF medium used in the studies on light-grown calli reported here contained DMAAP, no auxin, and none of the other additives. Homonal and nutritional differences between culture media, along with differences in culture conditions (light versus dark), offer likely explanations for the differences in patterns or starch accumulation during shoot formation $n$ these studies.

To summarize the results presented in this section, increases in ti sue density, chlorophyll concentration, and starch content are apparent withir the first days after subculture of tobacco callus to SF medium. Similar changes were not observed in tissue subcultured to NSF medium. These results suggest that specific changes in intermediary metabolism might al so be detected which could further increase our understanding of the biochemical regulation of organ initiation and development. 
5. Chapter 2: Tables and Figures. 
Table 1. Composition of one-half-strength modified Hoagland's nutrient solution used for growing tobacco plants.

Micronutrients

mmol / I

ppm

PpR

$\mathrm{KNO}_{3}$

25.0

$\mathrm{Fe}$

2.5

Zn

0.125

$\mathrm{Ca}\left(\mathrm{NO}_{3}\right)_{2}$

25.0

CI

1.0

Cu

0.015

$\mathrm{MgSO}_{4}$

1.0

B

0.125

Mo

0.015

$\mathrm{KH}_{2} \mathrm{PO}_{4}$

0.5

Mn

0.125 
Table 2. Inorganic and organic nutrient concentrations in modified Linsmater and Skoog (1965) media used for initiating callus from stem pith tissue, for maintaining established callus cultures, and for inducing shoot formation from callus tissue. Inorganic nutrients are identical to those prescribed by Murashige and Skoog (1962).

\section{Inorganic salts}

Macronutrients

Micronutrients

\begin{tabular}{lrlrlr}
\hline & $\mathrm{mmol} / \mathrm{1}$ & & $\mathrm{umol} / \mathrm{l}$ & $\mathrm{mnol} / \mathrm{I}$ \\
$\mathrm{NH}_{4} \mathrm{NO}_{3}$ & 20.60 & $\mathrm{H}_{3} \mathrm{BO}_{3}$ & 100.0 & $\mathrm{Na}_{2} \mathrm{MoO}_{4}$ & 1.0 \\
$\mathrm{KNO}_{3}$ & 18.80 & $\mathrm{MnSO}_{4}$ & 100.0 & $\mathrm{CuSO}_{4}$ & 0.1 \\
$\mathrm{CaCl}_{2}$ & 3.00 & $\mathrm{FeSO}_{4}$ & 100.0 & $\mathrm{CoCl}_{2}$ & 0.1 \\
$\mathrm{MgSO}_{4}$ & 1.50 & $\mathrm{ZnSO}_{4}$ & 30.0 & & \\
$\mathrm{KH}_{2} \mathrm{PO}_{4}$ & 1.25 & $\mathrm{KI}$ & 5.0 & & \\
\hline
\end{tabular}

Organic nutrients

$$
\text { umol } / 1
$$

sucrose $\quad 87.6 \quad$ thiamine $-\mathrm{HCl} \quad 11.9$

myo-inositol $\quad 0.56$ 
Table 3. Ability of media with different concentrations of naphthalene acetic acid (NAA) and $6(\gamma, \gamma$-dimethylallylamino)-purine (DraAP) to induce shoot fomation in tobacco calli which had been maintained on medium containing $3 \mathrm{mg} / 1$ NAA and $0.3 \mathrm{mg} / 1$ DMAAP. 25 pieces of callus were tested with each homone combination. Data were collected 4 weeks after subculture.

Concentration of hormones (mg / 1)

NAA DMAAP
Appearance of calli

after 4 weeks

$\begin{array}{lrl}2.00 & 2.0 & \text { fim, no shoots } \\ 0.01 & 1.0 & 100 \% \text { with shoots } \\ 0.0 & 1.0 & 100 \% \text { with shoots } \\ 0.0 & 2.0 & 90 \% \text { with shoots } \\ 0.0 & 4.0 & \text { dead } \\ 0.0 & 10.0 & \text { dead }\end{array}$


Table 4. Comparison of percentages of ca:li which formed shoots in tissue which was taken from either the interior or outer-surfaces of NSF calli. Twenty-five pieces of each type of calli were used in each experiment. Data was collected 3 weeks after subculture. Calli which did not form shoots were brown, and apparently either dead or dying.

Experiment No.

Region of tissue

used for subculture
Percentage of callus

pieces with shoots

1

outer surfaces

97

interior

30

2

outer surfaces

100

interior

75 
Table 5. Growth of four independent lines of tobacco callus on shootforming (SF) and non-shoot-foming (NSF) media during the first 15 days after subculture from NSF medium. Types A, B, C, and D initiated on four separate dates. Data expressed ds averages of four repl tcate samples standard error of the mean. (Milligrams fresh weight, mGFW; militigrams ary weight, mGDW).

days mGFW mGDW mGSil / mGFW

Callus type A

NSF

$\begin{array}{rrrrrr}1 & 108 & 9 & 4.8 & 0.4 & 0.044 \\ 5 & 120 & 14 & 4.7 & 0.5 & 0.040 \\ 10 & 298 & 27 & 11.8 & 1.0 & 0.040 \\ 15 & 537 & 107 & 19.9 & 3.9 & 0.037\end{array}$

SF

$\begin{array}{rrrrrr}1 & 104 & 10 & 4.7 & 0.6 & 0.045 \\ 5 & 184 & 23 & 8.3 & 0.7 & 0.046 \\ 10 & 382 & 81 & 19.4 & 0.6 & 0.054 \\ 15 & 482 & 116 & 30.4 & 0.8 & 0.062\end{array}$

Callus type $B$ NSF

$\begin{array}{rrrrrr}1 & 108 & 5 & 4.8 & 0.3 & 0.044 \\ 5 & 129 & 9 & 6.0 & 0.1 & 0.044 \\ 10 & 295 & 19 & 12.7 & 0.9 & 0.043 \\ 15 & 913 & 77 & 34.7 & 0.3 & 0.038\end{array}$

SF

$\begin{array}{rrrrrr}1 & 95 & 7 & 4.9 & 0.5 & 0.051 \\ 5 & 159 & 25 & 9.2 & 0.9 & 0.053 \\ 10 & 300 & 54 & 19.4 & 2.9 & 0.055 \\ 15 & 290 & 39 & 17.1 & 2.0 & 0.059\end{array}$


Table 5 (continued).

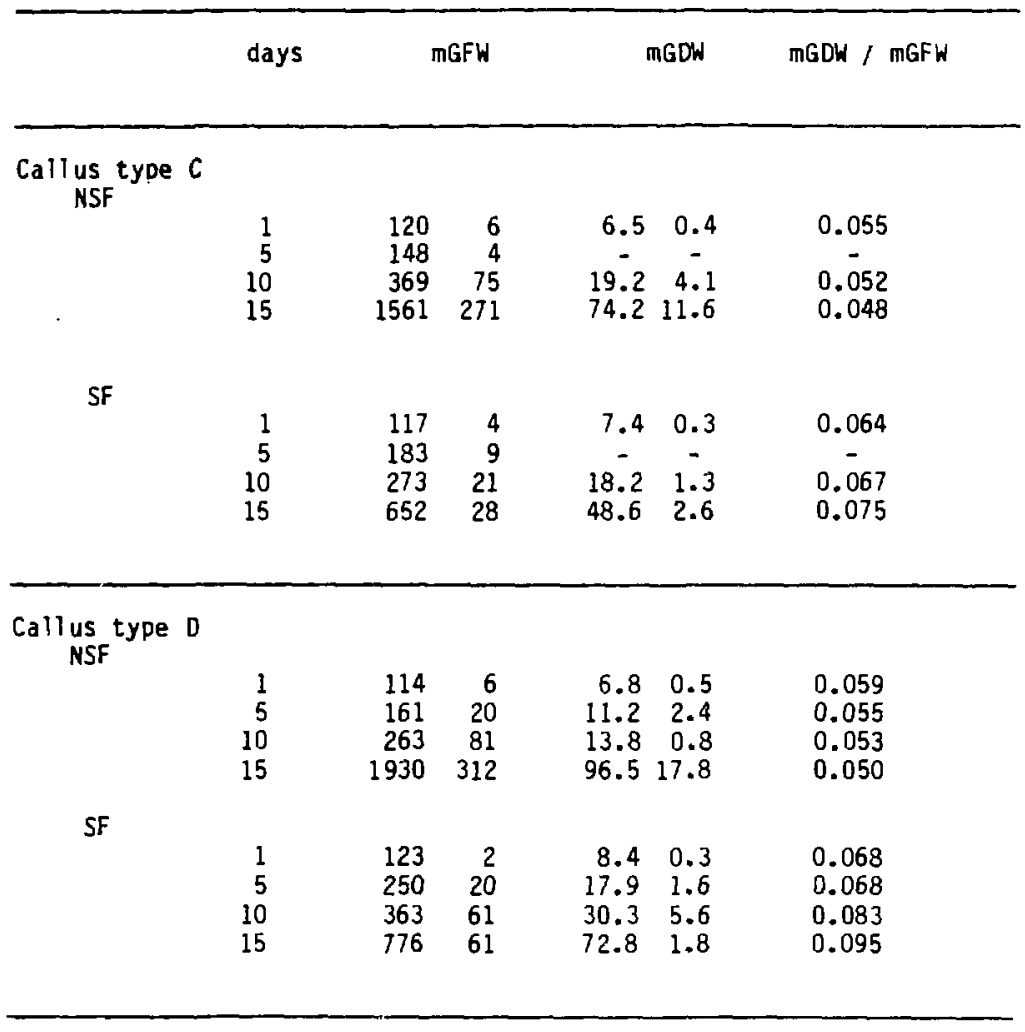


Table 6. Verification of enzymatic procedure for starch digestion using known amounts of potato starch. Results for duplicate treatments reported.

mg starch

xig glucose

after digestion

\begin{tabular}{rrr}
1 & 0.5 & 1.1 \\
5 & 5.9 & 5.9 \\
10 & 11.2 & 10.1 \\
20 & 20.5 & 21.7 \\
\hline
\end{tabular}


Table 7. Comparison of changes in starch concentrations duririg the first week of growth after subculture of unorganized tobacco callus tisue to either non-shoot-forming (NSF) or shoot-forming (SF) medium. Data from 5 separate experiments; expressed as mg starch / $g$ fresh weight callus tisue. Each value for Experiments 1 and 3 represents averige of 3 separate medsurements, and for Experiments 2, 4 and 5 averages of 2 separate measurements.

days after
subculture

\section{starch \\ (mg / gfw)}

NSF

SF

SF / NSF

Experiment 1

$\begin{array}{llll}1 & 1.5 & 1.5 & 1.0 \\ 2 & 1.1 & 2.1 & 2.0 \\ 3 & 1.4 & 2.9 & 2.1 \\ 5 & 1.2 & 3.3 & 2.6 \\ 7 & 0.9 & 3.9 & 4.2\end{array}$

Experiment 2

$\begin{array}{llll}1 & 1.8 & 2.4 & 1.3 \\ 2 & 2.1 & 5.9 & 2.8 \\ 3 & 2.4 & 6.3 & 2.6 \\ 4 & 1.4 & 6.0 & 4.2\end{array}$

Experiment 3

$\begin{array}{llll}1 & 2.4 & 3.5 & 1.5 \\ 4 & 1.7 & 8.7 & 5.9 \\ 7 & 1.0 & 6.7 & 6.5\end{array}$

Experiment 4

$\begin{array}{llll}3 & 0.7 & 1.3 & 1.9 \\ 7 & 0.5 & 2.5 & 4.9\end{array}$

Experiment 5

$\begin{array}{llll}3 & 1.1 & 2.6 & 2.3 \\ 7 & 1.2 & 5.8 & 4.9\end{array}$


Figure 1a. Phiotograph of non-shoot-forming tobicco call us grown for 3 weeks on NSF medtum. 


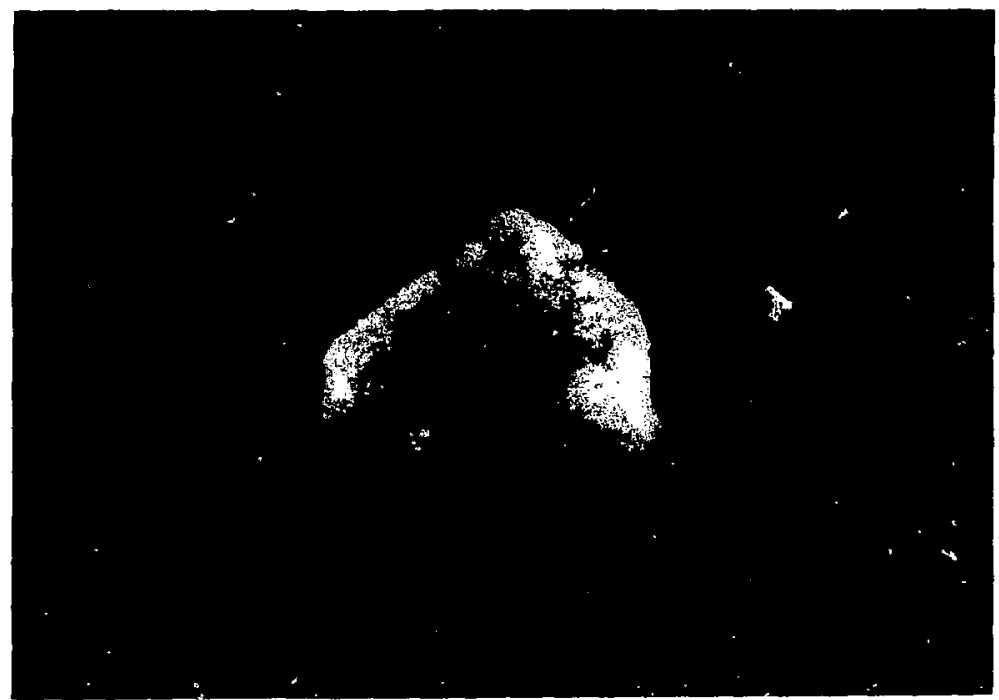

CBB $806-7634$ 
Figure 1b. Photograph of shoot-forming tobacco calli grown for 3 weeks on SF medium. 


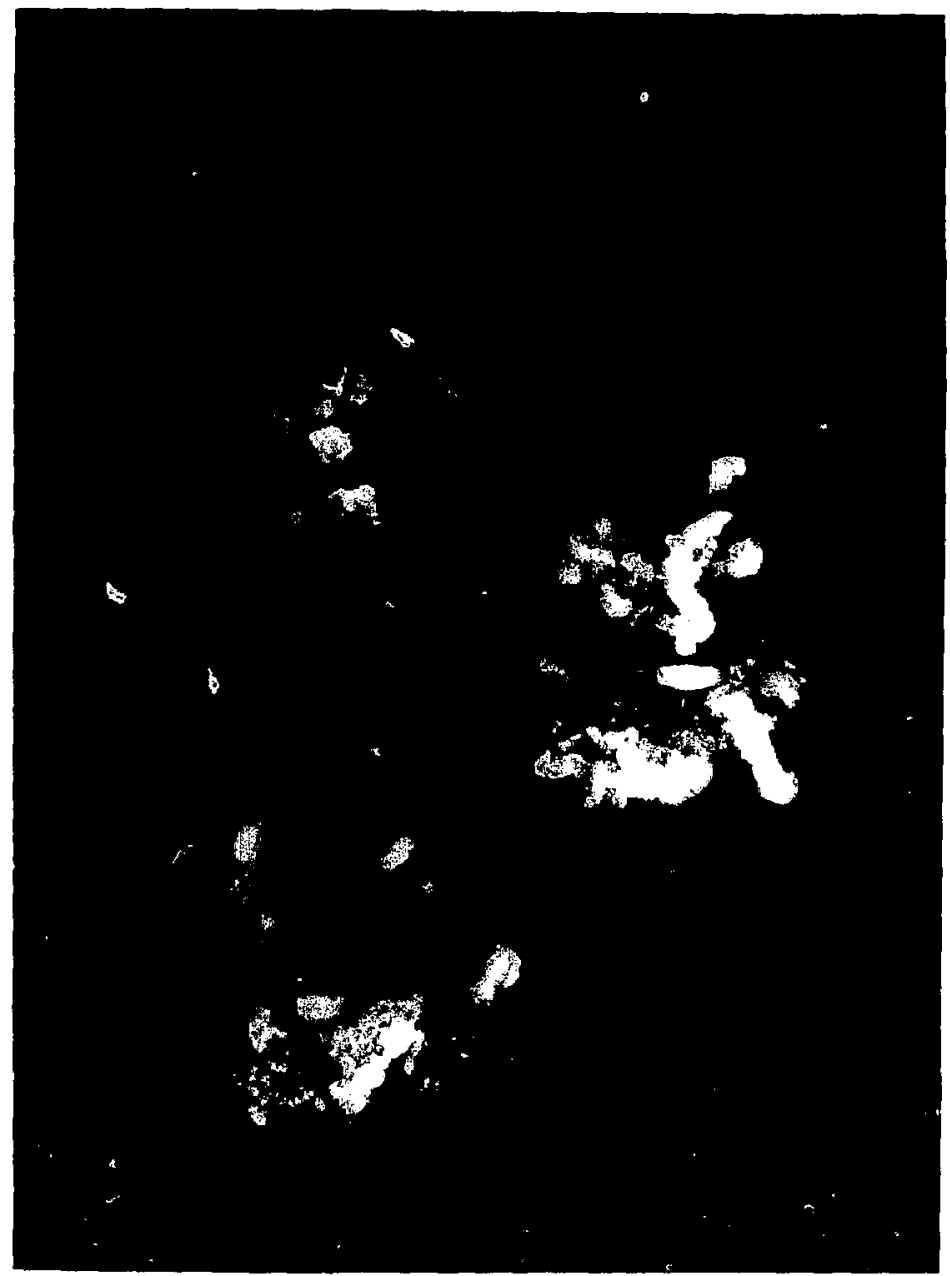

CBB $806-7632$ 
Figure 2. Growth of non-shoot-forming (closed circles, solid lines) and shoot-forming (open circles, dasher, lines) tobacco callus cultures during the first 15 days after subculture to NSF and SF media, respectively. A, B, C, and D refer to four types of callus iniliated on separate dates from different tobacco plants. 

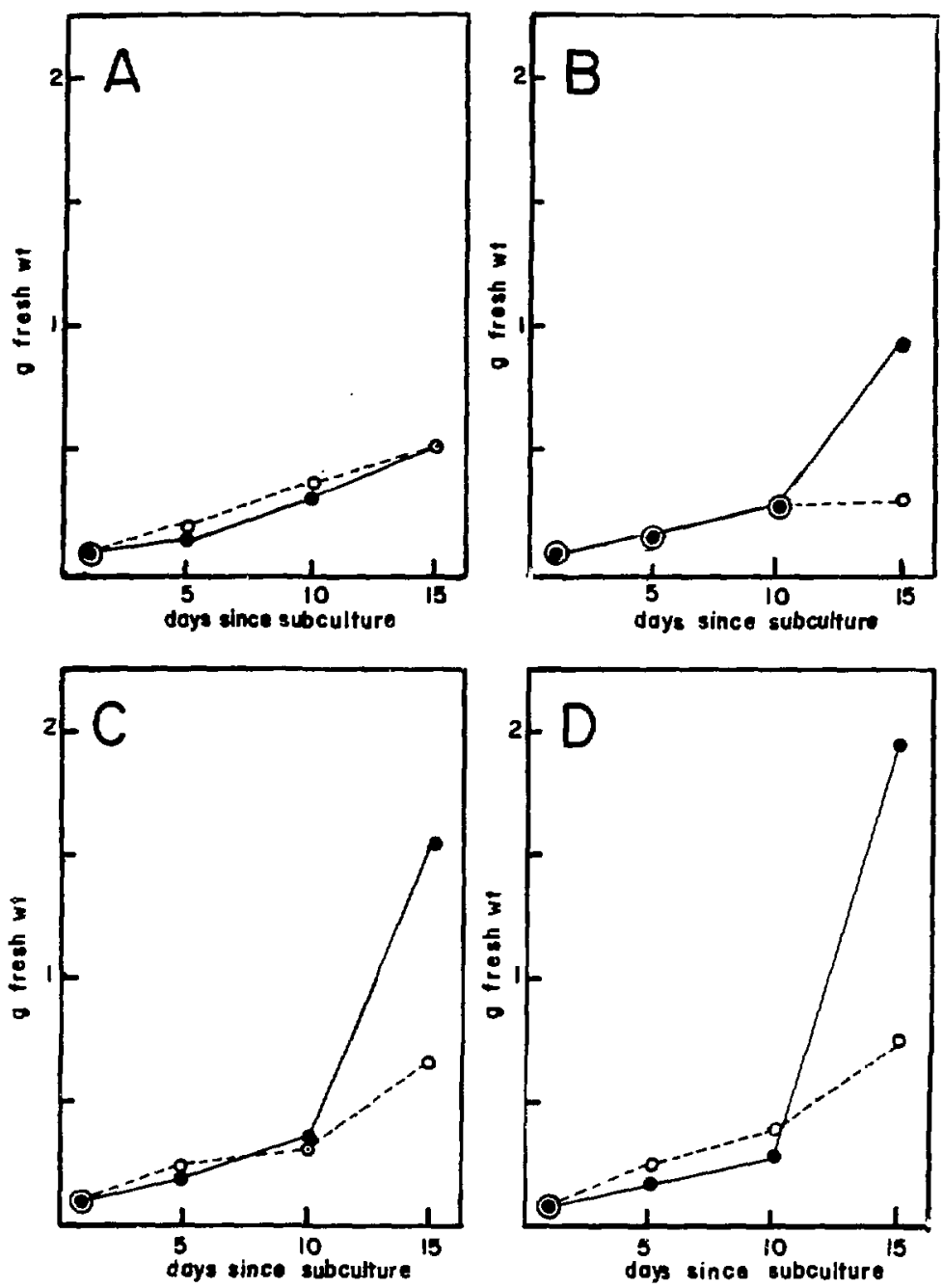

XBL 828-11330 
Figure 3. Changes in chlorophyll content of non-shoot-forming (closed circles, solid lines) and shoot-forming (open circles, dashed lines) tobacco callus cultures during the first 15 days after subculture to NSF and SF media, respectively. Each data point represents the aerage of duplicate samples. 


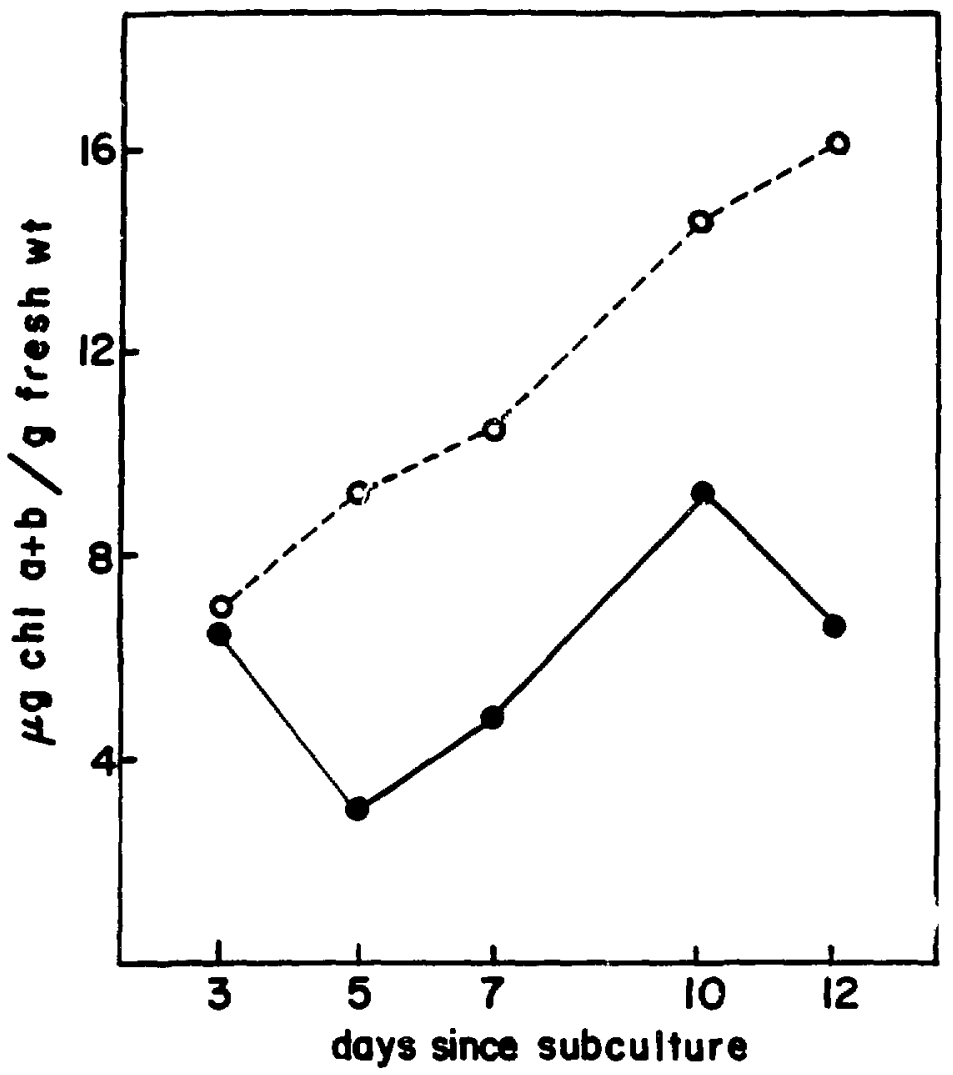

XBL \&?8-11329 
Figure 4. Changes in starch concentrations in non-shoot-forming (closed circles, solid lines) and shoot-forming (open ctrcles, dashed lines) tobacco callus cultures at selected times after subculture to NSF and SF media, respectively. Each data point represents average of replicate samples; error bars designate standard error of the mean. 


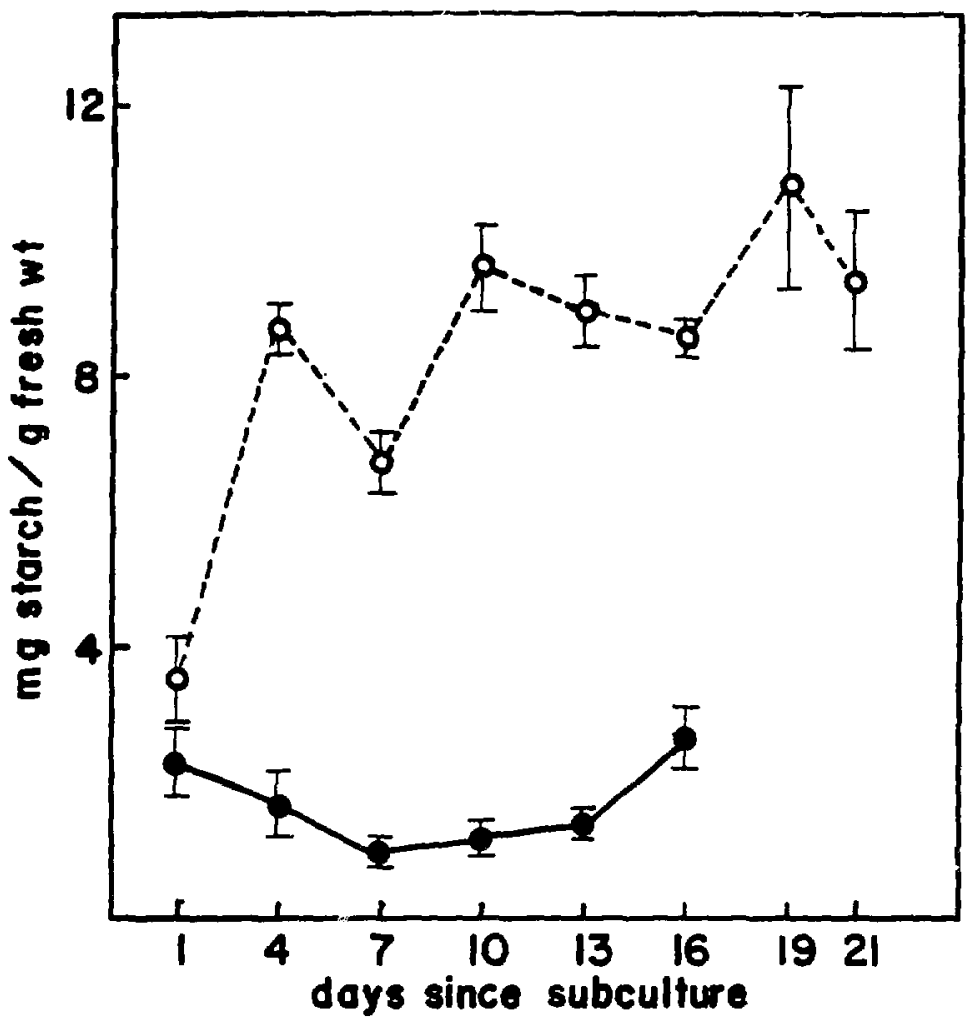

XBL $828-11328$ 


\section{CHAPTER 3}

\section{SUCROSE METABOLISH IN NON-SHOOT-FORMING}

\section{AND SHODT-FORHING TOBACCO CALI.US CULTURES}

In Chapter 2 conditions were described for establishing tobacco callus cultures from stem pith explants, for maintaining this tissue in an unorganized state, and for inducing the formatiun of shoots from unorganized callus tissue. Differences between the growth rates, chlorophyll contents, and starch concentrations of shoot-forming and non-shoot-forming callus cultures were al so presented and discussed. Studies designed to measure changes in sucrose metabolism during shoot formation will be described and interpreted in the present chapter. The complete experimental and analytical methods will be explained first, followed by appropriate control experiments. Methods were modified for some control experiments; these will be diszussed with the individual experiments.

1. Methods for studies on sucrose netabolism in calius cultures.

\section{a. Assay for sucrose metabolism.}

Known amounts, $0.2-1.0 \mathrm{~g}$ fresh wetght, of callus tissue were carefully placed on the botton of $5 \mathrm{ml}$ Fernbach flasks. The friable NSF tissue was gently spread on the botton of the flasks to a thickness of less than $4 \mathrm{~mm}$. Immediately prior to the experiments, 
the more crisp SF tissue was carefully sliced to a thickness of approximately $2 \mathrm{~mm}$ using new single-edged razor blades and a dissecting microscope. (Potential problems associated with slicing SF ti isue will be discussed Section 4 of this chapter). The slices were then evenly distributed on the botton of flasks. Thin layers of callus were used to facilitate penetration of $\left[\mathrm{U}_{-}{ }^{14} \mathrm{C}\right]$ sucrose into the tissue, and to minimize diffusion gradients of the labelled substrate. Representative samples were set aside for dry weight / fresh weight deteminations (see Chapter 2).

The assay of sucrose metabolism began with addition of $0.5 \mathrm{mt}$ $0.3 \%(w / v)\left[U-{ }^{14} \mathrm{C}\right]$ sucrose $(25 \mathrm{mM}, 360 \mathrm{mCi} / \mathrm{mmol}, \mathrm{ICN}$ Corp., Irvine, CA), to each flask. The final specific activity of the radioactive sucrose was $2.4 \mathrm{mCi} / \mathrm{mg}$-atam carbon. The labelied sucrose solution was carefully dripped over the tissue to ensure uniform wetting. A shortened $1.5 \mathrm{ml}$ plastic centrifuge tube, containing a $1.7 \mathrm{~cm} \times 2.0 \mathrm{~cm}$ Whatman No. 42 filter paper wick soaked with 50 ul of $3 \mathrm{~N} \mathrm{XOH}$, was placed in the center of each flask to allow measurement of ${ }^{14} \mathrm{CO}_{2}$ release. The flasks were sealed with rubber serum stoppers, and attached to a water bath shaker such that the bottom of each flask was immersed in the $30^{\circ} \mathrm{C}$ water bath. Shaker speed was set at $50 \mathrm{rpm}$, and experiments were performed under room lighting.

Representative flasks were removed from the shaker apparatus 15, 30 , and 60 min after addition of labelled sucrose, The ${ }^{14} \mathrm{CO}_{2}-$ containing wicks were placed in glass scintillation counting vials containing $0.5 \mathrm{mi}$ Protosol (New England Nuclear, Boston), and $15 \mathrm{ml}$ Permafluor (a nonaqueous counting solvent, Packard Instrument Co. Downers Grove, IL) were added to each vial. Labeliting of $\mathrm{CO}_{2}$ was 
detemined by liquid scintillation counting (Packard Tri-Carb 460 CD liquid scintillation counter). Callus tissue was quickly transferred with $3 \mathrm{ml} 0.3 \%(\mathrm{w} / \mathrm{v})$ unlabelled sucrose to a Millipore microfilter apparatus (Millipore Corp, Bedford, MA). The tissue was washed twice with $10 \mathrm{ml} 0.3 \%(w / v)$ unlabelled sucrose, followed by three washes with $10 \mathrm{ml}$ water to remove extracellular $\left[{ }^{14} \mathrm{C}\right]$ sucrose. Washes were allowed to stand for $5 \mathrm{sec}$ before removal by vacuum. Tissue was retained on whatman No. 1 filter paper discs (2.5 cm diameter). The entire procedure for harvesting and washing callus required less than $2 \min$.

\section{b. Extraction of callus tissues.}

Callus was quickly transferred from the filter paper disc to a 35 ml Kontes glass homogenizing tube (Kontes Glass Co., Vineland, NJ), and hamogenized on ice with $1 \mathrm{ml}$ cold methanol:chlorofonm:water $(12: 5: 3, v / v / v)$ (MCW). The homoyenate was transferred to a $15 \mathrm{ml}$ glass conical centrifuge tube with an additional $1 \mathrm{ml} \mathrm{MCW}$. Methanol, $4 \mathrm{ml}$, plus $1.6 \mathrm{ml} \mathrm{chl}$ orofom were added per gram fresh weight of callus tissue to reestablish a monophasic solution. Tissue homogenates were covered with Parafilm " $M$ " (American Can Co., Greenwich CT) and refrigersed at $4{ }^{\circ} \mathrm{C}$ overnight.

Homogenized callus tissue was centrifuged 4 times, $180 \times \mathrm{g}$, at room temperature, for $10 \mathrm{~min}$, the pellet being resuspended in $2 \mathrm{ml} \mathrm{MCW}$ each time. Supernatants were combined in $40 \mathrm{ml}$ glass conical centrifuge tubes, and $2 \mathrm{ml}$ water added to create a biphasic solution. Following centrffugation, $200 \times \mathrm{g}, 4^{\circ} \mathrm{C}, 30 \mathrm{~min}$, the aqueous phase was removed with a transfer pipeite. Chloroform-soluble matertals were 
transferred to glass vials, and chlorofom was remuved by blowing $\mathrm{N}_{2}$ ges over the surface. Permafluor, $15 \mathrm{ml}$, was added for scintillation counting. The chloroform-soluble extracts will be referred to as the lipid fraction.

\section{c. Fractionation and chromatography of aqueous extracts.}

The aqueous layer obtalned above was reduced to approximately 1 $\mathrm{ml}$ by blowing $\mathrm{N}_{2}$ gas over the surface, and the concentrated solution was applied to a column of cation-exchange resin $10.5 \mathrm{~cm} \times 4 \mathrm{~cm}$, 8ioRad 50W-x8, hydrogen form, $200-400$ mesh, Bio-Rad Labs, Richmond, (A). (The resin had been prewashed to remove impurities with approximately 10 resin volumes boiling methanol, followed by 20 resin volumes $1 \mathrm{~N} \mathrm{NaOH}$, then 20 resin volumes $1 \mathrm{~N} \mathrm{HCl}$, and finally 10 resin volumes Milli-D water (Millipore Corp.)) The column was flushed with $4 \times 1 \mathrm{ml}$ Milli-Q water to yield an effluate which contained sugars, organic acids, and phosphate esters. The column was then eluted with $4 \times 1 \mathrm{ml} I \mathrm{M}$ aqueous pyridine to give a fraction containing neutral and acidic amino acids. Finally, basic amino acids and amines were eluted with $4 \times 1 \mathrm{ml} 3$ "qo"eous ammonia. Duplicate aliquots of each fraction were removed for liquid seintillation counting. These methods were origlnally devaloped by 0 . Peder Larsen for use in studies on metabolism of isolated spinach cells (Larsen, et al., 1981).

The effluent was reduced in volume to $1 \mathrm{ml}$, by use of a stream of $\mathrm{N}_{2}$. A fraction containing approximately $2 \times 10^{6} \mathrm{dpm}$ was subjected to two-dimensional descending paper chromatography on whatman No. 1 filter paper $(57.5 \mathrm{~cm} \times 46 \mathrm{~cm})$ in the standard system used by this 
laboratory (see Pedersen, et al., 1966). Solvent A was prepared by mixing 11.91 "liquified phenol" (Aallinckroft, St. Louis) with 51 water, and $83.5 \mathrm{~g} \mathrm{NaCO}_{3}$. The mixture was stirred overnight, then the bottom layer was removed. Water in equilibrium with this solution was adjusted to $\mathrm{pH} 4.1$ - 4.4 by adding approximately $300 \mathrm{ml} \mathrm{glacial} \mathrm{acetic}$ acid to the phenol-water mixture. (Final ratio phenol:yater was approximately 12:5, v/v). Two papars were suspended from each solvent trough, which contained $100 \mathrm{ml}$ Solvent $A$. Up to 10 papers were enclosed in each air-tight metal box, and chruinc ograms were allowed to develop for 26 hours at room temperature. hromatography in the second dimenston was effected using $120 \mathrm{ml}$ so ent $B /$ trough, and chromatograms were developed for 20 hours. Solvent B contained butanol:propionic acid:water $(8: 5: 4, v / v v)$. It was prepared immediately prior to use by mixing equal volumes of butanol:water $(15: 1, v / v)$ with propionic acid:water $(9: 1 \quad v / v)$.

Paper chromatugrams were marked at the corners with ${ }^{14} \mathrm{C}$ ink (prepared by adding $\left.:{ }^{14} \mathrm{C}\right] \mathrm{glucose}$ to ind $i$ ink), exposed to Kodak SB-5 $x$-ray film for 2 weeks at room temperature, then developed using koaak chemicals (Eastman Kodak Co., Roches $r$, NY). The pavers and films were aligned by matching the marked Jrners, and labelled areas of the paper which corresponded to darkeneu regions on the film were removed with a scalpel blade. The paper spots were cut into small pieces and shaken for 1 hour with $2.5 \mathrm{ml}$.ter in glass scintfllation counting vials. Radioactivity in ea, spot was determined by liquid scintillation counting after addition of $15 \mathrm{ml}$ Aquassure (an aqueous counting solvent, New Englar. Nuclear, Boston).

values of ${ }^{14}$ C-labelling were obtained for citrate, malate, 
fructose, glucose, sucrose, and glucose- and fructose-monophosphates. These compounds were previously identified by cochromatoraphy and autoradiography using known standards, and were routinely located by their $R_{f}$ values. Organic acids were detected as yellow spots on a blue background after spraying papers with a mixture containing $0.04 \mathrm{~g}$ bramocresol green, $95 \mathrm{ml}$ ethanol, and $5 \mathrm{ml}$ water, adjusted to $\mathrm{pH} 5.5$ with $\mathrm{NaOH}$, as reported by Lugg and Overell (1948). Sugars were detected as dark-brown spots on a light-brown background using silver nitrated dissolved in acetone. The solvent was prepared by adding 0.5 mI saturated aqueous $\mathrm{AgNO}_{3}$ to $100 \mathrm{ml}$ acetone plus sufficient water to dissolve the precipitate. Papers were dipped quickiy into this solution. aried papers were sprayed with a solurion containing $20 \mathrm{~g}$ $\mathrm{NaOH}$ (dissolved in a mirimal amount of water) and 11 ethanol. Sugar phosphates and sugar nucleotides were datected as iliue spots on a whita background after spraying papers with a mixture of $5 \mathrm{ml} 70 \%$ (w/v) perchloric acid, $10 \mathrm{ml} \quad \mathrm{l} N \mathrm{NCl}$, and $25 \mathrm{ml} 4 \mathrm{~F}(\mathrm{w} / \mathrm{v}$ ) $\left(\mathrm{NH}_{4}\right)_{6} \mathrm{MO}_{7} \mathrm{O}_{;}$, , as reported by Hanes and : sherwood (1949).

The pyricine eluate, containing neutrat and acidic amino acids, was dried using a stream of $\mathrm{N}_{2}$, then resuspended in $0.2 \mathrm{mi}$ water. Approximately $10^{4} \mathrm{dpm}$ were spotted for two-dimensional descending paper chromatography. The solvent for the first dimension, solvent $C$, contained butanoliwater:glacial aceric acid $(12: 5: 3, v / v / v)$. Chramatograms were developed for 20 hours, using $150 \mathrm{ml}$ of solvent c/ trough from which 2 papers were hung. Chromatography in the second dimension used $150 \mathrm{ml}$ soivent $\mathrm{D} /$ trough, and the development time was 24 hours. Solvent D container butanol :methylethyl ketone:ammonium hydroxide $(58 \%, v / v)$ :water $(5: 3: 1: 1, v / v / v / v)$. Both dimensions were 
chromatographed at room temperature. Autoradiography was accomplished as described above, except that the $x$-ray filns were exposed for 3 weeks. Anino acids were identified by their $R_{f}$ values, which were previously determined using known amino acid standards (Sigma Chemical Co.). The nonradioactive standards were located after spraying papers with $0.1 \%(w / v)$ ninhydrin dissolved in $95 \%$ ethanol, then heating them at $70{ }^{\circ} \mathrm{C}$ for $10 \mathrm{~min}$. Quantification of radioactivity in individual paper spots was achieved as described above.

\section{d. Fractionation of $\mathrm{MCH}$-insoluble macromolecules.}

.IThe pellet obtairad after MCW extraction of tissue homogenates was fractionated and analyzed using a modification of the methods of Dickson (1979). It was first washed with $2 \mathrm{ml}$ water, followed by 20 minutes centrifugation at room temperasure, at $180 \times \mathrm{g}$, to remove traces of chloroform and methanol. Duplicate aliquots of the supernatant were renloved for liquid scintillation counting. The water-insoluble protein was solubilized after addition of $2 \mathrm{ml} 0.08 \%$ (w/v) Protease (Signa Chemical Co.) in $0.05 \mathrm{M}$ tris(hydroxymethyl) amino methane (TRIS) buffer, $\mathrm{pH} 7.4$, to each sample. Samples were covered with Parafilm "M" and incubated for 24 hours in a water bath shaker, $30{ }^{\circ} \mathrm{C}$, with continuous agitation at $100 \mathrm{rpm}$. Peptide fragments were removed by collecting te supernatant after 30 min centrifugation of samples at room tomperature, at $180 \times \mathrm{g}$, followed by 2 washes with 2 $\mathrm{ml}$ water. Duplicate aliquots of the combined supernatants were removed for liquid scintillation counting to determine the radioactive-labelling of protein. These results were combined with those from the initial water wash of the pellet, which removed some 
soluble proteins, to yield an estimate of total protein labelling during the assay.

Pellet starch was then digested using Clarase 900 (Miles Laboratories, Elkhart, IN) and quantified colorimetrically as described in Chapter 2. Duplicate aliquots of this fraction were also removed to measure radioactive labelling of starch by liquid scintillation counting.

The pellet residue, which contained mostly cell wall debris, was suspended in $1 \mathrm{ml}$ water, and duplicate aliquots were removed for scintillation counting.

A summary of these fractionation procedures is presented in Figure 1.

2. Ethanol interferes with sucrose metabol ism.

A preliminary experiment revealed the importance of removing the ethanol from $\left[\mathrm{U}_{-}{ }^{14} \mathrm{C}\right]$ sucrose solutions prior to metabolic studies with callus tissue. Ethanol, $20 \%(\mathrm{v} / \mathrm{v})$, was added to the radioactive sucrose purchased from ICN Corporation to retard growth of bacteria. If rot renoved before the radioactive labelling experiments, the final concentration of ethanol in the incubation solution was $4 \%(v / v)$.

Methods. NSF callus tissues, 1 week after subculture, were supplied with $\left[U_{-}{ }^{14} \mathrm{C}\right]$ sucrose for 60 minutes in the presence or absence of ethanol. Ethenol was removed from control assay solutions by drying the radioactive sucrose solution under a stream of $\mathrm{N}_{2}$ before dddition of an appropriate volume of nonradioactive $0.3 \%$ ( $v / v)$ sucrose. Duplicate samples were obtained for each tratment. Callus samples were homogenized and extracted as described in section lb of 
this chapter, and fractionated using cation-exchange resin as described in Section 1c of this chapter. The acidic and neutral amino acids were separated by applying the pyridine eluate from the cationexchange column to a similar column containing prewashed anionexchange resin $(0.5 \mathrm{~cm} \times 4.0 \mathrm{~cm}$, Bio-Rad $A G 1-\times 8$, acetate form, 200 400 mesi:: Bio-Rad Labs, Richmond, CA). The columns were flushed with $4 \times 1 \mathrm{ml}$ Milli-Q water to yield an effluent containing neutral amino acids. Acidic anino acids were eiuted with $4 \times 1 \mathrm{ml} 2 \mathrm{~N}$ acetic acid (procedure developed by Dr. Peder Larsen). Radioactivity in duplicate aliquots of each fraction was quantified by liquid scintillation counting.

Results and Discussion. Differences were observed in the percentage of total ${ }^{14} \mathrm{C}$ in aqueous extracts distributed between the three amino acid fractions from the two assay conditions (Table 1). Metabolism of $\left[U-{ }^{14} \mathrm{C}\right]$ sucrose to acidic and basic amino acids was inhibited in the presence of ethanol, and synthesis of neutral amino acids was stimulated by ethanol, relative to control samples assayed wi thout ethanol. Though the differences in results fram the two assay conditions were not large, they are considered significant because results obtained with duplicate samples were almost identical. In all subsequent experiments, ethanol was removed frum the radioactive sucrose solutions prior to metabolism studies.

3. Variabifity in replicate samples of calius tissue.

Because large numbers of samples were required for analysis of $\left[\mathrm{U}-{ }^{14} \mathrm{C}\right]$ sucrose metabolism by SF and NSF callus tissues, it was not feasible to obtain true replicates. A separate control experiment was 
therefore performed to provide an estimate of the metabolic variability in unorganized callus tissue.

Methods. This study was performed before selection of the NSF medium described in chapter 2, and calli were initiated and subcultured on a medium which was identical in nutrient camposition to NSF medium, but which containej $2 \mathrm{mg} / 1$ indole-3-acetic acid (IAA) as auxin, and $0.1 \mathrm{mg} / 1$ 6-benzylaminopurine (BAP) as cytokinin. Callus was subcultured two weeks prior to the experiment described here.

Some modifications of the standard experimental procedures were used in this study. Callus tissue was incubated in $0.3 \%(w / v)$ [U ${ }^{14} \mathrm{C}$ ] sucrose of a lower specific activity $(0.8 \mathrm{mCi} / \mathrm{mg}$-atom $\mathrm{C})$, washed with $10 \mathrm{ml}$ water, then homogenized in $2 \mathrm{ml} 80 \%(\mathrm{v} / \mathrm{v})$ aqueous ethanol, followed by washes with $2 \mathrm{ml} 80 \%(\mathrm{v} / \mathrm{v})$ aqueous ethanol, 2 $\mathrm{ml} 20 \%(\mathrm{v} / \mathrm{v})$ aqueous ethanol, and $2 \mathrm{ml}$ water. The combined extracts were spotted directly for paper chromatography without prior fractionation, using solvents $A$ and $B$, as described above.

Results and Discussion. The culture medium used in this experiment maintained calli in an unorganized state, though the texture of the calli was crisp and compact and in this respect resembled SF calli prior to the emergence of shoots. The cytokinins BAP and OMAAP have been reported to have similar effects on shoot fomation in tobacso calli (Murashige, 1974). IAA is a less potent auxin in tissue culture studies than the artificial auxin, NAA. This is partially explained by in vivo inactivation of the natural homone (Murashige, 1970). Shoot formation was less reproducibly induced in calli grown on media containing IAA and BAP compared to calli gromn on media containing NAS and DMAAP, hence the selection of the latter 
hormones for metabolic studies on shoot formation.

Average radioactive-labelling rates for selected metabolites from 4 replicate samples are presented in Table 2. For the three sugars the calculated rates for incorporation of ${ }^{14} \mathrm{C}$ at 15 and $30 \mathrm{~min}$, and at 30 and $60 \mathrm{~min}$ were not significantly different $(p=0.05\}$. (Significance tests were performed using Student's t-test for differences between mean values. In subsequent discussions, the term significant is used when the probability of error in accepting the hypothesis of significantly different mean values was less than 0.05 ). Rates of labelling of malate, citrate, giutamate, and aspartate increased significantly betwann 15 and $60 \mathrm{~min}$. Similar labelling kinetics for these metabolites were observed in studies using NSF and SF calli, presented in Section 5 of this chapter. Explanation of these results will be deferred to that section.

In this experiment, almost $97 \%$ of the ${ }^{14} \mathrm{C}$ extracted from callus tissue remained in sucrose (Table 2), a large fraction of which was probably of extracellular (free space) origin. Subsequent experiments employed more extensive washing with $0.3 \%(w / v)$ sucrose ald wister before homogenization, as outlined in Section $I$ of the present chapter. Under these conditions, ${ }^{14} \mathrm{C}$ remaining in sucrose decreased to between $20 \%$ and $40 \%$ of the tnta?. When callus was washed more extensively, rates of glucose and fructose labelling with ${ }^{14} \mathrm{C}$ were similar to those observed in this experiment, and the amount of sucrose approximately equalled that of glucose and fructose. The greater ${ }^{14} \mathrm{C}$-labelling of glucose than of fructose in this experiment (Table 2), is explained by known cochromatoraphy of serine and glycine with glucose. 
be interpreted with caution. In studies reported below, only those differences in sucrose metabolism of NSF and SF calli that are greater than $30 \%$ will be considered significant.

4. Use of $0.3 \%$ sucrose for metabolic studies with callus tissue.

A preliminary study revealed that $\left[U-{ }^{14} C\right]$ sucrose uptake during the assay described in Section 1 of this chapter was proportional to the concentration of sucrose supplied. However, the total amount of radioactive sucrose which must be added to $3 \%(w / v)$ sucrose solutions to obtain a specific activity sufficient for detection of most intemediary metabolites prohibited the use of sucrose at this concentration during studies comparing SF and NSF calli. The following experiment was designed to detemine whether significant differences in metabolite concentrations resulted from the use of $0.3 \%(w / v)$ sucrose instead of $3.0 \%(w / v)$ sucrose solutions during studies of sucrose utilization.

Methods. Non-shoot-forming tobacco callus tissue was subcultured to NSF medium containing $\left[\mathrm{U}-{ }^{14} \mathrm{C}\right]$ sucrose at a specific activity of 8.5 $\times 10^{-3} \mathrm{mCi} / \mathrm{mg}$-atom sucrose. The radioactive sucrose was added by filter sterilization to freshly-prepared NSF madium before the medium was poured into Petri dishes. Aliquots of medium were removed, and radioactivity was determined by liquid scintillation counting. This allowed accurate determination of the specific activity of culture mediun, Calli were grown for 3 weeks on this medium, then subcultured to identical [U- $\left.{ }^{14} \mathrm{C}\right]$ sucrose NSF medium. Control experiments described in Chapter 4, Section 1 revealed that metabolite pools were saturated with ${ }^{14} \mathrm{C}$ under these conditions. Callus tissue was removed for use in 
metabolite labelling studfes one week after the second subculture to $\left[U-{ }^{14} \mathrm{C}\right]$ sucrose medium.

Samples of callus tissue of known fresh weight were incubated for $60 \mathrm{~min}$ in four assay solutions. Solution A contained $0.3 \%(w / v)$ $\left[{ }^{14} \mathrm{C}\right]$ sucrose in water; Solution $B$ contained $\left.0.3 \%(w / v) L^{14} \mathrm{C}\right]$ sucrose in 1 iquid NSF medium; Solution $C$ contained $3.0 \%(w / v)\left[{ }^{14} \mathrm{C}\right]$ sucrom in water; and Solution $D$ contained $3.0 \%(w / v)\left[{ }^{14} \mathrm{C}\right]$ sucrose in liquis NSF

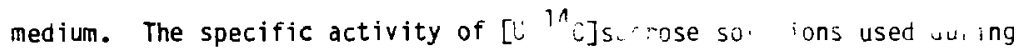
the 60 min metabolism studies was identical to that of the iredi $n \mathrm{rn}$ which calli were grown. : e NSF mediu used for these assay ias 2 same as that described in Chapter 2, except thac it lacked as and contained the designated concentrations of sucr. Con' ul sus tissue was washed in the usual manner to remove extraceliular s,

but was not incubated in any of the $\left[{ }^{14} c\right]$ sucrose solutions. With he exception of the assay solutions, the experimental ard sibiytir. procedures used in these studies wers identical to those Section 1. An unidentified systematic error was observed $r$ ts for duplicate samples of callus assayed using the fo sucrose solutions described above. Therefore, only results for single s: exposed to each assay condition are presented $b_{2} J w$. Res $i^{7} t s$ for control samples represent averages of duplicate determinations.

Results and Discussion. Metabolite conce rations were calculated by dividing the radir tivitymeasured in a particular compound by the specific activity of the sucrose in the medium on which calli were grown; ng-atams $C$ were converted to 1 . Jles by dividing by the number of carbori atams ner molecule: results westandardized by dividing moles by the fresh wi it if $f$ samfie. 
Concentrations of selected metabolites after 60 min incubation in the various solutions were divided by the corresponding mean metabolite concentrations calculated for control samples. Results are presented in Table $3 a$.

With the exceptions of proline, alanine, $Y$-aminobutyric acid, and ACC, which will be discussed separately, metabo? ite concentrations in callus incubated in $3.0 \%(w / v)$ sucrose in NSF Tedium (Solution D) were quite similar to those in the control calli (Table 3a). Although sufficient samples were not available to perform statistical analysis, the differences abserved between metabolite concentrations in the control and in the sample incubated in Solution 0 were less than those observed between duplicate control samples, and are therefore not considered significant.

Most differences between experimentals and controls are only partially expiained by leakage of metabolites from broken cells in the sliced tissues. The differences in sugar concentrations between sliced and intact calli were less than $5 \%$ (Table 4). Similar differ: ces between sliced and intact calli were observed for most other metabolites, suggesting that only a small percentage of cells were broken during the freparation of callus tissue for the assays.

Sucrose concentrations were approximately $10 \%$ lower in callus samples iricubated in $0.3 \%(w / v)$ sucrose, Solutions $A$ and $B$, than in corresponding samples incubated in $3.0 \%(w / v)$ sucrose, Solutions $C$ and D. (Table 3a). These differences in sucrose concentrations caii be explained by differences in rates of passive uptake of $\left[{ }^{14} \mathrm{C}\right]$ sucrose during the 60 min assay. Preliminary experiments revealed that rates of sucrose incorporation are proportional to the concentration of 
surrose supplied in the assay solution. Camparison with other experiments where metabolism of unlabelled callus tissue was assayed using $\left[{ }^{14} \mathrm{C}\right]$ sucrose reveals that uptake of $\left[{ }^{14} \mathrm{C}\right]$ sucrose from $0.3 \%$ (w/v) sucrose solutions during the $60 \mathrm{~min}$ assay accounts for approximately $0.5 \%$ to $1.0 \%$ of the total sucrose pools. Assuning $10-$ fold greater rates of sucrose uptake in $3.0 \%$ sucrose solutions, sucrose concentrations in callus tissue incubated in Solutions $C$ and $D$ would be $5 \%$ to $10 \%$ greater than sucrose concentrations in callus incubated in Solutions $A$ and $B$. This is exactly what was observed in this experiment.

Concentrations of glucose and fructose ware approximately $30 \%$ lower in tissue incubated in aqueous sucrose, Solutions $A$ and $C$, compared to tissue incubated in NSF medium with the corresponding sucrose concentrations, Solutions $B$ and $D$ respectively (Table 3a). Results presented below show that cell wall invertase hydrolyzes much of the sucrose metabolized by callus tissues. The difierences between samples assayed in aqueous sucrose and in NSF medium can be explained by decreased activity of cell wall invertase in the former samples. Tliorpe and Meier (1972) demonstrated a pH optimum of 5.0 for cell wall invertase isolated from tobacco callus cultures, Solutions $B$ and D were adjusted to $\mathrm{pH} 5.8$ prior to the assay. Solutiolis $A$ and $C$ were approximately pH 7. Medium $\mathrm{pH}$ was not measured after tne 60 min incubations.

The differences in concentrations of hexose monophosphates and citrate between samples incubated in the four assay solutions and control samples were less than those observed between duplicate control samples (Table 3a). This shows that two major pathways of 
sucrose metabolism, glycolysis and the tricarboxylic acid cycle, were not significantly altered during the 60 min assays.

Malate and aspartate concentrations in calli incubated in $0.3 \%$ sucrose solutions were $30 \%$ to $40 \%$ less than in calli incubated in $3.0 \%$ sucrose solutions. No satisfactory explanation for these differences is available at the present time. Comparison of these results with those from other radioactive labeling experiments reveals that less than $0.1 \%$ of the ${ }^{14} \mathrm{C}$ in the intemediary metabolites was derived from $\left[{ }^{14} \mathrm{C}\right]$ sucrose supjlied during the 60 min assays. Therefore differences observed between metabolite concentrations of experimentals and controls are due primarily to metabolism of compounds synthesized prior to the assays.

There was no discernable trend in the differences observed between the glutamate and glutamine concentrations of experimental samples and controls (Table 3a). Samples incubated in $3.0 \%$ sucrose in water (Solution C) contained $15 \%$ and $30 \%$ less glutamate and glutamine, respectively, than samples incubated in $0.3 \%$ sucrose solutions (Solutions $A$ and $B$ ). Glutamate concentrations in samples incubated in $0.3 \%$ sucrose solutions were approximately $20 \%$ less than the mean glutamate concentrations in controls; siutamine concentrations in samples incubated in $0.3 \%$ sucrose solutions were approximately $10 \%$ greater than the mean glutamine concentrations in controis. The apparent increase in glutamine and decrease in glctamate concentrations could result from increased activity of glutamine synthetase in samples incubated in $0.3 \%$ sucrose. This enzyme has been isolated from tobacco callus tissues (Skokut, et al., 1978). However no explanation for the apparent increasd activity of 
this enzyme in these samples is available at the present time. It is possible that differences in glutamate and glutamine concentrations between samples assayed in $0.3 \%(w / v)$ sucrose solutions and controls reflect the heterogeneity of the callus samples. These differences were similar to the differences observed between duplicate control samples.

The amount of proline in calli incubated in $3.0 \%$ sucrose solutions, Solutions $C$ and $D$, was only one-half that observed in samples incubated in $0.3 \%$ sucrose solutions, Solutions $A$ and $B$; yet proline concentrations in the latter more closely resembled those of the control samples (Table 3a). No satisfactory explanation for this observation is available at the prcsent time, though it is interesting to note that prolise concentrations in intact calli incubated in Solution Doid not decrease during the 60 min assay (Table 4). The large variability in proline concentrations in these tissues suggests either heterogeneous distribution of this amino acid in the intact calli, or that synthesis and degradation of this amino acid is extremely sensitive to enviromental perturbations. Hanson and Hitz (1982) recently reviewed regulation of proline metabolism during water stress, where proline concentrations can increase 100-fold during hours to days of moderate to severe water deficit. Proline also accumulates in response to various other types of stress, including mineral deficiency, salt stress, low temperatures, and anaerobic conditions (Steward and Lahrer, 1980). Although not directly analogous, these studies support the contention that proline levels vary considerably with enviromeital conditions.

Alanine and $Y$-aminobutyric acid concentrations were approximately 
1.5- and 2.5-fold greater, respectively, in calli incubated in the four assay solutions, relative to control tissues which were not incubated in sucrose solutions prior to extraction (Table 3a). The concentrations of these two amino acids also increased in intact callus tissue incubated in jolution $D$ fo: $60 \mathrm{~min}$, suggesting that possible wounding associated with slicing of callus tissue was not responsible for the observed changes (Table 4). Streeter and Thampson (1972) reported accumulation of alanine and $Y$-aminobutyric acid in radish leaves within 30 mill after exposure to anaerobic conditions. They suggested that anaerobic incubation may have caused a loss of intracellular compartmentation, resulting in exposure of metabolically inactive precursor pools to enzymes involved in the synthesis of these amino acids. Changes in intracellular pH might also have triggered the accumulation of alanine and $\gamma$-aminobutyric acid (Streeter and Thampson, 1972). Because the oxygen tension in aqueaus solutions is low relative to that of nomal atmospheric conditions, partial anaerobiosis during incubation of callus tissues in the four assay solutions described here may explain the observed accumulation of these amino acids.

1-aminocyclopropane-1-carboxylic acid (ACC) concentrations increased approximately $15 q$ during the $60 \mathrm{~m}$ in assays in the four sucrose solutions (Table $3 a$ ). ACC also accumulated in intact calli assayed in Solution D (Table 4). This amino acid is the direct precursor to ethylene, and concentrations of ACC often parallel the rate of ethylene production in plant tissues (Adams and Yang, 1981). Ethylene production often increasts many-fold within one hour after mechanical wounding of plant tissues (Apelbaum, et al., 1981, and Yu 
and Yang, 1980). The mere $15 \%$ increase in ACC concentrations in samples reported here suggests that major damage to the callus tissues was not inflicted during the slicing and handing of calli prior to the 60 min assays.

concentrations of the three pellet fractions, (protein, starch, and residue), in callus tissues incubated for $60 \mathrm{~min}$ in the four sicrose solutions are presented in Table 3b. Results for control samples are not available. However, because intermediary metabolite concentrations in callus tissue incubated in solution $D$ were quite similar to those of the controls, it is reasonable to expect that end-product concentrations in this sample would also be much like those of calli not assayed in sucrose solutions. Differences in results from the four experimental conditions were not greater than $20 \%$. Because the variability observed in matabolite concentrations of duplicate control samples averaged $15 \%$, these differences in endproduct concentrations of the experimental samples are probably not significant.

Only small differences in tissue respiration, lipid concentrations, and basic anino acid pools were observed between samples incubated in water and NSF madium, or $0.3 \%$ and $3.0 \%$ sucrose solutions (Table 3b). Respiration from unsliced tissue incubated in Solution $\mathrm{D},\left(7\right.$ unole ${ }^{14} \mathrm{CO}_{2}$ released / 9 fresh weight. / hour) was approximately $20 \%$ lower than respiration in the corresponding sliced sample. This suggests a mild wound response in the fresh callus slices. An immediate 5-fold $r^{i}$ se in respiration is often observed after slicing potato tuber tissue (Kahl, 1974), and tomato pericarp tissue (Lee, et al., 1970). (This response is not the same as the 
induced wound response observed in storage tissue slices, which reaches a maximum 1 - 2 days after slicing). The sudden release of $\mathrm{CO}_{2}$ in fresh tissue slices is explained by release of $\mathrm{CO}_{2}$ previously trapped within the tissues (Kahl, 197\%), and al so by increased rates of lipid oxidation (Laties, 1978).

It is not possible at this time to provide explanations for all of the individual results presented in Tables $3 a$ and $b$. Though incubation for 60 min in $3.0 \%$ sucrose in NSF medium affected callus metabolite concentrations the least, this assay solution was not a feasible choice for experiments requiring assay of numerous samples. Because assay solutions containing $0.3 \%$ sucrose in water and MSF medium resulted in similar alterations of intermediary metabolite concentrations, subsequent experiments were performed using the most simple solution, $0.3 \%$ sucrose in water. (Although invertase activity was apparently decreased in samples incubated in water, the use of NSF medium was considered undesirable for assays with SF calli. Possible shurt-term metabolic responses to homones, though not welldocumented, would introduce additional variables and complicate interpretation of results).

Absolute rates of radioactive labelling of specific metibolites in tissues assayed using the methods described here will contain same error due to uncontrolled effects of incubation in the assay solutions on tissue metabolism. However metabolite labellings reported below for NSF and SF callus tissues should reflect differences in intemediary metabolism in the two types of calli. Both were treated identically, and any changes in metabolism that resulted from the assay conditions should be similar in both NSF and SF samples. 
To detemine whether appreciable losses of intracellular metabolites occur during the rinsing of callus tissue to remove extracellutar sucrose, duplicate samples of callus tissue were homogenized directly from the Petri dishes, without prior rinsing. The average concentrations of metabolites in these samples are compared with those in samples which were rinsed prior to homogenization (Table 5). Tissues were not incubated in sucrose solutions. Sucrose, glucose, and fructeso concentrations decreased dinost $50 \%$ in the rinsed tissue, compared to tissue which was not rinsed. This result offers substantial support for the hypothesis that cell wall invertase actively hydrolyzes much of the sucrose supplied to tobacco callus. Straus (1962) demonstrated the occurrence of Invertase in cell wall fractions of tissue cultures of several different plant species, including tobacco. Thorpe and Meier (1972) al so observed invertase activity associated with the insoluble (cell wall) fraction from tobaccc tissue cultures.

Giutamine, proline, and alanine concentrations were reduced by $18 \%, 22 \%$, and $28 \%$ respectively in the rinsed sumples. Glutamine is the predominate free aming acid found in tobacco calli, and the decrease observed in rinsed tissues suggests that excess amounts of this amino acid are actually secreted from the tissues. Glutamine accumulation wiil b. discussed in more detail in Chapter 4. The decreases in alanine and proline concentrations in rinsed samples also suggests active elimination of these amino acids from the callus tissues, though as discussed above, proline levels in t'iese calli varied considerably, and the decrease in rinsed samples may be the result of heterogeneous concentrations of this amine acid in intact. 
calli. Differences in concentrations of other metabolites (hexose monophosphates, malate, citrate, aspartate, glutamate, asparagine, -aminobutyric acid, and $A C C$ ), from rinsed and unrinsed samples were less than $10 \%$. These differences probably reflect metabolic heterogeneity inherent in the callus tissues, as this amount of variability was not uncommon in replicate samples (see Section 3 of this chapter). of course, it is al so possible that approximately $10 \%$ of the cells were broken during the rinsing of calli. Without homogeneous samples of callus tissue, it is not possible to distinguish between these alternatives.

\section{Sucrose metabolism by MSF and SF calli.}

The following experiment was designed to detect characteristic differences in the intermediary metabolism of SF and NSF tobacco calli. Due to limitations discussed above in the procedures used to assay sucrose metabolism, discussion will be limited to major differences between the two types of calli, and will focus primarily on patterns of metabolism, rather than specific results. 


\section{a. Methods and general results.}

Methods. Specific metabolic differences between NSF and SF tobacco callus cultures were characterized using the procedures outlined in Section 1. Samples of both types of callus tissue were incubated with $0.3 \%(\mathrm{w} / \mathrm{v})\left[\mathrm{U}-{ }^{14} \mathrm{C}\right]$ sucrose for 15,30 , and $60 \mathrm{~min}$ at 1 , $4,7,10,13$, and 16 days after subculture to NSF or SF medium. . . days 7 - 16, calli were subdivided into top and bottom regione relative to the agar medium prior to assays with $\left[\mathrm{U}-{ }^{14} \mathrm{C}\right]$ sucrose solutions. Most results are expressed in ng-atom carbon units, which were calculated by dividing radioactivity measurements by the specific activity of the $\left[U_{-}{ }^{14} \mathrm{C}\right]$ sucrose supplied to tissues $\left(2.4 \mathrm{mCi}{ }^{14} \mathrm{C} / \mathrm{mg}\right.$ atan C).

Results and Discussion. At the initiation of this study, five pieces of callus were subcultured to each of 20 Petri dishes which were set aside for use in detemining the percentage of SF cultures which formed shoots. On day 16, dark-green spots indicative of shoot fomation were visible on about 50 of the SF calli. (Light microscopy confirmed that dark-green spots were the macroscopic equivalent of small shoot primordia). By 19 days after subculture, 75 \% of these calli contained young shoot buds, and by 4 weeks extensive shoot formation was observed in $96 \%$ of the callus pieces.

All results were standardized to $g$ dry weight of tissue by multiplying the fresh weight of each sample by the dry weight / fresh weight ratio calculated for each type of tissue on each sampling day. This serves to decrease many apparent differences between metabolism of MSF and SF calli, relative to measurements based on $g$ fresh weight, 
because while SF calli were generally more active metabolically, dry weight / fresh wight ratios for SF calli were almost twice as great as those for NSF calli after 10 days of culture on the appropriate media (Table 6).

Results obtained at 15,30 , and $60 \mathrm{~min}$ will be presented for the metabolic fractions and end-products. ${ }^{14} \mathrm{C}$-labellings at 15,30 , and 60 min will also be presented for hexose monophosphates, malate, and citrate from 7 day samples. Changes in rates of $\left[{ }^{14} \mathrm{C}\right]$ labelling of these metabolites with time were similar for samples obtained on other days. For amino acids, only ${ }^{14} \mathrm{C}$-labellings at $60 \mathrm{~min}$ will be presented. Radioactive-labellings of amino acids with time paralleled those for the neutral anc acidic amino acid fractions.

Though no true replicates were obtained due to the large numbers of samples required for this survey, exposing samples of the 4 types of tissue (NSF, tor half; NSF, bottom half; SF, top half; and SF, bottom half) to $\left[{ }^{14} \mathrm{C}\right]$ sucrose for 15,30 , and $60 \mathrm{~min}$ provided a measure of the variability in results.

SF calli were subdivided to facilitate detection of metabolic characteristics of the SF process. Ross and Thorpe (1973) presented evidence that top and bottom regions of SF calli are physiologically dissimilar. This trait was assoctated with the observation that shoots initially arise preferentially fram the bottom portion of the SF callus cultures. In the studies described here, metabolic differences between NSF and SF calli were usually accentuated in the botton halves of SF tissues. Though NSF tissues were subdivided originally as a control measure, differences in $\left[{ }^{14} \mathrm{C}\right]$ sucrose metabolism were in fact detected for the two halves of NSF calli. 


\section{b. Tota? incorporation of sucrose.}

The kinetics of total incorporation of $\left[\mathrm{U}^{-14} \mathrm{C}\right]$ sucrose into NSF and SF callus tissues are presented in Table 7 . No consistent differences in this respect were observed between NSF and SF tissues. Incorporation generally increased with increased exposure to the radioactively-labelled substrate, though the rates of incorporation were not linear.

Incomplete removal of extracellular sugars may explain the lack of linearity in sucrose incorporation obseryed for some samples. The rate of incorporation of ${ }^{14} \mathrm{C}$ at $60 \mathrm{~min}$ for the top region of NSF calli at 7 days was 2 -fold greater than that observed for 7-day samples of SF calli (Table 7); this result is not reflected in any of the metabolic fractions except the one which contained sugars. Table 8 shows that $99 \%$ of the radioactivity incorporated in this sample remained in sucrose, glucose, and fructose.

Heterogeneity of callus samples may also explain some of the variability in atterns of total ${ }^{14} \mathrm{C}$ incorporation. Examples of metabolic heterogeneity in callus tissues are quite common, as was discussed in Section 3 of this chapter. In most studies, $20-30 \%$ variabilfty between replicate samples was nomal.

Greater than $90 \%$ of the radioactivity incorporated into callus tissues renained in sucrose, glucose, and fructose (Table 8 ), hence total incorporation reflects primarily the amount of ${ }^{14} \mathrm{C}$ present in these three sugars. This result shows that uptake of sucrose from the culture medium is not a rate-limiting step in tobacco callus tissue metabol isn. 
The relative amounts of ${ }^{14} \mathrm{C}$ in sucrose, glucose, and fructose were not constant in these samples (Table 8), though in general calli contained greater amounts of ${ }^{14} \mathrm{C}$-labelled glucose and fructose than sucrose. No trends in the distribution of $14 \mathrm{C}$, between glucose, sucrose, and fructose were observed. Metabolic heterogeneity and possibly incomplete removal of extracellular sugars remain the most likely explanations for this observation. As discussed in Section 4, cell wall invertase hydrolyzes much of the sucrose supplied to callus tissues. This hypothesis is supported by the observation that approximately equal amounts of radioactivity were detected in glucose and fructose (Table 8).

A slightly larger percentage of the incorporated ${ }^{14} \mathrm{C}$ was metabolized beyond sugars in SF callus samples taken on days $7-16$, compared to NSF samples (Table 8). Whereas 95 - $99 \times$ of the total ${ }^{14} \mathrm{C}$ remained in sucrose, glucose and fructose in NSF samples, only 92 - 94 z of the ${ }^{14} \mathrm{C}$ in SF samples remained in these sugars. Details of this increased metabolism in SF callf will be discussed in the following sections.

A representative example of the distribution of radioactivity between the various metabolic fractions is presented in Table 9. (The sum of percentages of total radioactivity in the various fractions is less than 100. This is explained by loss of volatile compounds during concentration of aqueous extracts. Total incorporation was calcuiated by addition of ${ }^{14} \mathrm{C}$ in the $\mathrm{MCW}$ extracts, ${ }^{14} \mathrm{CO}_{2}$, and the 3 pellet fractions.) 


\section{c. Hexose monophosphates labelling.}

The first step in sugar metabolism involves phosphorylation, and it is here that consistent differences between SF and NSF cultures become apparent (Tables 10 and 11). Neither tissue type showed saturation of ${ }^{14} \mathrm{C}$-labelling of hexose monophosphates at 7 days (Table 10). Because a steady-state between catabolism and anabolism of ${ }^{14} \mathrm{C}$ labelled metabolites was not attained during the $60 \mathrm{~min}$ assays, no inferences about metabolic pool sizes can be made from these data.

Rates of labelling of hexose monophosphates in SF samples increased by a factor of approximately 1.5 between 30 and 60 min (Table 10). This may reflect both heterogeneity of callus samples and rates of ${ }^{14}$-labelling of metabolically-active sucrose and glucose pools. It is important to recall that $2 \mathrm{~mm}$ thick slices of callus tissue were used in the assays of $\left[{ }^{14} \mathrm{C}\right]$ sucrose metabolism. Assuming an average cell dianeter of $50 \mathrm{um}$, the $2 \mathrm{~mm}$ slices of tissue wouid be 40 cells thick. A lag in diffusion of labelled sugar to cells located in the interior of the slices would be expected; this may also explain the increase in labelling rates of various metabolites during the 60 $\min$ assays.

The amount of ${ }^{14} \mathrm{C}$ present in sucrose, glucose, and fructose at 60 min was often 500-fold greater than that found in the phosphorylated sugars. The calculated equilibrium constant for the exothermic reaction catalyzed by hexose kinase is 661 (Lehninger, 1975). Obviously the hexose kinase reaction in callus tissues is a nonequilibrium reaction. These observations show that phosphorylation of glucose and fructose is an important rate-limiting reaction in 
tobacco callus cul ture metabolism.

Labelling of hexose monophosphates was greater in SF tissues than in NSF tissues (Table 11). This difference was apparent 1 day after subculture, but was most pronounced at 7 and 13 days. On these days, the amount of $\left[{ }^{14} \mathrm{C}\right]$ hexose monophosphates at $60 \mathrm{~min}$ in tissues from the bottom portions of SF calli was approximately 5-fold greater than that observed in NSF calli. The decreased rates of ${ }^{14} \mathrm{C}$-labelling of hexose monophosphates in SF samples collected 10 days after subculture may represent a decrease in rates of cell division between periods of active "meristemoid" formation at 7 days and active shoot-meristem formation at 2 weeks (Maedz and Thorpe, 1979). A short gap between these two processes requiring accelerated rates of cell division could be required to replenish starch reserves (Chapter 2, Section 4c), and also for differentiation of special cell types (eg. tracheary elements) involved in the nutrition of developing shoots. By 16 days no significant differences were observed between SF and NSF calli. Hexose monophosphate labelling was approximately equal in SF samples collected on days 13 and 16 , while labelling of these metabolites increased 5-fold Jetween NSF samples collected at 13 days, and samples collected at 16 days.

Though it is not possible to conclude from these results alone that hexose kinase activity was greater in SF calli during the first two weeks after subculture, results from pool size measurements presented in Chapter 4 offer adequate support for this conclusion (see Chapter 4, Section 2c). Thorpe and Laishey (1973) reported a 4-fold increase in the activity of this enzyme in SF calli, compared to NSF calli, 6 days after subculture. These observations suggest increased 
requirements for energy and carbon-skeleton production in SF tissue during the initiation of "meristemoid" formation, which begins approximately one week after subculture to SF medium (Maeda and Thorpe, 1979). This process requires accelerated rates of cell division, which in turn requires increased rates of carbon metabolism.

Samples taken from the bottom regions of SF calli contained more $\left[{ }^{14} \mathrm{C}\right]$ hexose monophosphates at $60 \mathrm{~min}$ than samples from top regions of these calli (Table 11). Seven days after subculture, bottan regions of SF calli contained approximately 1.5 -fold more $\left[{ }^{14} \mathrm{C}\right]$ hexose monophosphates at 60 min than top regions of SF calli; at 10 days the two regions differed by a factor of only 1.02; and at 13 and 16 days the amount of $\left[{ }^{14} \mathrm{C}\right]$ hexose monophosphates in botton sections of SF calli exceeded than in top sections by a factor of 1.2 (Table 11). These differences correlate with the observation that shoots are initially formed in the bottom regions of SF calli, a process which begins about 1 week after subculture (Maeda and Thorpe, 1979). The decrease in differential labellings at 10,13 , and 16 days is probably due to initiation of shoot formation in upper regions of calli.

Labelling of hexose monophosphates in NSF calli was greater in samples from the upper than from the botton regions of these calii on days 7 - 13. This may reflect relative rates of cell division in these two regions. Tissue proliferation in MSF calli occurs preferentially near the exposed margins of calli (Aitchison, et al., 1977). Samples taken from the top halves of NSF calli would contain a greater proportion of exposed surfaces than samples taken from the bottom halves of these calli, and would therefore be expected to contain aore actively dividing regions of tissue. 
A continuous increase in labelling of most metabolies was observed for 60 min NSF samples collected $7,10,13$, and 16 days after subculture. This increase correlates with the log phase of growth of NSF calli reported in Chapter 2, Section 4a. The increases in rates of sucrose metabolism by NSF calit may be required for both increasing rates of cell division, and accumulation of metabolites for turgor-driven cell enlargement.

d. Labelling of malate and citrate, and release of $\mathrm{CO}_{2}$.

Radioactive-labelling of malate and citrate, two intermediates of the tricarboxylic acid (TCA) cycle, was also greater in SF tissues than in NSF tissues (Table 11). For these compounds, differences between NSF and SF tissues were apparent 1 day after subculture, but were most pronounced in samples obtained 7 and 13 days after subculture. This trend reflects that observed for hexose monophosphates, and is interpreted in a similar fashion. At 7, 10, and 13 days, rates of accumulation of $\left[{ }^{14} \mathrm{C}\right]$ malate were approximately 3- to 4-fold greater at $60 \mathrm{~min}$ in samples from the bottom haives of SF tissue than in samples from the bottom halves of NSF tissue (Table 11). By 16 days, the differences between NSF and SF calli had decreased to factors of only 1.1 and 1.8 for top and bottom regions respectively. This decrease in the ratio of SF to NSF labelling was the result of increased malate labelling in the NSF samples. At 7 days after subculture, approximately 7 -fold more $\left[{ }^{14} \mathrm{C}\right]$ citate accumulated in the top and botton halves of SF calli at 60 min than in the corresponding regions of NSF calli (Table 11). The increased rates of malate and citrate labelling at 7 days suggest increased TCA 
cycle activity during the period of active cell division associated with "meristenoid" formation. The relatively greater stimulation of citrate than of malate labelling at this time implies that a part of the $\left[{ }^{14} \mathrm{C}\right]$ malate was not involved in mitochondrial respiration, and was perhaps associated with the role of malate as a source of reducing power via reductive decarboxylation. The difference in rates of $\left[{ }^{14} \mathrm{C}\right]$ citrate accumulation in NSF and SF calli was only 2-fold at 13 days, and at 16 days the amount of $\left[{ }^{14} \mathrm{C}\right]$ citrate in NSF calli exceeded that observed in SF calli. As discussed above, the increased rates of metabolism observed in NSF calli result in decreased differences in labelling rates between NSF and SF calli, and correlate with the log phase of growth of this tissue.

At 7,10 , and 13 days after subculture, the amount of $\left[{ }^{14} \mathrm{C}\right]$ malate and $\left[{ }^{14} \mathrm{C}\right]$ citrate in samples taken from the bottom halves of NSF calli was approximately 2-fold lower than in samples taken from the top halves of these calli (Table 11). This result may reflect relative rates of cell division in the two regions of calli. As discussed above, top regions of NSF calli are thought to contain more actively dividing regions than bottom regions of calli, and increased metabolic activity is associated with these growth processes.

Given the observation that 30 \& variability between replicate callus samples is not uncommon, most differences between top and botton halves of SF calli are probably not significant. That the increased rates of hexose monophosphates labelling in the bottom halves of SF tissue were not reflected in the TCA cycle intermediates can be explained by the somewhat greater stimulation of pentose phosphate pathway enzymes, relative to glycolytic enzymes, in bottam 
halves of SF calli (Thorpe and Laishey, 1973). (Intemediary metabolites of the pentose phosphate pathway were not synthesized in sufficient quantities in these experiments for detection on paper chromatograms).

Measurements of ${ }^{14} \mathrm{CO}_{2}$ synthesis in these callus tissues are presented in Table 12. The rate of ${ }^{14} \mathrm{CO}_{2}$ synthesis at $60 \mathrm{~min}$ was 2fold or more greater than that observed at $30 \mathrm{~min}$, which in turn was 2-fold or more greater than that observed at $15 \mathrm{~min}$. Increases in the rates of ${ }^{14} \mathrm{C}$-labelling of hexose monophosphates, malate, and citrate between samples obtained at 30 and $60 \mathrm{~min}$ were also observed (Table 10). These changes in labelling rates were most pronounced for SF samples. Phosphorylation of hexoses is a major rate-limiting reaction in the metabolism of sucrose by tobacco calli. It is not surprising that increases in rates of labelling of the phosphorylated sugars were reflected in subsequent metabolites. The accentuated differences Letween 15 and 60 min labellings of subsequent metabolites implies differential rates of labelling of metabolites synthesized in different subcellular compartments. For example, labelling of TCA cycle intermediates and related amino acids increased many-fold during the 60 min studies, while labelling of hexose monophosphates increased by a factor of only 1.5. The increase in rate of ${ }^{14} \mathrm{CO}_{2}$-release probably reflects the amount of time required for ${ }^{14} \mathrm{C}$ derived from sugars to be metabolized to TCA cycle intenmediates and then respired, as well as the time required for labelling of oxidative pentose phosphate pathway (PPF) intermediates.

The increasing rates of ${ }^{14} \mathrm{CO}_{2}$-release are probably not related to slicing of SF callus tissues. As discussed in section 3 of this 
chapter, respiration in sliced callus tissues was only $20 \%$ greater than that measured for intact calli. Furthermore, immediate increases in respiration in the well-studied sliced potato system are explained by release of $\mathrm{CO}_{2}$ previously trapped within the tissue (Kahl, 1974), arid by increased rates of lipid oxidation (Laties, 1978). These explanations do not apply to the resoiatory rise observed in callus tissues in the studies reported here, where only ${ }^{14} \mathrm{CO}_{2}$-release from recently metabolized $\left[{ }^{14} \mathrm{C}\right]$ sucrose was measured. In disks of tomato pericarp tissue, rates of $\mathrm{CO}_{2}$-release 15 minutes after slicing were 7fold greater than those measured for intact fruit (Lee, et al., 1970). However, in this tissue, respiration decreased approximately 2-fold between 15 and $60 \mathrm{~min}$. This wound response to slicing is also unlike that observed for ${ }^{14} \mathrm{CO}_{2}$-release from callus tissues, which often increased 5-fold between 15 and 60 min.

No differences in ${ }^{14} \mathrm{CO}_{2}$-release from NSF and SF calli were detected 1 day after subculture, though at 4 days SF calli released $30 \%$ more ${ }^{14} \mathrm{CO}_{2}$ than NSF calli (Table 12). At 7 days, respiration in bottom portions of SF tissue was about 4-fold greater than respiration in botton portions of NSF tissue, supporting the hypothesis of increased energy requirements for SF tissues during "meristemoid" initiation. This difference decreased to about 2-iold at 13 days, due to a steady increase in rates of ${ }^{14} \mathrm{CO}_{2}$ synthesis in MSF calli between days 7 and 16. This trend, as discussed above, relates to the $\log$ phase of NSF callus growth. Samples from top and botton regions of NSF and SF calli released similar anounts of ${ }^{14} \mathrm{CO}_{2}$.

${ }^{14} \mathrm{CO}_{2}$-release occurs by at least. 3 major metabolic pathways in plants: the TCA cycle, photorespiration, and the oxidative pentose 
phosphate pathway (PPP). It is not possible to determine from the results reported here the relative contributions of these different pathways to the ${ }^{14} \mathrm{CO}_{2}$ formed during assays of callus metabolism. Results fram other laboratories suggest stimulation of both the TCA cycle and the PPP in SF calli. Thorpe and Laishey (1973) reported a greater increase in activity of PPP enzymes than of glycolytic enzymes in SF compared to NSF calli. Ross and Thorpe (1973) reported increased $0_{2}$-consumption in SF calli compared to NSF calli. Nothing is known about the relative activities of photorespiatory metabolism in SF and NSF calli.

\section{e. Amino acid labelling.}

Greater rates of ${ }^{14} \mathrm{C}$-labelling of neutral and acidic amino acids in SF calli, relative to NSF calli, were evident 1 day after subculture (Table 13). At 7 days, the samples from the botton regions of SF calli contained about 7-fold more ${ }^{14} \mathrm{C}$ in this fraction than samples from the botton regions of $N$ : 111i. On most other sampling days, tissue from the botton halves of SF calli contained about twice as much ${ }^{14} \mathrm{C}$ in this fraction, cosipared to bottom halves of NSF calli. However, for samples collected 16 days after subculture, the ${ }^{14} \mathrm{C}$ labelling of anino acids in bottom regions of NSF calli was approximately 1.5-fold greater than in SF calli. A continuous increase in accumulation of $\left[{ }^{14} \mathrm{C}\right]$ amino acids was observed for samples from bottom halves of NSF tissue assayed between days $7-16$. This trend, as discussed above, relates to the log phase of NSF callus growth. Labelling of many of the individual neutral and acidic amino acids with ${ }^{14} \mathrm{C}$ reflected the patterns seen in the gross neutral and 
acidic amino acid fraction (Table 14).

Because approximately $0.1 \%$ of the total pools of most amino acids was labelled with ${ }^{14} \mathrm{C}$ during $60 \mathrm{~min}$ incubations with $\left[{ }^{14}\right]$ sucrose, rates of labelling of anino acids with ${ }^{14} \mathrm{C}$ probably reflect rates of synthesis of these compounds. Even if $90 \%$ of the total concentrations of anino acids in callus tissues represented metabolically-inactive pools (eg. amino acids in vacuoles), the specific activity of metabolically-active pools would stili be sufficiently low to rule out the possibility that catabolism of ${ }^{14} \mathrm{C}$ labelled amino acids significantly affected the observed labelling rates. Protein synthesized during the $60 \mathrm{~min}$ incubations accounts for only approximately $0.02 \%$ of the total protein in callus tissues (see Chapter 4). This result älso supports the hypothesis that catabolism of ${ }^{14}$ C-labelled amino acids was insignificant during the kinetic studies of sucrose metabolism reported here: if the amion acid precursor pools from which protein was synthesized were saturated with ${ }^{14} \mathrm{C}$ during the $60 \mathrm{~min}$ incubations, it would take approximately 200 hundred days for synthesis of the total amount of protein in callus tissues. On the contrary, results presented in Chapter 4, Section 1 show that 10 \% of the total protein in callus tissues is saturated with ${ }^{14} \mathrm{C}$ from $\left[{ }^{14}\right]$ sucrose in 2 days.

Tissue from the bottom portions of SF calli often contained about twice as much ${ }^{14} \mathrm{C}$ in neutral and acidic amino acids as tissue from the top regions of these calli (Table 13). This rerlects the observation that shoots are initially formed preferentiaily in bottom regions of SF calli. Ho consistent differences in neutral and acidic amino acid labelling were observed between callus tissue from top and bottom 
regions of NSF calli on the different sampling days.

More ${ }^{14} \mathrm{C}$ was observed in alanine than in any other amino acid (Table 14). Concentrations of amino acids in NSF and SF callus cultures will be presented in Chapter 4 , though it is relevant to mention here that alanine was not observed in particularly high concentrations relative to other amino acids. The relative rates of alanine accumulation probably reflect intracellular compartmentation and the flow of ${ }^{14} \mathrm{C}$ from sucrose through the various metabolic intermediates. Alanine is synthesized directly fram pyruvate, a glycolytic pathway intermediate. Radioactive-labelling of amino acids derived from TCA cycle intermediates may be delayed because $\left[{ }^{14} \mathrm{C}\right]$ acetyl-CoA must pass through mitochondrial membranes.

One day after subculture the amount of $\left[{ }^{14} \mathrm{C}\right]$ alanine in SF callus samples was 1.5-fold greater than in NSF callus samples (Table 14). At 3 days this difference had increased to 3-fold, and at 7 days callus tissue from botton portions of SF cultures synthesized 10-fold more $\left[{ }^{14} \mathrm{C}\right] \mathrm{a}$ lanine than NSF callus tissues. At 10 and 13 days these tissues differed by a factor of only about 1.5 , and at 16 days NSF calli synthesized more $\left[{ }^{14} \mathrm{C}\right]$ alanine at $60 \mathrm{~min}$ than $\mathrm{SF}$ calli. These changes in the ratio of alanine accumulation in SF and NSF calli are the result of changes in growth patterns in both types of calli. "Meristemoid" formation in SF calli begins 1 week after subculture (Maeda and Thorpe, 1979). Rapid cell division associated with this process requires increased rates of carbon metabolism. Increased rates of alanine synthesis may be required for increased rates of protein synthesis associated with cell diviston. In addition to its role as a protein amino acid, alanine may serve as an amino donor for 
both glycine synthesis fran ọlyoxylate, and serine synthesis from hydroxypyruvate (Keys, 1980). These reactions are common in tissues lacking active photorespiration. Alanine seems to be the major amino donor for serine biosynthesis in shoot meristems (Cheung, 1968). Following "meristemoid" formation, cell division continues at accelerated rates in SF tissue due to the formation and growth of shoot meristens. This latter process begins approximately 10 days after subculture to SF medium (Maeda and Thorpe, 1979). Meanwhile, NSF calli are recovering from subculture, and begin a log phase of growth approximately 7 - 10 days after subculture (see Chapter 2, Section $4 \mathrm{a}$ ). Therefore, although rates of ${ }^{14} \mathrm{C}$-labelling of alanine in SF tissues remained approximately constant between days 7 and 16, the differences between NSF and SF calli steadily decreased.

Samples from the botton regions of both NSF and SF calli accumulated betweew 2- and 4-fold more $\left[{ }^{14} \mathrm{C}\right]$ al anine than samples from the top regions of these calli (Table 1.4). Although "meristemoid" fomation is initiated preferentially in botton halves of SF calli 7 days after subculture, this process rapidly spreads throughout the tissue (Maeda and Thorpe, 1979). Other as yet unidentified differences between the two halyes of SF calli must therefore be postulated to explain the differential rates of alanine labelling on days 10 - 16. Cell division occurs preferentially in the peripheral regions of NSF calli, so rates of cell division should be greater in top than in botton regions of these tissues. As with SF calli, differential rates of cell division cannot explain increased accumulation of $\left[{ }^{14} \mathrm{C}\right]$ alanine in bottom halves of NSF calli. Possibly either preferential cell differentiation or cell expansion in bottom 
regions of these calli explain the observed differential rates of alanine accumulation. Feeding-experiments using $\left[{ }^{14} \mathrm{C}\right]$ alanine should be performed to detemine the fate of labelled alanine synthesized in the experiments described here.

For samples of callus tissue assayed on days $4-13$, levels of $\left[{ }^{14} \mathrm{C}\right]$ serine were generally about 5 times greater in SF callus tissues than in NSF tissues (Table 14 ). Increased rates of $\left[{ }^{14} \mathrm{C}\right]$ serine biosylithesis in SF tobacco calli reflect the general increased rates of metabolism of sucrose in SF calli associated with cell divison for "meristemoid" and shoot meristem fomation. $\left[{ }^{14} \mathrm{C}\right]$ serine accumulation was atout 1.5-fold greater in tissues taken from bottom than from the top regions of NSF and SF calli, and in this respect resembled patterns of alanine labelling in these calli. However, unlike alanine, rates of $\left[^{14} \mathrm{C}\right]$ serine accumulation in NSF callus tissue were similar on days 1 - 13, then increased approximately 6-fold between days 13 and 16. No explanation for this anamalous trend is available at the present time.

At 7 days, $\left[{ }^{14} \mathrm{C}\right]$ methionine + valine accumulated in 8 -fold greater amounts in samples from botton halves of SF calli, relative to samples from botton halves of NSF calli (Table 14). At 10 and 13 days this difference decreased to approximately 3-fold, and by 16 days ${ }^{14} \mathrm{C}$-labeliing of these amino actds was 1.4-fold greater in liSF than in SF calli. The interpretation of these trends is simflar to that proposed above for alanine.

Seven days after subculture, accumulation of $\left[{ }^{14} \mathrm{C}\right]$ phenylalanine was about 15-fold greater in samples from the bottom regions of SF cultures than in NSF samples (Table 14). Concentrations of 
phenylalanine in SF calli were only 3 -fold greater than those in NSF calli 7 days after subculture (Chapter 4, Section 2e), suggesting that $\left[{ }^{14} \mathrm{C}\right]$ phenylalanine synthesized in these $60 \mathrm{~min}$ labelling experiments musc ultimately be metabolized to other products. No difference was observed at 1 day, though at 4, 10, and 13 days after subculture the SF tissues synthesized about twice as much $\left[{ }^{14} \mathrm{C}\right]$ phenylalanine as the NSF tissues (Table 14). The dramatic increase in phenylalantine labelling in SF calli at 7 days correlates with the increased numbers of lignified tracheary elements reported in SF callf 19 days after subculture (Maeda and Thorpe, 1979). Changes in peroxidase isoenzyme patterns in SF calli also suggest increased rates of lignin biosynthesis in these calli, compared to NSF calli (Mader, et al., 1975, and Thorpe and Gaspar, 1978). Increased activities of many enzymes associated with phenylalanine metabolism were observed during lignification in tobacco cell suspension cultures (Yamada, et al., 1978). Sampies from the bottom haives of both types of calli contained greater amounts of $\left[{ }^{14} \mathrm{C}\right]$ phenylalanine than tissues from the top halves of the calli, suggesting greater rates of lignification in the bottom regions of calli.

SF callus samples obtained 7 days after subculture synthesized about twice as much $\left[{ }^{14} \mathrm{C}\right]$ tryptophan as similar samples of ISF calli (Table 14) = Only minor differences were observed between SF and MSF tissues on other sampling days. Samples taken from the top halves of SF calit at 7,10 , and 13 days after subculture synthesized approximately 2-fold more $\left[{ }^{14} \mathrm{C}\right]$ tryptophan than samples from the botton halves of SF calli.

Seven days after subculture, SF callus tissues synthesized 7-fold 
more ${ }^{14} \mathrm{C}$ glutamate + aspartate, two amino acids derived from TCA cycle intermediates, than NSF callus tissues (Table 14). (These tom amiro acids were not resolved on many chromatograms, and results were therefore combined. Rates of $\left[{ }^{14} \mathrm{C}\right]$ glutamate accumulation were usually twice as great as those for $\left[{ }^{14} \mathrm{C}\right]$ aspartate on those chromatograms where the two amino acids were resolved). No differences between SF and NSF tissues were evident 1 day after subculture, though at 4,10 , and 13 days after subculture bottom halves of SF calli synthesized almost twice as much $\left[{ }^{14} \mathrm{C}\right]$ glutamate + aspartate as bottom halves of NSF calli. Because concentrations of glutamate were only 2-fold greater in SF than in NSF calli sampled 7 days after subculture (Chapter 4, Section 2e), a large portion of the $\left[{ }^{14} \mathrm{C}\right] g$ lutamate synthesized in these $60 \mathrm{~min}$ assays must eventually be used for either protein or secondary product biosynthesis. Metabolic compartmentation may explain the apparent accumulation of large amounts of glutamate during this study.

On days 10 and 13, top regions of SF calli synthesized almost 2fold more more $\left[{ }^{14} \mathrm{C}\right] \mathrm{glutamate}+$ aspartate than bottom regions of these callus tissues. The increased ${ }^{14} \mathrm{C}$-labelling of both these amino acids and tryptophan in samples from top halves of SF calli, compared to samples from bottom halves of SF calli, is not associated with known patterns of shoot development. No explanation for these results is available at the present time.

Pulse-chase experiments using $\left[{ }^{14} \mathrm{C}\right]$ glutamate and $\left[{ }^{14} \mathrm{C}\right]$ tryptophan would provide information useful in determining the metabolic fates of these amino acids. Glutamate is the precursor to nicotine, and nicotine accumulates in SF tobacco cally (Tabata, et al., 1971, and 
Waller and Nowacki, 1978). Tryptophan is the precursor to indole compounds, of which indole-3-acetic acid is of special interest in plant development. Insufficient evidence is avaflable at the present time to distinguish whether increased rates of ${ }^{14} \mathrm{C}$-labeliting of these amino acids in top halves of SF calli are related to changing patterns of protein synthesis or to the synthesis of developmentally-important secondary products.

No differences in rates of accumulation of $\left[{ }^{14} \mathrm{C}\right]$ glutamine + asparagine in MSF and SF tissues were observed at 1 and 4 days after subculture (Table 14). (As was the case with glutamate and aspartate, the two amines were not resolved on many chronatograms. Rates of $\left[{ }^{14} \mathrm{C}\right]$ g] utamine accumulation were usualiy 3 -told greater than rates of $\left[{ }^{14} \mathrm{C}\right]$ asparagine accimulation on those chromatograns where the two were resolved). $\left[{ }^{14} \mathrm{C}\right] g$ lutamine + asparagine was present in about $10-, 5-$, and 15-fold greater amounts in samples taken from botton halves of SF calli at days 7,10 , and 13 respectively, compared to bottom halves of NSF calli. Accumulation of $\left[{ }^{14} \mathrm{C}\right] \mathrm{glutamine}+$ asparagine by samples from bottom halves of SF calli increased 3-fold between 7 and 16 days after subculture. Amino acid concentrations in SF callus tissue presented in Chapter 4 suggest that this increase is associated with accumulation of glutamine in SF calli. This observation will be discussed in detail in Chapter 4; glutamine is the primary donor of amino groups for biosynthesis of many amino acids from their keto acid precursors. Increased rates of glutamine labelling in SF calli are related to increased rates of protein synthesis during periods of rapid cell diviston and cell differentiation. At 7 and 10 days, tissue from top halves of both NSF and SF calli synthesized more of 
these amines than tissue from bottom halves of these callif. The reverse situation was observed for samples assayed 13 and 16 days after subculture.

${ }^{14}$ C-labelling of basic amino acids was approximately 2-fold greater in bottom regions of SF calli at 7 days, compared to bottom regions of NSF calli (Table 15). On other sampling days, no differences in rates of ${ }^{14} \mathrm{C}$-labelling of these compounds were detected between SF and NSF calli. The difference at 7 days reflects the increased flow of carbon from sucrose into all metabolites examined in SF calli, and corresponds to the initiation of "meristemoids". That no differences between SF and NSF calli were abserved on other sampling days illustrates that although many metabolic pathways were more active in SF calli, this increase was not uniform for all metabolites studied. Shoot fomation is a special process involving cell and organ differentiation. These data show that there are characteristic metabolic requirements for this event. Increased rates of metabolism are certainly required for increased rates of cell division and growth, but the formation of shoots requires obviously greater increases in activity of some pathways than of others.

Before discussing end-product biosynthesis in NSF and SF calli, it is useful to review some of the general observations on amino biosynthesis in these calli. The continuous increase in rates of ${ }^{14} \mathrm{C}$ labelling of many amino acids observed in NSF callus samples assayed between 7 and 16 days after subculture correlates with the rapid increase in fresh weight of NSF calli observed between 1 and 2 weeks (Chapter 2, Section 4b). The differences in ${ }^{14}$ C-labelling of amino acids between top and bottom halves of MSF tissues were not expected. 
NSF tissue is often considered undifferentiated, and it is therefore difficult to correlate metabolic differences between the two regions of the callus tissues with known morphological phenamena. Murashige (1974) mentioned that unorganized callus cultures often contain truly differentlated cells, eg. tracheary elements. However, no published reports show a pattern of differentiation which predominates in either upper or lower regions of MSF calli. As stated earlier, NSF calli proliferate from meristems located near exposed margins of the tissue (Altchison, et al., 1977). This may explain increased metabolic activity in the upper halves of NSF calli, assuming that these regions contain a greater proportion of dividing cells than bottom regions of these calli. However, for some amino acids, ${ }^{14} \mathrm{C}-1$ abelling in tissue samples from botton halves of calli exceeded that in samples from top regions of calli. Careful anatomical studies on these calli are also needed so that biochenical differences observed between top and bottom halves of tissue can be confidently interpreted in terms of changes in tissue morphology.

Al though the general picture of increased rates of carbohydrate metabolism in SF calli, compared to NSF calli, was also observed for ${ }^{14} \mathrm{C}$-labelling of anino acids, it is important to note that the ratio of labelling of different compounds in SF and NSF tissues was not constant. For example, for the 7 day samples, in which the difference between SF and NSF calli was most pronounced, the ratios SF / MSF for hexose monophosphates, citrate, basic amino acids, serine, glutamate + aspartate, alanine, glutamine + asparagine, and phenylalanine were 4, $5,2,5,7,10,10$, and 15 respectively. These results suggest that regulation of metabolisin in SF tissues occurs not only at the level of 
phosphorylation of hexoses, but rather at many metabolic sites. Possible explanations for differerential rates of accumulation of some amino acids have al ready been proposed. As discussed above, only a small fraction of total amino acid pools were labelled with ${ }^{14} \mathrm{C}$ during the 60 min incubations. Catabolism of ${ }^{14} \mathrm{C}$-labelled amino acids probably did not significantly influence profiles of amino acid accumulation observed in these experiments. Experiments designed to determine the fate of the specific amino acids are needed to distinguish between the many possible fates for most amino acids in both NSF and SF calli. Insufficient evidence is available at the present time to state whether differential rates of accumulation of the various amino acids reflect the changing composition of proteins synthesized in the callus tissues, or the synthesis of developmentally-significant secondary products.

It is not possible to determine from these types of experiments whether the differences between SF and NSF calli are due to large changes in only a few cells in SF callus tissues, or to smaller changes in the metabolism of many cells. Histochemical studies on starch accumulation in SF calli revealed that the most of the tissue was acting like a "source" for the much smaller region of cells, "meristemoids", that could be considered "sinks" (Maeda and Thorpe, 1979). It is probable that a similar phenomenon is occurring with many of the metabolic changes reportad here for SF tissues, and that metabolic differences reflect changes in the majority of cells in SF calli. 
f. Lipid, protein, starch, and cell wall synthesis.

The incorporation of ${ }^{14} \mathrm{C}$ into the lipid fraction was quite variable, and probably reflects contamination of this fraction with ${ }^{14} \mathrm{C}$-labelled sucrose, glucose, and fructose.

With the exception of 1 day samples, rates of protein synthesis in SF callus tissues were at least 2-fold greater than those observed in NSF callus tissues. This difference was most pronounced in 7 and 10 day samples (Table 16), and reflects increased rates of cell division associated with "meristenoid" formation in SF calli (Thorpe and Murashige, 1970, and Maeda . and Thorpe, 1979). Protein synthesis in NSF calli increased continuously between 7 and 16 days, and reflects the $\log$ phase of growth of these tissues. The differential rates of $\left[{ }^{14} \mathrm{C}\right]$ protein synthesis between SF and NSF callus tissues were often apparent only in the 60 min samples, and reflect the labelling kinetics of precursor amino acids. As discussed above, only $0.02 \%$ of the total protein in callus tissues was synthesized from ${ }^{14} \mathrm{C}$-amino acids during these experiments. At 7 and 10 days, botton halves of SF calli synthesized approximately $30 \%$ more $\left[{ }^{14} \mathrm{C}\right]$ protein than top halves of these calli, while at 13 and 16 days botton halves synthesized approximately $10 \%$ more $\left[{ }^{14} \mathrm{C}\right]$ protein than top halves of these calli. These results support the contention that although "meristemoids" are initialiy formed preferentialiy in botton halves of SF calli one week after subculture, differences in this respect between the two regions of the callf diminish rapidly, and shoots ultimately emerge in a randon fashion from all surfaces of the callus tissue.

otfferences in starch synthesis between SF and NSF calli were 
al so most apparent for 7 day samples, where synthesis in SF tissue occurred at triple the rate observed in NSF tissues (Table 17). Slightly increased rates of starch synthesis in bottom regions of SF tissue, compared to top regions of these calli, were observed at all days on which the tissue was subdtvided. For NSF callus tissue, consistent differences in $\left[{ }^{14} \mathrm{C}\right]$ starch synthesis between top and bottom halves were not observed. As with other metabolites, starch synthesis in bottom regions of NSF calli increased continuously" between 7 and 16 days.

Results presented in Chapter 2, Section 4c showed approximately 3-fold greater amounts of starch / $g$ dry wefght in SF calli sampled on days $4-16$, compared to corresponding samples of NSF calli. Starch synthesis from $\left[{ }^{14} \mathrm{C}\right]$ sucrose in SF calli was only 2-fold greater than that observed in NSF calli 4 days after subculture. The differences between the ratio of total starch in SF and NSF calli, and the ratio of starch synthesis in SF and NSF calli suggest greater rates of starch degradation in NSF samples immediately after subculture, relative to SF samples. A net decrease in starch content of NSF calli was observed during the first week after subculture, whereas in SF calli rapid accumulation of starch was observed between days 1 and 4 (Chapter 2, Section 4c). Seven days after subculture, starch synthesis in SF calli occurred at: 3-fold greater rates than were observed in NSF calli, and at approxinately twice the rate observed in SF samples on other days. (Synthesis in top and bottom regions were added together for these comparisons). This increased rate of atarch synthesis at 7 days is consistent with the observation that al though total starch levels in SF calli showed a transfent decrease at 7 days, 
by 10 days starch content of these calli had increased to the level observed at 4 days. The transient decrease in starch levels in 7-day samples from SF calli is probably required to support the accelerated rates of energy metabolism during "mertstemoid" formation. At 10,13 and 16 days, starch synthesis in SF samples approxtmately equaled that in NSF samples, though total starch remained 3-fold greater in SF, compared to NSF calli. Apparently the greater amounts of total starch in SF callt are maintained by both decreased rates of starch degradiation, and increased rates of starch synthesis. The possib7y increased contribution of photosynthetically-derived sugars to starch synthesis in SF calli may also serve to maintain the greater starch levels in SF calli, compared to NSF calli (see Chapter ", section 4c).

Incorporation of ${ }^{14} \mathrm{C}$ into the residue fraction, which is believed to contain mostly cell wall debris, was approximately twice as great in SF calli as in NSF calli assayed 1 and 4 days after subculture (Table 18). At 7 days labelling of this fraction in samples from bottom halves of SF calii was approximately 4-fold greater than in samples fran NSF calli. The rate of ${ }^{14} \mathrm{C}$ labelling of this fraction on other days was about tivice as great in samples taken from the bottom halves, compared to the top halves, of SF calli. Both the e observations reflect the increased rates of cell division associated with "meristemoid" and shoot meristem production in SF calli, which begins preferentially in the bottom halves of these tissues (Maeda and Thorpe, 1979). Orfferences in residue-labelling between SF calli and bottom halves of NSF calli were not apparent at 13 and 16 days, due to increased rates of residue-labelling in NSF calli associated with 
the $\log$ phase of growth.

${ }^{14} \mathrm{C}$-labelling of the residue fraction at 60 min was 2.5-fold greater in samples from bottom halves of NSF calli 16 days after subculture, compared to samples assayed 7 days after subculture. Between 5 and 15 days after subculture, the rate of increase in fresh weight of NSF calli increased approximately 20-fold. The relatively small difference between rates of cell wall synthesis at 6 and 16 days supports the hypothesis presented in Chapter 2: the cell wall / cytoplasm ratio in NSF calli decreases during the log phase of growth.

g. Conclustons.

Changes in rates of sucrose metabolism in NSF and SF calli generally correlate with known growth patterns in these calli. Differences in carbon metabolism between NSF and SF calli were most pronounced one week after subculture, at which time "meristenoid" formation begins in SF calli, and these calli are commited to a different developmental fate.

Differences in rates of sucrose metabolism were observed for top and bottom regions of both NSF and SF calli. Thase results reflect established patterns of shoot formation in SF calli; they also show that it is unrealistic to consider a piece of NSF callus as a cluster of uniform undifferentiated cells.

Sucrose uptake is not a rate-limiting step in callus tissue metabolism. Rather, the phosphorylation of hexoses is the primary rate-limiting reaction for sucrose metabolism in both NSF and SF calli. Differences in this respect between SF and NSF calli precede 
reported differences in callus morphology, and may serve as useful markers for shoot induction during the first week after subculture of tobacco callus tissue.

Because differences between NSF and SF calii in rates of synthesis of many amino acids were more pronounced than differences in general sugar metabolism, the former may provide better markers for processes involved in shoot formation. Differential rates of phenylalanine, glutamine, and alanine accumulation are good candidates for metabolic markers of shoot induction.

The time-courses for amino acid accumulation in NSF and SF calli paralleled those for protein synthesis, yet differences between NSF and SF calli in rates of protein synthesis were much less than those for synthesis of phenylalanine, glutamine, glutamate, and alanine. Either these amino acids accumulate preferentially in SF calli. or they are subsequently metabolized to secondary products. Pul se-chase experiments using radioactively-labelled anino acids must be performed to determine the metabolic fate of amino acids which accumulate during these 60 min incubations with $\left[{ }^{14} \mathrm{C}\right]$ sucrose.

Similar studies to those reported here for tobacco calli must be conducted with calli from other plant species to confirm the significance of these observations to the transition from unorganized to organized development. 
6. Chapter 3: Tables and Figures. 
Table 1. Labelling of various metabolite fractions with ${ }^{14} \mathrm{C}$ after incubation of NSF callus tissue for 60 min in solution which contained $0.3 \%(w / v)[U-14 C]$ sucrose and either $4 \%$ ethanol, or no ethanol. Results expressed as (14C in metabolite fraction / total $14 \mathrm{C}$ in aqueous extracts) $\times 100$; values represent averages of duplicate treatments.

metabol ite

fraction

\section{with}

ethanol without

ethanol

$\begin{array}{lrr}\text { acidic amino acids } & 0.56 \% & 0.72 \% \\ \text { basic amino acids } & 0.15 \% & 0.20 \% \\ \text { neutral amino acids } & 1.17 \% & 0.91 \% \\ \begin{array}{l}\text { sugars, phosphate } \\ \text { esters, organic acids }\end{array} & 98.26 \% & 98.35 \%\end{array}$


Table 2. Rates of incorporation of ${ }^{14} \mathrm{C}$ into selected metabol tes by unorganized tobacco callus after 15, 30, and 60 minutes of incubation in solution containing $0.3 \%(\mathrm{w} / \mathrm{v})[\dot{U}-14 C]$ sucrose. Callus subcul tured two weeks prior to experiment. Results expressed as averages of four rep!icate samples standard error of the mean. Mean rate values expressed as $n g$-atoms $\mathrm{C} / \mathrm{g}$ fresh weight / min. Percent variability calculated as (standard error of mean / mean value) $X 100$.

\begin{tabular}{|c|c|c|c|c|}
\hline compound & time & \multicolumn{2}{|c|}{ rate } & I variability \\
\hline sucrose & $\begin{array}{l}15 \\
30 \\
60\end{array}$ & $\begin{array}{l}318.3 \\
274.2 \\
230.1\end{array}$ & $\begin{array}{l}26.2 \\
24.2 \\
30.1\end{array}$ & $\begin{array}{r}8 \\
9 \\
13\end{array}$ \\
\hline glucose & $\begin{array}{l}15 \\
30 \\
60\end{array}$ & $\begin{array}{l}6.4 \\
4.9 \\
4.4\end{array}$ & $\begin{array}{l}0.8 \\
0.3 \\
0.2\end{array}$ & $\begin{array}{r}13 \\
6 \\
5\end{array}$ \\
\hline fructose & $\begin{array}{l}15 \\
30 \\
60\end{array}$ & $\begin{array}{l}3.8 \\
3.1 \\
2.8\end{array}$ & $\begin{array}{l}0.5 \\
0.3 \\
0.2\end{array}$ & $\begin{array}{r}13 \\
10 \\
5\end{array}$ \\
\hline malate & $\begin{array}{l}15 \\
30 \\
60\end{array}$ & $\begin{array}{l}0.61 \\
0.93 \\
1.68\end{array}$ & $\begin{array}{l}0.12 \\
0.24 \\
0.13\end{array}$ & $\begin{array}{r}20 \\
25 \\
8\end{array}$ \\
\hline citrate & $\begin{array}{l}15 \\
30 \\
60\end{array}$ & $\begin{array}{l}0.26 \\
0.31 \\
0.47\end{array}$ & $\begin{array}{l}0.05 \\
0.08 \\
0.06\end{array}$ & $\begin{array}{l}19 \\
26 \\
14\end{array}$ \\
\hline glutamate & $\begin{array}{l}15 \\
30 \\
60\end{array}$ & $\begin{array}{l}0.41 \\
0.61 \\
0.92\end{array}$ & $\begin{array}{l}0.05 \\
0.13 \\
0.09\end{array}$ & $\begin{array}{l}13 \\
22 \\
10\end{array}$ \\
\hline aspartate & $\begin{array}{l}15 \\
30 \\
60\end{array}$ & $\begin{array}{l}0.13 \\
0.29 \\
0.26\end{array}$ & $\begin{array}{l}0.02 \\
0.02 \\
0.01\end{array}$ & $\begin{array}{r}18 \\
13 \\
8\end{array}$ \\
\hline
\end{tabular}


Table 3a. Comparison of concentrations of selected metabolites in tobacco callus cultured on $[U-14 C]$ sucrose NSF medium to saturate pools, then incubated for $60 \mathrm{~min}$ in various solutions which contained [U-14C] sucrose. Condition $A: 0.3 \%(w / v)$ sucrose in water; Condition B: $0.3 \%(w / v)$ sucrose in NSF medium; Condition C: $3.0 \%(w / v)$ sucrose in water; Condition $D: 3.0 \%(w / v)$ sucrose in NSF medium. Control sampled directly from Petri dish, without prior incubation in sucrose solutions. Results expressed as fraction of control mean value. Control values expressed as average nmol $/ \mathrm{g}$ fresh weight. Numbers in parenthesis represent the percent difference between duplicate control samples, calculated as $100 \times$ difference between duplicates / control mean value.

\begin{tabular}{|c|c|c|c|c|c|c|}
\hline compound & A & B & c & D & Control & \\
\hline sucrose & 0.67 & 0.69 & 0.77 & 0.84 & 23,623 & $(15 x)$ \\
\hline glucose & 0.46 & 0.73 & 0.65 & 0.88 & 24,799 & $(23 x)$ \\
\hline fructose & 0.47 & 0.74 & 0.65 & 0.86 & 25,804 & $(17 x)$ \\
\hline hexose-p & 0.89 & 0.90 & 0.90 & 1.04 & 474 & $(25 x)$ \\
\hline malate & 0.60 & 0.77 & 1.01 & 1.04 & 5,741 & $(10 \%)$ \\
\hline citrate & 0.93 & 1.06 & 0.88 & 1.08 & 1,070 & $(18 x)$ \\
\hline aspartate & 0.66 & 0.58 & 0.95 & 1.07 & 957 & $(16 \%)$ \\
\hline glutamate & 0.81 & 0.76 & 0.66 & 0.98 & 3,142 & $(21 \%)$ \\
\hline glutamine & 1.12 & 1.11 & 0.74 & 0.94 & 11,481 & $(6 \%)$ \\
\hline proline & 1.23 & 1.11 & 0.51 & 0.54 & 1,410 & $(15 \%)$ \\
\hline alanine & 1.35 & 1.48 & 1.47 & 1.70 & 1,764 & $(16 \%)$ \\
\hline$y$-aminobutyrate & 2.76 & 3.03 & 2.52 & 2.30 & 332 & $(5 \%)$ \\
\hline$A C C$ & 1.13 & 1.13 & 1.17 & 1.18 & 84 & $\langle 14 x\rangle$ \\
\hline
\end{tabular}


Table 3b. Comparison of concentrations of selected metabolic fractions in tobacco callus cultured on [U-14C]sucrose NSF medium to saturate pools, then incubated for $60 \mathrm{~min}$ in various solutions containing $[U-14 C]$ sucrose. Condition $A: 0.3 \%(w / v)$ sucrose in water; Candition $B: 0.3 \%(w / v)$ sucrose in NSF medium; Condition $C: 3.0 \%$ $(w / v)$ sucrose in water; Condition D: $3.0 \%(w / v)$ sucrose in NSF medium. Results expressed as ug-atan $C / g$ fresh weight. (See text for elaboration of experimental conditions).

\begin{tabular}{lcccc}
\hline compound & A & B & C & D \\
& & & & \\
& & (ug-atom C/g fresh weight) & \\
respiration & 8 & 10 & 9 & 9 \\
basic amino acids & 29 & 26 & 22 & 110 \\
lipids & 104 & 107 & 95 & 218 \\
starch & 262 & 269 & 236 & 281 \\
residue & 234 & 273 & 259 & 436 \\
protein & 399 & 421 & 375 & \\
\hline
\end{tabular}


Table 4. Comparison of concentrations of selected metabolites from tobacco callus cultured on [U-14C]sucrose NSF medium to saturate pools, then incubated for 60 min in $3 \%(w / v)[U-14 C]$ sucrose in NSF medium. Condition D: callus sliced to $2 \mathrm{~mm}$ average thickness prior to incubation in labelled sucrose solution; Condition $E$ : callus not sliced. Control sampled directly from Petri dish, without prior incubation in labelled sucrose solution. Results expressed as fraction of control mean value. Control values expressed as average mol / g fresh weight. (See text for elaboration of experimental conditions).

\begin{tabular}{lllr}
\hline compound & $D$ & $E$ & Control \\
\hline sucrose & 0.84 & 0.81 & 23,623 \\
glucose & 0.88 & 0.91 & 24,799 \\
fructose & 0.86 & 0.90 & 25,804 \\
hexose-p & 1.04 & 1.09 & 474 \\
malate & 1.04 & 0.90 & 5,741 \\
citrate & 1.08 & 1.08 & 1,070 \\
aspartate & 1.07 & 0.95 & 957 \\
glutamate & 0.98 & 1.07 & 3,142 \\
glutamine & 0.94 & 1.08 & 1,481 \\
proline & 0.54 & 1.26 & 1,410 \\
alanine & 1.70 & 1.82 & 1,764 \\
Y-aninobutyrate & 2.30 & 2.11 & 332 \\
ACC & 1.18 & 1.15 & 84 \\
\hline
\end{tabular}


Table 5. Comparison of concentrations of selected metabolites in tobacco callus cultured on $[U-14 C]$ sucrose NSF medium. Callus tissue either rinsed with unlabelled sucrose and water prior to homogenization and extraction of metabolites (rinsed); or callus homogenized and extracted without prior washing to remove extracellular metabolites (not rinsed). Duplicate samples obtained for each treatment. Resuits expressed as average nmol / g fresh weight. (See text for elaboration of experimental conditions).

compound

rinsed

not rinsed

(mol/g fresh weight)

sucrose

23,623

37,782

glucose

24,799

48,500

fructose

25,804

49,695

hexose-p

474

521

malate

5,741

5,766

citrate

1,070

1,154

aspartáte

957

909

glutamate

3,142

3,450

asparagine

370

402

glutamine

11,481

14,023

proline

1,410

1,797

alanine

1,764

2,590

$\gamma$-aminobutyrate

332

331

ACC

84

87 
Table 6. Dry weight / fresh weight ratios for top and bottom haives of shoot-forming and non-shoot-forming tobacco calius cultures used for studies of $[U-14 C]$ sucrose metabol ism. Values represent averages of three replicate samples.

\begin{tabular}{ccccc}
\hline $\begin{array}{l}\text { days after } \\
\text { subculture }\end{array}$ & \multicolumn{2}{c}{ NSF bottom } & top ${ }^{\text {SF }}$ bottom \\
\hline & & & (dry weight / fresh weight) & \\
1 & - & 0.04 & - & 0.04 \\
4 & - & 0.04 & - & 0.04 \\
7 & 0.04 & 0.05 & 0.05 & 0.07 \\
10 & 0.04 & 0.05 & 0.09 & 0.09 \\
13 & 0.04 & 0.05 & 0.09 & 0.08 \\
16 & 0.04 & 0.05 & 0.09 & 0.08 \\
\hline
\end{tabular}


Table 7. Time course for total incorporation of ${ }^{14} \mathrm{C}$ from $0.3 \%(w / v)$ [U-14C]sucrose into non-shoot-forming (NSF) and shoot-forming (SF) tobacco callus tissues on selected days after subculture to NSF and SF media. At $7,10,13$ and 16 days after subculture, calli divided into bottom and top halves prior to incubation in sucrose solutions. Results expressed as ng-atams $\mathrm{C} \times 10^{-4} / \mathrm{g}$ dry weight callus tissue.

\begin{tabular}{|c|c|c|c|}
\hline days after & time & NSF & SF \\
\hline subcul ture & $(\min )$ & battom & bottom \\
\hline
\end{tabular}

\begin{tabular}{rrrrrr}
\hline & & \multicolumn{3}{c}{ (ng-atams $C \times 10^{-4} / \mathrm{g}$ dry weight) } \\
1 & 15 & - & 2.7 & - & 5.1 \\
1 & 30 & - & 9.0 & - & 9.4 \\
1 & 60 & - & 12.2 & - & 13.4 \\
& & & & & \\
4 & 15 & - & 10.4 & - & 6.9 \\
4 & 30 & - & 12.9 & - & 15.7 \\
4 & 60 & - & 14.6 & - & 15.4 \\
7 & 15 & 7.7 & 4.9 & 5.4 & 5.6 \\
7 & 30 & 6.5 & 6.5 & 5.3 & 7.3 \\
7 & 60 & 22.4 & 7.5 & 11.5 & 13.6 \\
& & & & & \\
10 & 15 & 2.1 & 5.1 & 4.0 & 3.5 \\
10 & 30 & 6.4 & 7.8 & 6.6 & 4.7 \\
10 & 60 & 6.4 & 8.5 & 6.7 & 7.4 \\
13 & 15 & 3.5 & 3.2 & 4.6 & 5.0 \\
13 & 30 & 2.4 & 6.0 & 6.1 & 5.4 \\
13 & 60 & 2.7 & 14.4 & 7.7 & 10.1 \\
16 & 15 & 6.4 & 10.3 & & \\
16 & 30 & 12.8 & 11.5 & 7.6 & 7.0 \\
16 & 60 & 15.4 & 21.9 & 12.1 & 14.7 \\
& & & & & \\
\hline
\end{tabular}


Table 8. Percentage of total ${ }^{14} \mathrm{C}$ incorporated which remained in sucrose, or was metabolized to glucose and fructose after 60 min incubation of non-shoot-forming (NSF) and shoot-forming (SF) tobacco callus in $0.3 \%(w / v)$ [U-14C]sucrose solution. Calli subdivided into top and bottan regions prior to exposure to sucrose solution on 7,10 , 13, and 16 days after subculture.

\begin{tabular}{|c|c|c|c|c|c|c|}
\hline & \multicolumn{6}{|c|}{ days after subcultise } \\
\hline & 1 & 4 & 7 & 10 & 13 & 16 \\
\hline NSF top & \multicolumn{6}{|c|}{ (percent total ${ }^{14} \mathrm{C}$ incorporated) } \\
\hline $\begin{array}{l}\text { Sucrose } \\
\text { Glucose } \\
\text { Fructose }\end{array}$ & - & - & $\begin{array}{l}20 \\
40 \\
39\end{array}$ & $\begin{array}{l}21 \\
38 \\
36\end{array}$ & $\begin{array}{l}30 \\
34 \\
32\end{array}$ & $\begin{array}{l}39 \\
30 \\
28\end{array}$ \\
\hline Sum & - & - & 99 & 95 & 96 & 97 \\
\hline \multicolumn{7}{|c|}{ NSF botton } \\
\hline $\begin{array}{l}\text { Sucrose } \\
\text { Gl ucose } \\
\text { Fructose }\end{array}$ & $\begin{array}{l}16 \\
41 \\
40\end{array}$ & $\begin{array}{l}31 \\
33 \\
33\end{array}$ & $\begin{array}{l}25 \\
36 \\
35\end{array}$ & $\begin{array}{l}24 \\
37 \\
35\end{array}$ & $\begin{array}{l}21 \\
37 \\
37\end{array}$ & $\begin{array}{l}23 \\
37 \\
36\end{array}$ \\
\hline Sum & 97 & 97 & 96 & 96 & 95 & 96 \\
\hline \multicolumn{7}{|l|}{ SF top } \\
\hline $\begin{array}{l}\text { Sucrose } \\
\text { Gl ucose } \\
\text { Fructose }\end{array}$ & $\begin{array}{l}- \\
-\end{array}$ & $\begin{array}{l}- \\
-\end{array}$ & $\begin{array}{l}23 \\
36 \\
34\end{array}$ & $\begin{array}{l}24 \\
36 \\
34\end{array}$ & $\begin{array}{l}33 \\
31 \\
28\end{array}$ & $\begin{array}{l}30 \\
33 \\
31\end{array}$ \\
\hline Sum & - & - & 93 & 94 & 92 & 94 \\
\hline
\end{tabular}


Table 8 (continued).

\begin{tabular}{|c|c|c|c|c|c|c|}
\hline & \multicolumn{6}{|c|}{ days after subzul ture } \\
\hline & 1 & 4 & 7 & 10 & 13 & 16 \\
\hline SF hrottom & \multicolumn{6}{|c|}{ (percent total ${ }^{14} \mathrm{C}$ incorporated) } \\
\hline $\begin{array}{l}\text { Sucrose } \\
\text { Glucose } \\
\text { Fructose }\end{array}$ & $\begin{array}{l}19 \\
39 \\
38\end{array}$ & $\begin{array}{l}31 \\
33 \\
33\end{array}$ & $\begin{array}{l}29 \\
32 \\
32\end{array}$ & $\begin{array}{l}24 \\
34 \\
34\end{array}$ & $\begin{array}{l}20 \\
? 7 \\
36\end{array}$ & $\begin{array}{l}36 \\
32 \\
28\end{array}$ \\
\hline Sum & 96 & 97 & 93 & 92 & 93 & 94 \\
\hline
\end{tabular}


Table 9. Distribution of ${ }^{14} \mathrm{C}$ between the various metabolic fractions after 60 min incubation of $S F$ callus tissue with $[U-14 C]$ sucrose. Callus sample obtained 4 days after subculture to SF medium. Results expressed as percentage of totai $14 \mathrm{C}$ incorporated.

metabolic fractiın

$\%$ total ${ }^{14} \mathrm{C}$

$\begin{array}{ll}\text { sugars, phosphate esters, } & 97.16 \\ \text { and organic acids } & \\ \text { neutral and acidic amino acids } & 0.66 \\ \text { basic amino acids } & 0.06 \\ { }^{14} \mathrm{CO}_{2} & 0.18 \\ \mathrm{lipids} & 0.24 \\ \text { protein } & 0.66 \\ \text { starch } & 0.24 \\ \text { residue } & 0.15\end{array}$


Table 10. Time course for incorporation of ${ }^{14} \mathrm{C}$ from $[U-14 \mathrm{C}]$ sucrose into hexose monophosphates, malate, and citrate in non-shoot-forming (NSF) and shoot-forming (SF) tobacco callus tissues 7 days after subculture to NSF and SF media. Calli divided into bottom and top halves prior to incubation in $0.3 \%(w / V)$ [U-14C] sucrose solutions. Results expressed as ng-atoms C / g dry weight callus tissue.

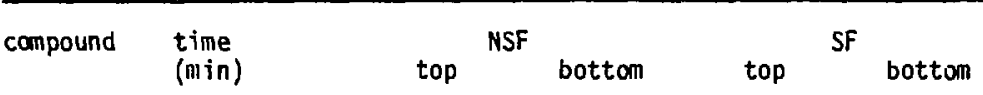

HEXOSE MONOPHOSPHATES

(ng-atoms C /g dry weight)

$\begin{array}{rrrrr}15 & 49 & 57 & 93 & 148 \\ 30 & 86 & 88 & 147 & 233 \\ 60 & 219 & 141 & 497 & 699\end{array}$

MALATE

$\begin{array}{rrrrr}15 & 23 & 16 & 32 & 34 \\ 30 & 29 & 24 & 67 & 50 \\ 60 & 149 & 84 & 307 & 348\end{array}$

CITRATE

$\begin{array}{rrrrr}15 & 8 & 5 & 11 & 9 \\ 30 & 10 & 6 & 17 & 14 \\ 60 & 13 & 8 & 87 & 59\end{array}$


Table 11. incorporation of ${ }^{14} \mathrm{C}$ into hexose monophosphates, malate, and citrate for non-shoot-forming (NSF) and shoot-forming (SF) tobacco callus cultures incubated for $60 \mathrm{~m}$ in with $0.3 \%(\mathrm{w} / \mathrm{v})$ [U-14C] sucrose solution. Callus sampled on indicated days after subculture. Calli divided into top and bottom regions on 7,10,13, and 16 days after subculture. Results expressed as ng-atoms C / g dry weight.

compound $\begin{aligned} & \text { days after } \\ & \text { subculture }\end{aligned}$ top ${ }^{\text {NSF }}$ bottom top ${ }^{\text {SF }}$ bottom

HEXOSE MONOPHOSPHATES

$$
\text { (ng-atoms C / g dry weight) }
$$

\begin{tabular}{lrrrrr} 
& 1 & - & 150 & - & 353 \\
& 4 & - & 335 & - & 424 \\
& 7 & 219 & 141 & 497 & 739 \\
& 10 & 339 & 239 & 326 & 332 \\
& 13 & 245 & 108 & 402 & 568 \\
& 16 & 302 & 590 & 447 & 553 \\
\hline \multirow{2}{*}{ MALATE } & 1 & - & 104 & - & 130 \\
& 4 & - & 101 & - & 140 \\
& 7 & 149 & 84 & 307 & 348 \\
& 10 & 108 & 82 & 284 & 230 \\
& 13 & 121 & 57 & 271 & 209 \\
& 16 & 147 & 163 & 180 & 291 \\
\hline \multirow{2}{*}{ CITRATE } & 16 & & & & \\
& 1 & - & 23 & - & 18 \\
& 4 & - & 23 & - & 37 \\
& 7 & 13 & 8 & 87 & 57 \\
& 10 & 40 & 11 & 31 & 25 \\
& 13 & 16 & 8 & 28 & 20 \\
& 16 & 27 & 48 & 18 & 34
\end{tabular}


Table 12. Time course for release of ${ }^{14} \mathrm{CO}_{2}$ from non-shoot-forming (NSF) and shoot-forming (SF) tobacco callus tissues incubated in $0.3 \%$ $(w / v)[U-14 C]$ sucrose on selected days after subcul ture to NSF and SF media. At $7,10,13$ and 16 days after subculture, calli divided into bottom and top halves prior to incubation in sucrose solutions. Results expressed as $\mathrm{mol}^{\mathrm{CO}_{2}}$ released / $\mathrm{g}$ dry weight callus tissue.

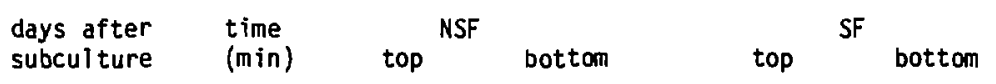

\begin{tabular}{rrrrrr} 
& & \multicolumn{5}{c}{ (nmol $\mathrm{CO}_{2} / \mathrm{g}$ dry weight) } \\
1 & 15 & - & 7 & - & 4 \\
1 & 30 & - & 40 & - & 31 \\
1 & 60 & - & 229 & - & 233 \\
& & & & & \\
4 & 15 & - & 45 & - & 32 \\
4 & 30 & - & 71 & - & 99 \\
4 & 60 & - & 275 & & 358 \\
7 & 15 & 13 & 6 & 7 & 32 \\
7 & 30 & 41 & 42 & 49 & 46 \\
7 & 60 & 215 & 135 & 518 & 535 \\
& & & & & \\
10 & 15 & 6 & 14 & 19 & 10 \\
10 & 30 & 64 & 61 & 96 & 38 \\
10 & 60 & 186 & 192 & 467 & 444 \\
13 & 15 & 8 & 5 & 7 & 10 \\
13 & 30 & 33 & 26 & 116 & 135 \\
13 & 60 & 121 & 323 & 427 & 415 \\
16 & 15 & 8 & 16 & 3 & 11 \\
16 & 30 & 57 & 94 & 27 & 83 \\
16 & 60 & 154 & 600 & 395 & 482 \\
& & & & & \\
\hline
\end{tabular}


Table 13. Time course of incorporation of ${ }^{14} \mathrm{C}$ from $[U-14 \mathrm{C}]$ sucrose into metabolite fraction containing neutral and acidic amino acids for nonshoot-forming (NSF) and shoot-forming (SF) tobaccs callus tissues on selected days after subcuiture to NSF and SF media. At $7,10,13$ and 16 days after subculture, calli divided into top and bottom halves prior to incubation in $0.3 \%$ (w/v) [U-14C]sucrose solutions. Results expressed as ng-atoms C/g dry weight callus tissue.

$\begin{array}{llll}\text { days after } & \text { time } & \text { NSF } & \\ \text { subculture } & \text { (min) } & \text { top } & \text { bottom }\end{array}$

\begin{tabular}{rrrrrr} 
& & \multicolumn{5}{c}{ (ng-atoms C / g dry weight) } \\
1 & 15 & - & 64 & - & 54 \\
1 & 30 & - & 122 & - & 123 \\
1 & 60 & - & 492 & - & 866 \\
& & & & & \\
4 & 15 & - & 216 & - & 179 \\
4 & 30 & - & 297 & - & 1530 \\
4 & 60 & - & 608 & & \\
7 & 15 & 101 & 59 & 96 & 352 \\
7 & 30 & 128 & 178 & 330 & 590 \\
7 & 60 & 400 & 275 & 1880 & 2410 \\
& & & & & \\
10 & 15 & 22 & 91 & 181 & 267 \\
10 & 30 & 283 & 302 & 636 & 449 \\
10 & 60 & 617 & 768 & 1230 & 1720 \\
13 & 15 & 55 & 88 & 99 & 205 \\
13 & 30 & 122 & 244 & 564 & 1060 \\
13 & 60 & 390 & 1400 & 1600 & 2817 \\
16 & 15 & 53 & 95 & 138 & 279 \\
16 & 30 & 425 & 297 & 409 & 608 \\
16 & 60 & 591 & 2680 & 1090 & 2590 \\
& & & & & \\
\hline
\end{tabular}


Table 14. Incorporation of ${ }^{14} \mathrm{C}$ into selected neutral and acidic amino acids for non-shoot-forming (NSF) and shoot-forming (SF) tobacco callus cultures incubated for 60 min with $0.3 \%(w / v)$ [U-14C]sucrose solution. Callus sampled on indicated days after subculture. Calli divided into top and bottom regions on $7,10,13$, and 16 days after subculture. Results expressed as ng-atoms C/g dry weight.

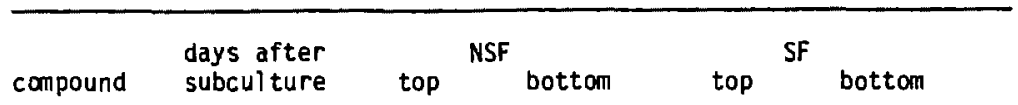

\begin{tabular}{|c|c|c|c|c|c|}
\hline \multirow[b]{2}{*}{ ALANINE } & \multirow[b]{2}{*}{$\begin{array}{r}1 \\
4 \\
7 \\
10 \\
13 \\
16\end{array}$} & \multicolumn{4}{|c|}{ (ng-atoms $C / g$ dry weight) } \\
\hline & & $\begin{array}{c}- \\
- \\
84 \\
111 \\
179 \\
269\end{array}$ & $\begin{array}{r}201 \\
256 \\
97 \\
421 \\
892 \\
1550\end{array}$ & $\begin{array}{c}- \\
- \\
493 \\
240 \\
342 \\
561\end{array}$ & $\begin{array}{r}318 \\
713 \\
977 \\
727 \\
1160 \\
1090\end{array}$ \\
\hline SERINE & $\begin{array}{r}1 \\
4 \\
7 \\
10 \\
13 \\
16\end{array}$ & $\begin{array}{r}- \\
30 \\
44 \\
57 \\
95\end{array}$ & $\begin{array}{r}51 \\
39 \\
30 \\
41 \\
46 \\
317\end{array}$ & $\begin{array}{l}- \\
149 \\
147 \\
195 \\
180\end{array}$ & $\begin{array}{r}63 \\
169 \\
175 \\
250 \\
288 \\
242\end{array}$ \\
\hline \multicolumn{6}{|c|}{ METHIONINE + VALINE } \\
\hline & $\begin{array}{r}1 \\
4 \\
7 \\
10 \\
13 \\
16\end{array}$ & $\begin{array}{l}- \\
- \\
5 \\
8 \\
6 \\
6\end{array}$ & $\begin{array}{r}11 \\
11 \\
3 \\
6 \\
7 \\
16\end{array}$ & $\begin{array}{r}- \\
15 \\
17 \\
18 \\
3\end{array}$ & $\begin{array}{r}9 \\
9 \\
24 \\
19 \\
23 \\
10\end{array}$ \\
\hline
\end{tabular}


Table 14 (continued).

days after
compound
subculture top bottom top $^{S F}$ bottom

$$
\text { (ng-atoms } C / g \text { dry weight) }
$$

PHENYLALANINE

$\begin{array}{rrrrr}1 & - & 32 & - & 47 \\ 4 & - & 47 & - & 60 \\ 7 & 16 & 12 & 96 & 178 \\ 10 & 19 & 30 & 40 & 58 \\ 13 & 14 & 26 & 55 & 63 \\ 16 & 14 & 74 & 20 & 42\end{array}$

\begin{tabular}{lrrrrr}
\hline RRYPTOPHAN & 1 & - & 9 & - & 6 \\
& 4 & - & 11 & - & 10 \\
& 7 & 7 & 5 & 17 & 13 \\
& 10 & 7 & 7 & 10 & 5 \\
& 13 & 11 & 14 & 23 & 12 \\
& 16 & 21 & 59 & 35 & 24
\end{tabular}

GLUTAMATE + ASPARTATE

$\begin{array}{rrrrr}1 & - & 175 & - & 151 \\ 4 & - & 160 & - & 264 \\ 7 & 72 & 64 & 560 & 490 \\ 10 & 289 & 148 & 400 & 293 \\ 13 & 152 & 188 & 538 & 307 \\ 16 & 190 & 591 & 415 & 391\end{array}$


Table 14 (continued).

compound $\begin{aligned} & \text { days after } \\ & \text { subculture }\end{aligned}$ top NSF bottan top ${ }^{S F}$ bottom

(ng-atoms C / g dry weight)

GLUTAMINE + ASPARAGINE

$\begin{array}{rrrrr}1 & - & 68 & - & 53 \\ 4 & - & 135 & - & 126 \\ 7 & 53 & 23 & 416 & 315 \\ 10 & 81 & 40 & 281 & 197 \\ 13 & 20 & 25 & 298 & 400 \\ 16 & 93 & 535 & 276 & 940\end{array}$


Table 15. Time course for incorporation of $14_{C}$ from $[U-14 C]$ sucrose into metabolite fraction containing basic amino acids in non-shootforming (NSF) and shoot-forming (SF) tobacco callus tissues on selected days after subculture to NSF and SF media. At $7,10,13$ and 16 days after subculture, calli divided into bottom and top halves prior to incubation in $0.3 \%(w / v) \quad[U-14 C]$ sucrose solutions. Results expressed as ng-atoms $\mathrm{C} / \mathrm{g}$ dry weight callus tissue.

\begin{tabular}{|c|c|c|c|c|c|}
\hline \multirow[t]{2}{*}{$\begin{array}{l}\text { days after } \\
\text { subculture }\end{array}$} & \multirow[t]{2}{*}{$\begin{array}{l}\text { time } \\
(\min )\end{array}$} & \multicolumn{2}{|c|}{ NSF } & \multicolumn{2}{|c|}{ SF bottom } \\
\hline & & & (ng-atoms & ry wei & \\
\hline $\begin{array}{l}1 \\
1 \\
1\end{array}$ & $\begin{array}{l}15 \\
30 \\
60\end{array}$ & $\overline{-}$ & $\begin{array}{r}5 \\
14 \\
72\end{array}$ & I & $\begin{array}{r}5 \\
16 \\
85\end{array}$ \\
\hline $\begin{array}{l}4 \\
4 \\
4\end{array}$ & $\begin{array}{l}15 \\
30 \\
60\end{array}$ & $\overline{-}$ & $\begin{array}{l}28 \\
32 \\
65\end{array}$ & - & $\begin{array}{l}14 \\
54 \\
80\end{array}$ \\
\hline $\begin{array}{l}7 \\
7 \\
7\end{array}$ & $\begin{array}{l}15 \\
30 \\
60\end{array}$ & $\begin{array}{l}12 \\
18 \\
53\end{array}$ & $\begin{array}{l}12 \\
21 \\
39\end{array}$ & $\begin{array}{r}7 \\
10 \\
48\end{array}$ & $\begin{array}{l}16 \\
23 \\
84\end{array}$ \\
\hline $\begin{array}{l}10 \\
10 \\
10\end{array}$ & $\begin{array}{l}15 \\
30 \\
60\end{array}$ & $\begin{array}{r}5 \\
29 \\
40\end{array}$ & $\begin{array}{l}12 \\
23 \\
52\end{array}$ & $\begin{array}{r}7 \\
19 \\
31\end{array}$ & $\begin{array}{r}8 \\
11 \\
52\end{array}$ \\
\hline $\begin{array}{l}13 \\
13 \\
13\end{array}$ & $\begin{array}{l}15 \\
30 \\
60\end{array}$ & $\begin{array}{r}7 \\
9 \\
16\end{array}$ & $\begin{array}{l}13 \\
16 \\
46\end{array}$ & $\begin{array}{r}3 \\
17 \\
35\end{array}$ & $\begin{array}{r}5 \\
15 \\
47\end{array}$ \\
\hline $\begin{array}{l}16 \\
16 \\
16\end{array}$ & $\begin{array}{l}15 \\
30 \\
6 C\end{array}$ & $\begin{array}{l}1 \\
3 \\
7\end{array}$ & $\begin{array}{r}4 \\
7 \\
30\end{array}$ & $\begin{array}{l}1 \\
3 \\
6\end{array}$ & $\begin{array}{r}4 \\
6 \\
19\end{array}$ \\
\hline
\end{tabular}


Table 16. Time course for incorporation of ${ }^{14} \mathrm{C}$ from $[U-14 \mathrm{C}]$ sucrose into protein of non-shoot-forming (NSF) and shoot-forming (SF) tobacco callus tirsues on selected days after subculture to NSF and SF media. At $7,10,13$ and 16 days after subculture, calli divided into botton and top halves prior to incubation in $0.3 \%(\mathrm{w} / \mathrm{V})[\mathrm{U}-14 \mathrm{C}]$ sucrose solutions. Results expressed as ng-atoms C / g dry weight callus tissue.

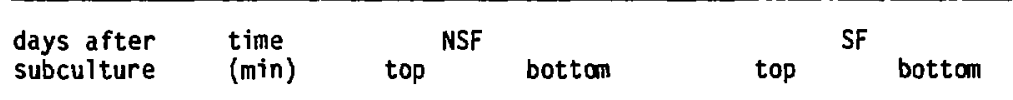

\begin{tabular}{|c|c|c|c|c|c|}
\hline \multirow[b]{2}{*}{$\begin{array}{l}1 \\
1 \\
1\end{array}$} & \multirow[b]{2}{*}{$\begin{array}{l}15 \\
30 \\
60\end{array}$} & \multicolumn{4}{|c|}{ (ng-atoms $C / g$ dry weight) } \\
\hline & & - & $\begin{array}{r}71 \\
84 \\
737\end{array}$ & $\begin{array}{l}- \\
-\end{array}$ & $\begin{array}{r}91 \\
359 \\
865\end{array}$ \\
\hline $\begin{array}{l}4 \\
4 \\
4\end{array}$ & $\begin{array}{l}15 \\
30 \\
60\end{array}$ & - & $\begin{array}{r}716 \\
902 \\
1056\end{array}$ & - & $\begin{array}{r}464 \\
615 \\
1632\end{array}$ \\
\hline $\begin{array}{l}7 \\
7 \\
7\end{array}$ & $\begin{array}{l}15 \\
30 \\
60\end{array}$ & $\begin{array}{l}127 \\
191 \\
416\end{array}$ & $\begin{array}{l}247 \\
428 \\
457\end{array}$ & $\begin{array}{r}206 \\
314 \\
1130\end{array}$ & $\begin{array}{r}227 \\
521 \\
1515\end{array}$ \\
\hline $\begin{array}{l}10 \\
10 \\
10\end{array}$ & $\begin{array}{l}15 \\
30 \\
60\end{array}$ & $\begin{array}{r}88 \\
305 \\
436\end{array}$ & $\begin{array}{l}258 \\
353 \\
646\end{array}$ & $\begin{array}{l}249 \\
625 \\
874\end{array}$ & $\begin{array}{r}319 \\
431 \\
1321\end{array}$ \\
\hline $\begin{array}{l}13 \\
13 \\
13\end{array}$ & $\begin{array}{l}15 \\
30 \\
60\end{array}$ & $\begin{array}{r}65 \\
166 \\
223\end{array}$ & $\begin{array}{r}174 \\
429 \\
1024\end{array}$ & $\begin{array}{r}450 \\
956 \\
1652\end{array}$ & $\begin{array}{r}578 \\
1329 \\
1790\end{array}$ \\
\hline $\begin{array}{l}16 \\
16 \\
16\end{array}$ & $\begin{array}{l}15 \\
30 \\
60\end{array}$ & $\begin{array}{l}386 \\
777 \\
906\end{array}$ & $\begin{array}{r}493 \\
992 \\
1542\end{array}$ & $\begin{array}{r}386 \\
845 \\
1922\end{array}$ & $\begin{array}{r}832 \\
1057 \\
1978\end{array}$ \\
\hline
\end{tabular}


Table 17. Time course for starch synthesis from $\left[\mathrm{U}^{14} \mathrm{C}\right]$ sucrose supplied to non-shoot-forming (NSF) and shoot-foming (SF) tobacco callus tissues on selected days after subculture to NSF and SF media. At $7,10,13$ and 16 days after subculture, calli divided into bottom and top halves prior to incubation in $0.3 \%(w / v)[U-14 C]$ sucrose solutions. Results expressed as ng-atoms $\mathrm{C} / \mathrm{g}$ fresh weight callus tissue.

$\begin{array}{lllll}\begin{array}{l}\text { days after } \\ \text { subculture }\end{array} & \begin{array}{l}\text { time } \\ (m i n)\end{array} \quad \text { top } & \text { bottom } & \text { top } & \text { SF bottom }\end{array}$

\begin{tabular}{rrrrrr} 
& & \multicolumn{5}{c}{ (ng-atons C / g dry weight) } \\
1 & 15 & - & 21 & - & 22 \\
1 & 30 & - & 40 & - & 58 \\
1 & 60 & - & 215 & - & 310 \\
& & & & & \\
4 & 15 & - & 167 & - & 50 \\
4 & 30 & - & 174 & - & 130 \\
4 & 60 & - & 292 & - & 316 \\
7 & 15 & 39 & 27 & 36 & 96 \\
7 & 30 & 50 & 68 & 92 & 122 \\
7 & 60 & 247 & 143 & 365 & 599 \\
& & & & & \\
10 & 15 & 30 & 44 & 42 & 45 \\
10 & 30 & 132 & 76 & 138 & 85 \\
10 & 60 & 252 & 216 & 252 & 328 \\
13 & 15 & 36 & 41 & 24 & 55 \\
13 & 30 & 52 & 72 & 148 & 251 \\
13 & 60 & 81 & 371 & 316 & 412 \\
16 & 15 & 20 & 61 & 24 & 67 \\
16 & 30 & 45 & 72 & 52 & 129 \\
16 & 60 & 119 & 427 & 233 & 380 \\
& & & & & \\
\hline
\end{tabular}


Table 18. Time course for incorporation of ${ }^{14} \mathrm{C}$ from $[U-14 \mathrm{C}]$ sucrose into residue (cell wall) fraction of non-shoot-forming (NSF) and shoot-forming (SF) tobacco callus tissues on selected days after subculture to NSF and SF media. At $7,10,13$ and 16 days after subculture, calli divided into bottom and top halves prior to incubation in $0.3 \%(w / v)[U-14 C]$ sucrose solutions. Results expressed as ng-atoms C / g dry weight callus tissue.

\begin{tabular}{|c|c|c|c|}
\hline days after & time & NSF & SF \\
\hline subcul & $(\min )$ & bottom & bottom \\
\hline
\end{tabular}

\begin{tabular}{rrrrrr} 
& & \multicolumn{5}{c}{ (ng-atoms C / g dry weight) } \\
1 & 15 & - & 13 & - & 14 \\
1 & 30 & - & 26 & - & 46 \\
1 & 60 & - & 142 & - & 202 \\
& & & & & \\
4 & 15 & - & 38 & - & 31 \\
4 & 30 & - & 56 & - & 111 \\
4 & 60 & - & 149 & - & 282 \\
7 & 15 & 25 & 21 & 24 & 69 \\
7 & 30 & 28 & 62 & 46 & 92 \\
7 & 60 & 142 & 96 & 277 & 477 \\
& & & & & \\
10 & 15 & 12 & 21 & 19 & 55 \\
10 & 30 & 69 & 51 & 64 & 138 \\
10 & 60 & 180 & 151 & 121 & 217 \\
13 & 15 & 14 & 18 & 13 & 33 \\
13 & 30 & 29 & 41 & 78 & 143 \\
13 & 60 & 47 & 215 & 214 & 273 \\
16 & 15 & 7 & 36 & 12 & 44 \\
16 & 30 & 17 & 48 & 31 & 84 \\
16 & 60 & 44 & 269 & 111 & 231 \\
& & & & & \\
\hline
\end{tabular}


CHAPTER 4

METABOLITE CONCENTRATIONS IN NON-SHOOT-FORMING

\section{ANO SHOOT-FORMING TOBACCO CALLUS CULTURES}

It is neces iary to know metabolite concentrations in order to distinguish whether the differenres in rates of ${ }^{14} \mathrm{C}$-labelling of individual metabolites observed between NSF and SF tobacco callus tissues are due to differential activities of enzymes involved in the biosynthesis and cagradation of these conpounás, or to differences in the specific activities of internal metabolite precursor pools. For example, as there ras no apparent difference in rates of uptake of [U $\left.{ }^{14} \mathrm{C}\right]$ sucrose by $\mathrm{NSF}$ and SF calli, increased labelling of hexose monophosphates in SF tissues could be explained by either increased activity of hexosa kinase, or increased specific activity of internal hexose pools. The latter would occur if metabolically-active intracellular glucose and fructose pools were smaller in SF callus tissue. Concentrations of selected intermediary metabolites in NSF and SF tobacco calli were measured to gain a better understanding of the observed differences in sucrose metabolism in these tissues. Because significani differences in sucrose metabolism were observed one week after sub ulture to NSF and SF media, the following studies focused on chariges in metabolism of NSF and SF callus tissue during the first week after subculture. Interesting differences in the concentrations of various metabolites in NSF and SF calli were 
observed during the first week after subculture. These differences provide adjitional metabolic markers for shoot initiation in tobacco callus tissue.

1. Saturation of metabolite pools with carbon-14.

Methods. This study was performed before selection of NSF medium described in Chapter 2, and calli were initiated and subcultured on a medium which was identical in nutrient composition to NSF medium, but which contained $2.0 \mathrm{mg} / \mathrm{l}$ indoleacetic acid (IAA) as auxin, and $0.1 \mathrm{mg} / \mathrm{l}$ 6-benzylaminopurine (BAP) as cytokinin.

$\left[U-{ }^{14} \mathrm{C}\right]$ sucrose was added by filter sterilization to freshlyprepared culture medium before the medium was poured into Petri dishes. Aliquots of medium were removed for liquid scintillation counting, and the calculated specific activity of the medium was 3.6 $\times 10^{-3} \mathrm{mCi} / \mathrm{mg}-\mathrm{atcm} \mathrm{C}$.

Callus tissue was subcultured to $\left[\mathrm{U}-{ }^{14} \mathrm{C}\right]$ sucrose medium at a density of either 5 or 15 pieces of callus / Petri dish. Each piece of callus was approximately $2 \mathrm{~mm}^{3}$. After $2,4,6,8,14$, and 21 days of growth on $\left[\mathrm{U}-{ }^{14} \mathrm{C}\right]$ sucrose medium, pieces of callus tissue were carefully removed from the mcifium and subdivided into top and bottom regions according to their orientation relative to the agar medium. Samples ranged from 0.54 to $1.56 \mathrm{~g}$ fresh weight. Care was taken to avoid contamination of callus samples with the agar medium. Petri plates containing the higher density of callus tissue were sampled 2, 4, and 6 days after subculture. Samples obtained on 8,14 , and 21 days after subculture were taken from Petri plates which contained 5 pieces of callus. Two samples were obtained for bottom regions of 
tissue, and one for top regions of tissue on each sampling day.

Tissues were washed twice with $10 \mathrm{ml} \quad 3 \%(w / v)$ unlabelled sucrose, followed by 3 washes with $10 \mathrm{ml}$ water to remove extracellular [U- $\left.{ }^{14} \mathrm{C}\right]$ sucrose, as described in Chapter 3 , Section la. Callus was humogenized and extracted using $\mathrm{MCW}(12: 5: 3 \mathrm{v} / \mathrm{v} / \mathrm{v})$, as described in Chapter 3, Section 1b. Supernatants and pellets obtained from the extraction procedure were stored at $0{ }^{{ }^{C}} \mathrm{C}$ until all samples were collected. After separation of the chioroform and aqueous phases, the water-soluble metabolites were fractionated using cation-exchange resin, as described in Chapter 3, Section 1c. The pellets were separated into protein, starch, and residue fractions, as described described in Chapter 3, Section 1d. Total starch was determined colorimetrically, as described in Chapter 2, Section $3 c$.

Results and Discussion. Calli cultured on medium containing $2 \mathrm{mg} / 1$ IAA and $0.1 \mathrm{mg} / 1$ BAP remained in an unorganized state. There is no reason to suspect that saturation of metabolic pools with ${ }^{14} \mathrm{C}$ in calli grown on NSF medium would occur at significantly different rates than were observed for the calli used in this study.

Though radioactive-labelling of fractions containing small molecules, (sugars, phosphate esters, carboxylic acids, and amino acids), was greater in the bottom than in the top halves of calli through the first 4 days after subculture to $\left[U-{ }^{14} \mathrm{C}\right]$ sucrose medium, by 6 days both regions of calli contained approximately equal amounts of ${ }^{14} \mathrm{C}$ in these fractions (Table 1 ). This reflects the time required for the utilization of residual unlabelled sucrose in the upper portions of the calli, and for diffusion of $\left[\mathrm{U}_{-}{ }^{14} \mathrm{C}\right]$ sucrose from the medium to extracellular spacas in these tissues, as well as transport 
of $\left[U-{ }^{14} \mathrm{C}\right]$ sucrose through symplastic connections from lower to upper regions of the callus tissues.

The fraction containing sugars, phosphate esters, and carboxylic acids was not saturated with ${ }^{14} \mathrm{C}$ during the three week study (Table 1). Results presented in the next section show that over $90 \%$ of the radioactivity in this fraction was located in sucrose, glucose, and fructose. The amount of radioactivity in this metabolite fraction increased approximately $25 \%$ in samples taken from top and bottom regions of calli at 3 weeks, compared to samples taken at 2 weeks. However, because radioactivity in all other metabolite fractions was ultimately derived from $\left[{ }^{14} \mathrm{C}\right]$ sucrose, and these other fractions were effectively saturated with ${ }^{14} \mathrm{C}$ during the 3 week study (Table 1 ), it is likely that a constant specific activity was also obtained in the fraction containing sugars. Results presented in Chapter 2, Section $4 a$ show that the fresh weight of NSF calli increases an average of 11fold diring the first two weeks following subculture. Assuming the concentration of sugars in calli remains constant during this time, an 11-fold increase in total sugars would accompany this increase in fresh weight. Even if none of the unlabelled sugar presented in callus tissue $a$ : the time of subculture was metabolized during the first two weeks of growth, this unlabelled sugar would account for only $9 \%$ of the total sugar in 2-week samples. It stigis improbable that the $25 \%$ increase in ${ }^{14} \mathrm{C}$-labelling of sugars between 2 and 3 weeks reflects a $25 \%$ increase in the specific activity of these sugars. It is much more likely that the increase in labelling of the sugar-containing fraction observed between 2 and 3 weeks after subculture resulted primarily from an increase in concentrations of 
sugars in NSF calli.

(The decrease in amount of radioactivity in this fraction for 4day samples from the bottom portion of callus tissue, compared to 6day samples, can be explained by inclusion of small amounts of the $\left[{ }^{14} \mathrm{C}\right]$ sucrose-containing agar medium containing with the 4 day tissue sample. All other metabolic fractions showed the expected increase in radioactivity between 4 and 6 days after subculture).

The amount of ${ }^{14} \mathrm{C}$ per $\mathrm{g}$ fresh weight in both amino acid fractions ceased to increase in samples from bottom and top regions of calli by 8 and 14 days after subculture, respectively (Table 1). This indicates that the specific activity of these compounds remained constant after two weeks, and was equal to that of the medium on which the calli were grown. The amount of neutral and acidic amino acids observed in top regions of calli at 3 weeks was approximately one-half that observed at 2 weeks. In bottom regions of calli, concentrations of these amino acids decreased almost $40 \%$ between 8 and 21 days. The decrease in concentrations of amino acids between 2 and 3 weeks implies changes in NSF callus tissue composition at this time. Because NSF callus tissues grow preferentially near exposed surfaces of calli (Aitchison, 1977), top portions of calli should contain greater proportions of dividing cells than bottan portions of calli. Assuming that accelerated rates of protein synthesis accompany increasing rates of cell division, it is not surprising that greater decreases in total concentration of amino acids were observed for top regions than for bottom regions of NSF calli during the log phase of callus tissue growth.

The lipid fractions of top and bottom sections of calli were 
saturated with ${ }^{14} \mathrm{C} 8$ days after subculture (Table 1). Protein and residue fractions were saturated by 2 weeks (Table 1). Top regions of calli contained between $30 \%$ and $40 \%$ lower concentrations of lipids, protein, and residue than bottom regions of calli. These results suggest that increases in vacuolation and average cell size, and decreases in cell wall thickness, accompany increased rates of cell division in uiper regions, relative to lower regions of calli. Plant vacuoles contain mostly inorganic ions and small organic compounds. Accumulation of these molecules in vacuoles could result in increases in tissue fresh weight that were not paralleled by increases in macromolecule concentratirs. Increased amounts of friable (vacuolated) tissue were commonly observed in the top halves of calli after prolonged periods without subculture.

Although the results presented in Table 1 suggest that the starch fraction from bottom regions of calli might not have attained a specific activity equal to that of the $\left[U-{ }^{14} \mathrm{C}\right]$ sucrose medium, the increase in ameunt of ${ }^{14} \mathrm{C}$ observed in this fraction between 2 and 3 weeks is more likely a refiection of starch accumulation in the callus tissues (Table 2). During the first 8 days after subculture there was net degradation of stored starch in both top and bottom regions of callus. Active starch synthesis occurred simultaneous with starch degradation, as evidenced by the continuous increase in ${ }^{14} \mathrm{C}$-labelling of this fraction (Table 1). After 8 days, and through the remainder of the 3 week study, net synthesis of starch was observed (Table 2). ${ }^{14}$ C-labelling of starch in samples from top and bottom portions of calli increased 2.4- and 3.2-fold respectively between 8 and 21 days after subculture, while total starch in these samples increased 2.6- 
and 3.4-fold respectively in top and bottom portions of calli. The similar increases in $\left[{ }^{14} \mathrm{C}\right]$ starch and total starch support the hypothesis that a constant specific activity of starch molecules was attained during the 3 week study.

i. surmary, the above study showed that intracellular metabolite pools are effectively saturated with ${ }^{14} \mathrm{C} 2$ weeks after subculture of callus tissue to medium containing $\left[\mathrm{U}-{ }^{14} \mathrm{C}\right]$ sucrose. Metabolite concentrations in NSF and SF calius tissues are determined in the following study by assuming that the specific activity of individual metabolites equals that of the culture medium 3 weeks after subculture of tissue to $\left[\mathrm{U}-{ }^{14} \mathrm{C}\right]$ sucrose medium.

2. Metabolite concentrations in NSF and SF calli.

a. Methods and general results.

Methods. Three different lines of callus were used in these experiments. Callus type $A$ was initiated from stem pith explants 9 weeks prior to sampling. Types $B$ and $C$ were initiated 39 and 45 weeks, respectively, prior to sampling.

Intracellular metabolite pools were saturated with radioactive carbon by inoculating callus at a density of 5 pieces of callus / Petri dish to NSF medium containing $\left[\mathrm{U}^{14} \mathrm{C}\right]$ sucrose $\left(1.0 \times 10^{-2} \mathrm{mCi} /\right.$ mg-atom carbon). Radioactive medium was prepared as described in Section 1 of this chapter. Each piece of callus was approximately 2 $\mathrm{mm}^{3}$. After 3 weeks of growth on radioactive medium, callus was subcultured at a density of 15 pieces of callus / Petri dish to either NSF or SF medium containing the same specific activity of [U- 
$1_{4 C}$ sucrose $\left(1.0 \times 10^{-2} \mathrm{mCi} / \mathrm{mg}\right.$-atom carbon).

Samples of callus type $A$ were collected after $1,2,3,5$, and 7 days of growth on ${ }^{14}$ C-labelled NSF or SF medium. Samples of callus types $B$ and $C$ were collected after 3 and 7 days of growth on the ${ }^{14} C$ labelled media. Each sample of callus consisted of all of the callus from one Petri dish. Three replicate samples were obtained on each sampling day for NSF and SF callus type A. For callus types B and C, duplicate samples were obtained at 3 days, and 3 replicate samples were obtained 7 days after subculture to the two media. Samples ranged from 0.2 to $0.7 \mathrm{~g}$ fresh weight.

Tissues were washed twice with $10 \mathrm{ml} 3 \%(w / v)$ sucrose followed by 3 washes with $10 \mathrm{ml}$ water to remove extracellular $\left[\mathrm{U}-{ }^{14} \mathrm{C}\right]$ sucrose, as described in Chapter 3, Section 1a. Callus was homogenized and extracted using $M C W(12: 5: 3, v / v / v)$, as described in Chapter 3 , Section 1b. Supernatants and pellets obtained from the extraction procedure were stored at $0^{\circ} \mathrm{C}$ until all samples were collected. After separation and concentration of the chloroform and aqueous phases, the water-soluble metabolites were fractionated using cation-exchange resin into a fraction containing sugars, phosphate esters, and carboxylic acids, one containing neutral and acidic acids, and a fraction containing basic amino acids and strong bases, as described in Chapter 3, Section 1C. Aliquots of the sugar and the neutral and acidic anino acid fractions were subjected to 2-dimensional paper chromatography, and individual metabolites quantified as described in Chapter 3, Sertion 1c. The pellets were separated into protein, starch, and residue fractions using methods described in Chapter 3 , Section 1d. Duplicate aliquots of each fraction were removed for 
1 iquid scintillation counting. Metabolite concentrations in callus tissues were determined by assuming that the specific activity of individual metabolites equaled that of the culture medium 3 weeks after subculture of tissue to $\left[U-{ }^{14} \mathrm{C}\right]$ sucrose medium.

\section{Verification of $A C C$.}

$\left[{ }^{14} \mathrm{C}\right] \mathrm{ACC}$ was identified by cochromatography with authentic ACC on the 2-dimensional paper chromatograms. (Authentic ACC was kindly provided by Dr. Doug Adams). The darkened region of the autoradiogram coincided precisely with ninhydrin-positive ACC.

Cochromatography of the radioactive spot with authentic ACC was at so observed in reversed-phase ion-pair high pressure liquid chromatography (HPLC), using a modification of the methods of Radjai and Hatch (1980). Equipment used in the HPLC apparatus included a Spectra-Physics Model 8000 liquid chromatograph assembly (SpectraPhysics, Santa Clara, CA); an Altex prepacked "ultrasphere" octadecyl silica (ODS) column, 25 am $\times 4.6 \mathrm{~mm}$ i.d., 5 um particle size (Al tex Scientific, Inc., Berkeley, CA); and a Schoeffel GM 770 LC Fluorometer equipped with a flow cell and cutoff filter of $\lambda=450 \mathrm{~mm}$. (Schoeffel Instruments, Westwood, NJ). The mobile phase for HPLC required gradient solvent programing for elution of many amino acids. Solvent A contained $0.125 \%(w / v)$ "specially pure" sodium dodecyl sulphate (SOS) (BDH Chemicals, Poole, United Kingdom), and $0.1 *(\mathrm{v} / \mathrm{v})$ phosphoric acid. The $\mathrm{pH}$ was adjusted to 2.45 using saturated $\mathrm{NaOH}$. Solvent B contained $0.125 \%(w / v)$ SDS, $0.1 \%(v / v)$ phosphoric acid, and $50 \%(\mathrm{v} / \mathrm{v})$ "distilled in glass" grade acetonitrile (Burdick and Jackson, Muskegon, Mich). Preliminary studies revealed the necessity 
of using high purity water (Burdick and Jackson) to obtain a stable baseline during gradient elution of amino acids. Solvents were filtered through a 0.45 un Millipore filter and degassed with helium prior to use. A typical solvent gradient program is presented in Table 19. ACC eluted in 55 min using this solvent program. Solvent flow rate was $1.0 \mathrm{ml} / \mathrm{min}$, column temp. was $37{ }^{\circ} \mathrm{C}$, and typical operating pressures were approximately 2500 p.s.i. Complete column regeneration required a minimum of $60 \mathrm{ml}$ solvent $A$. After flushing with water, the column was stored overnight in "distilled in glass" grade methanol (Burdick and Jackson).

Amino acids were detected by fluoresence $\left(\lambda_{e x}=340 \mathrm{~nm}\right)$ after postcolunn derivitization with Roth's reagent (Roth, 1981), supplied by a Varian 8500 pump (Varian Instruments, Los Altos, CA) at a flow rate of $10 \mathrm{ml} / \mathrm{hr}$. Roth's reagent contained $800 \mathrm{mg}$ o-phthalaldehyde (Sigma Chemical Co., St. Louis) and 200 ul 2-mercaptoethanol in $0.1 \mathrm{M}$ borate buffer, $\mathrm{pH}$ 10.4. To facilitate dissolution in the aqueous reagent, the 0-phthalaldehyde was first dissolved in $10 \mathrm{ml}$ methanol before addition to the borate buffer. Roth's reagent was stable for approximately 3 days at room temperature. Roth's reagent was introduced into the column effluent through a Teflon tee. A reaction coil with a delay time of approximately $20 \mathrm{sec}$ was situated between the tee where column effluent and reagents were mixed, and the detector. Figure 1 shows a typical chromatogram of a plant sarmple.

Further verification of ACC was accomplished using the assay of Lisada and Yang (1979). Paper chromatoram spots corresponding to putative $\left[{ }^{14} \mathrm{C}\right] \mathrm{ACC}$ from NSF calli were eluted with water and combitned. To an aliquot of this solution, corresponding to approximately $10 \mathrm{~mol}$ 
ACC as judged by HPLC, was added 1 umol $\mathrm{HgCl}_{2}$ and the volume was brought to $900 \mathrm{ul}$ with water. The $5 \mathrm{ml}$ reaction vesse 1 was sealed with a gas-tight silicon stopper, agitated on a vortex mixer, and kept on ice. Cold $5.5 \%(\mathrm{v} / \mathrm{v}) \mathrm{NaOCl}$ and saturated $\mathrm{NaOH}(2: 1 \mathrm{v} / \mathrm{v}), 100 \mathrm{ul}$, was injected into the reaction vessel, which was immediately agitated on a Vortex mixer for $5 \mathrm{sec}$ then incubated on ice for 2.5 min. The mixture was agitated again for 5 sec prtor to gas sampling.

Ethylene production from ACC was detected and quantified using a Varian Model 3700 Gas Chromatograph equipped with a flame ionization detector (Varian Instruments, Los Altos, CA), and a Supelco Carbosieve B $60 / 80$ column ( $3 \mathrm{ft}$. $\times 1 / 8$ in.). Operating conditions were as follows: column temp, $220{ }^{\circ} \mathrm{C}$; injector temp, $81{ }^{\circ} \mathrm{C}$; attenuation 1 ; range, $10^{-10}$ amps $/ \mathrm{mV} ; N_{2}$ carrier gas, $30 \mathrm{ml} / \mathrm{min}$; and hydroger and air at $30 \mathrm{ml} / \mathrm{min}$. Comparison of the amount of ethylene produced from 10 nmol putative $\left[{ }^{14} \mathrm{C}\right] \mathrm{ACC}$, as judged from HPLC chromatograms, with standard curves prepared using known amounts of ACC confirmed the assumption that the radioactive sample contained approximately $10 \mathrm{mmul}$ $\left[{ }^{14} \mathrm{C}\right] \mathrm{ACC}$. Appropriate controls were performed, and no ethylene production was detected from either $\left[{ }^{14} \mathrm{C}\right] A C C$ in water lacking reagents, or reagents without $\left[{ }^{14} \mathrm{C}\right] \mathrm{ACC}$.

Results. Because callus types $A, B$, and $C$ all formed shoots on SF medium, only those differences in metabolite concentrations between NSF and SF calli that were common to all three types of calli can be considered specific for the process of shoot formation. The percent variability in concentrations of individual metabolites observed between replicate samples ranged from $1 \%$ to $48 \%$, with a mean value of $10.6 \%$. (Percent variability is defined as $100 \times$ standard error of 
the mean / mean value). Differences between the NSF and SF calli which are less than $25 \%$ are generally insignificant. When a specific difference between SF and NSF callus tissues was observed for all three types of calli, Student's t-test for significance of the difference between mean values was performed. The hypothesis of significantly different mean values was routinely accepted if the probability of error in this decision was less than 0.05 . 
b. Changes in carbon content and general metabolite classes.

The distribution of carbon between the various classes of compounds in NSF and SF calli is presented in Table 3. Total amounts of carbon in samples were obtained by adding the calculated amoints of carbon in the 3 pellet fractions to the carbon content calculated for the MCW extracts. The sums of percent carbon in the 7 fractions presented in Table 3 do not equal $100 \%$, but rather average approximately $95 \%$. This can be explained by loss of volatile constituents during concentration of aqueous extracts.

No significant differences in total amounts of carbon in NSF and SF calli weire observed during the first 5 days after subculture. By 7 days, however, there were significantly greater amounts of carbon in the three types of SF calli than in the respective NSF calli. SF calli types $A, B$, and C contained $19 \%, 20 \%$, and $28 \%$ more total carbon, respectively, than NSF calli at 7 days. These differences are consistent with the increased dry weight / fresh weight ratios observed for SF calli, compared to NSF calli, at 1 week (see Chapter 2. Section 3a). (Dry weight measurenents are not available for the three types of calli used in this experiment. Macroscopic changes in texture of calli during growth on NSF and SF media suggest that they were similar to those reported in Chapter 2).

For samples of callus type A grown on both NSF and SF media, the percent of total carbon located in the fraction containing sugars decreased approximately $20 \%$ during the 7 day study (Table 3 ). This was accompanied by approximately $40 \%$ and $90 \%$ increases in the percent of total carbon located in the lipid and protein fractions, 
and probably reflects reinitiation of cell division following subculture to fresh medium. Significant increases in dry weight / fresh weight ratios were observed for SF calli during the first week after subculture (Chapter 2, Section 3a). The growth rate of NSF callus tissues increases signifisin $y$ during the second week after subculture (Chapter 2, Section 3a). The results presented here suggest that this log phase of growth is preceeded by significant increases in the lipid and especially the protein content of the callus tissues (Table 3 ).

No significant changes between days 3 and 7 were observed in protein and lipid fractions of NSF and SF calli types $B$ and $C$, nor were there significant decreases in the percent of total carbon located in the sugar-containing fractions of these calli (Table 3). No explanation for this inconsistency between callus type $A$ and callus tyoes $B$ and $C$ is available at the present time.

There was a significant decrease in the percent of total carbon located in the cell wall fraction of 7 day NSF samples from calli types $B$ and $C$, compared to samples collected 3 days after subculture. Similar changes were not observed for SF samples. These results suggest an decrease in average cell wall thickness in NSF calli types $B$ and $C$. The absence of a similar decrease in residue labelling in NSF type A callus cannot be reconciled at this time, but may be related to the difference in ages of the 3 types of calli. Calli types $B$ and $C$ were initiated 39 and 45 weeks respectively prior to this study, while callus type A was initiated only 9 weeks prior to the study. A continuous selection process for cell types with characteristics which enable them to grow well in tissue cultures 
occurs during repeated subculture of the callus tissues (Murashige, 1974).

One of the most interesting differences observed in the composition of NSF and SF calli was the increased percent of total carbon located in the neutral and acidic amino acid fraction of 7 day SF samples. This difference between 7 day SF and NSF calli was significant in all three types of calli, and was not foreshadowed by the 3 day samples. Paper chromatography of this fraction revealed that many of the individual amino acids were present in greater concentrations in SF calli 7 days after subculture, as will be discussed below.

Basic amino acid fractions from the three types of NSF calli contained consistently greater percentages of the total carbon than were observed for the corresponding fractions from SF calli (Table 3). The absolute amounts of carbon in basic amino acid fractions were also significantly greater in NSF calli types B and C, compared to SF calli of these types. (Variability in this fraction from type A calli was large, and the differences between NSF and SF calli were therefore not significant). This fraction of metabolites contains not only basic amino acids, but also other types of strongly basic organic molecules. Whether the observed difference between SF and NSF calli can be attributed to specific amino acids or to other types of basic compounds, such as polyamines, is not known. These results certainly warrant further investigations, considering the recent reports of specific changes in patterns of polyamine accumulation during embryogenesis in carrot cell cultures (Montague, et al., 1978, 1979), during developnent and germination of rice seeds (Sen, et al., 1981), 
and during various stages of development of tobacco plants (Perdrizet and Prevost, 1981).

\section{c. Sugar concentrations.}

Concentrations of sucrose, glucose, and fructose are presented in Tables 4, 5, and 6, respectively. Though uniformly greater average concentrations of these sugars were observed in the three types of SF calli than in the corresponding NSF calli 7 days after subculture, these differences were not judged significant at the 0.05 level by Student's t-test. No consistent changes in the amounts of these sugars in NSF or SF calli were observed during the first week after subculture, therefore changes in concentrations of these sugars are obviously not responsible for the induction of shoot formation. Similarly, no significant differences in rates of accumulation of 14 . labelled sucrose, glucose, or fructose were observed between NSF and SF calli (Chapter 3, Section 5b). Results from metabolism stadies presented in Chapter 3 show that phosphorylatinn of hexoses is the primary rate-limiting reaction in callus tissue metabolism, and that accelerated rates of sucrose metabolism in SF calli are first evidenced by increases in rates of labelling of hexose monophosphates. The results presented here show that the rate of this reaction is not limited by the availability of the hexose substrates.

Curiously, though the three types of calli contained similar concentrations of sucrose, type A calli contained significantly more glucose and iructose than calli types $B$ and $C$. This difference illustrates the metabolic variability often noted between different lines of tobacco callus tissues, and supports the hypothesis that the 
2 older types of calli (types $B$ and $C$ ) more resembled each other than they did the younger type of callus (type A). As mentioned earlier, this similarity between the older lines of callus can be explained by repeated selection for cells with characteristics that enable then to grow rapidly in culture (Murashige, 1974). No explanation for the possible selective advantage offered by lower reducing sugar concentrations is available at this time.

Uridine diphosphoglucose (UDPG) concentrations were similar in NSF and SF calli (Table 7). The increase in pool sizes of this metabolite observed between 1 and 3 days after subculture of type $A$ callus tissue is consistent with the increase in sucrose synthetase activity reported imnediately after subculture of light-grown tobacco callus (Thorpe and Meier, 1972b). The approximately 30-fold lower concentrations of UDPG compared to glucose and fructose, observed in both SF and NSF calli, suggest a relatively minor role for sucrose synthetase in the sucrose metabolism of callus tissues. As discussed in Chapter 3, Section 4, invertase enzymes hydrolyze large amounts of the sucrose supplied to tobacco calli. This hypothesis is supported by the almost equal amounts of glucose and fructose observed in all studies with callus tissues.

Hexose monophosphate concentrations in the various samples of callus tissue are presented in Table 8. No consistent differences were observed between the concentrations of these metabolites in NSF and SF calli. The lack of significant differences in the concentrations of glucose and fructose between NSF and SF calli supports the important hypothesis presented in Chapter 3: the greater rate of hexose monophosphates synthesis observed in SF calli, campared 
to NSF calli, is due to increased hexose kinase activity in SF calli, and not to increased specific activity of glucose and fructose pools. Because concentrations of hexose monophosphates were approximately equal in NSF and SF calli, the increased rates of synthesis of these phosphorylated sugars in SF calli one week after subculture, (see Chapter 3, Section 5c), are correctly interpreted as reflecting a general stimulation of sucrose utilization in SF calli, and not the accumulation of phosphorylated sugars.

\section{d. Malate and citrate concentrations.}

Three days after subculture, malate concentrations were at least 50 \% greater in the three types of SF calli than in the corresponding NSF calli (Table 9). (This difference was significant for the 3 types of calli at the 0.01 level). The difference in malate content of NSF and SF calli was transient, and was not statistically significant 5 or 7 days after subculture. Malate concentrations in SF calli type $A$ increased significantly between 1 and 3 days after subculture, then decreised by 7 days to approximately the same level observed at I day. Similar changes in malate content of SF calli were reported by Plumb-Dhindsa, et al. (1979), who observed 2-fold greater amounts of malate in SF calli than in NSF calli 4 days after subculture, and no differences between NSF and SF calli 8 days after subculture. Concentrations of malate in NSF cultures remained approximately constant during the first week after subculture (Table 9).

Citrate concentrations were also significantly greater in SF calli than in NSF calli 3 days after subculture (Table 10). No 
significant differences between citrate contents of NSF and SF tissues were observed 5 or 7 days after subculture. (The citrate content of the 7 day NSF sample of type A callus was not significantly less than the SF sample, due to large amounts of variability in the replicate NSF samples).

Citrate concentrations were approximately 5- and 10-fold lower than malate concentrations in callus type $A$, and callus types $B$ and $C$ respectively. Unlike malate concentrations, citrate concentrations in SF calli did not decrease significantly between 3 and 7 days. This result suggests that the transient increase in malate levels in SF calli at 3 days cannot be explained by a transient increase in TCA cycle activity. If this were the case, a decrease in citrate concentrations between 3 and 7 days would be expected.

Al though short-term ${ }^{14} \mathrm{C}$-labelling studies revealed greater rates of malate and citrate accumulation in SF calli than in NSF calli sampled 7 days after subculture, (see Chapter 3 , Section $5 d$ ), this is not inconsistent with results of metabolite concentrations presented here. Increased synthesis of malate and citrate observed in shortterm studies with SF calli was accompanied by increased release of ${ }^{14} \mathrm{CO}_{2}$, and therefore reflects greater TCA cycle activity in SF calli, rather than accumulation of the organic acids.

The trinsient increase in malate content of SF calli at 3 days precedes any histological changes which have been reported for these tissues. Plumb-Dhindsa, et al. (1979) suggested that malate serves as an osmoticum in SF tobacco callus tissues, and possibly also as a source of reducing power through reductive decarboxylation to form PEP, $\mathrm{CO}_{2}$, and $\mathrm{NADPH}$ during the very early stages of shoot formation. 
The latter explanation for malate accumulation is more consistent with reported changes in histology and ultrastructure of SF calli. Thorpe and Laishey (1973) reported increased activity of the reductive pentose phosphate pathway (PPP) in SF callus tissues approximately 1 week after subculture. The transient increase in malate concentations observed in SF calli at 3 days could provide an alternative pathway for generating increased amounts of reducing power in SF calli until sufficient quantities of PPP enzymes were synthesized. Brown and Thorpe (1980) reported a 10-fold increase in $\mathrm{NADP}^{+} / \mathrm{NADPH}$ ratios in SF calli during the first 6 day after subculture. These results also suggest greatly increased requirements for reducing power in the SF calli prior to reported increases in PPP activity.

An additional consequence of the increase in malate concentrations observed 3 days after subculture of callus tissue to SF medium is suggested by the rise in cytoplasmic $\mathrm{pH}$ which is envisaged as a response to malate accumulation in stomata (Raschke, 1975). An increase in intracelluiar pH would have numerous eifects on enzyme activites in the calli, and might perhaps play a primary role in regulating the metabolic changes required for the initiation of shoot formation.

It is important to determine whether SF calli from other plant species experience a similar transient increase in malate concentrations. For tobacco callus cultures, this event qualifies as the type of distinctive metabolic feature which might serve as an easily-assayed marker for shoot induction. It is specific for SF callus tissue and occurs within a defined period of time soon after subculture of tissue to SF medium. 
e. Amino acid concentrations.

As mentioned above, the neutral and acidic amino acid fractions for the three types of SF calli contained significantly greater percentages of the total carbon than were observed in the corresponding types of NSF calli 7 days after subculture. Glutamine was the most prominent amino acid in tobacco callus cultures, and accounted for approximately $60 \%$ of the total carbon in amino acids (Table 11). (Glutamine and asparagine were not consistently resolved on the paper chromatograms, and results for these 2 anino acids are therefore combined. On those chromatograms where the two amino acids were adequately separated, glutamine concentrations were approximately 10-fold greater than asparagine concentrations). Koiwai, et al. (1971) al so found greater amounts of glutamine than of any other amino acid in tobacco cell suspensions. These cells contained almost identical amounts of glutamine to those reported here for SF calli. Bergmann, et al. (1976) attributed the particularly large glutamine concentrations in tobacco callus cultures to the presence of large amounts of $\mathrm{NH}_{3}$ in Murashige and Skoog inorganic nutrient medium (Murashige and Skoog, 1962). Glutamine formation may serve to protect the callus tissues from otherwise toxic concentrations of free ammonia. Suspension cultured tobacco cells grown with nitrate as the major nitrogen source accumulated much lower concentrations of this anino acid. There is also a genetic component associated with the large concentrations of glutamine found in tobacco callus cells. Glutarine was the dominant amino acid in expressed sap (Noguchi, et a1., 1961) and stems (de la Burde, et al., 1963) of tabacco plants. 
In contrast, tissue cultures of rice and soybean accumulate $\gamma$-aminobutyric acid in the presence of high concentrations of $\mathrm{NH}_{3}$ (Kishinami and 0jima, 1980).

No differences were observed in the glutamine contents of SF and NSF callus cultures sampled 3 days after subculture (Table 11). However, significantly greater concentrations of glutamine were observed in SF callus type A sampled at 5 days, and in SF tissues of all three types of calli sampled 7 days after subculture, compared to corresponding types of NSF tissues. At 5 days, approximately 2-fold more glutamine was observed in SF calli, while at 7 days approximately 4-fold more glutamine was observed in SF calli than in NSF calli. This difference between SF and NSF calli is due to both a decrease in glutamine content of NSF calli between 3 and 7 days and a simultaneous increase in glutamine content of SF calli.

Though the large amounts of glutamine can be generally explained by the presence of high concentrations of ammonia in the culture medium, the increase observed in the amount of this amino acid in SF calli between 3 and 7 days was not seen in NSF calli, and must be attributed to the homonal differences in SF and NSF media. Lawyer, et al. (1981) observed twice as much glutamine in tobacco calli cultured in the light for 2 weeks on medium containing low levels of auxin as in calli cultured for 2 weeks on medium containing 10-fold greater concentrations of auxin. No shoots were formed in calli grown on either medium. Thir suggests that the lack of auxin in SF medium is at least partially resonsible for the increased glutamine concentrations observed in SF calli, compared to NSF calli, and that this response to SF medium is not totally specific for the process of 
shoot formation. However, because no time course was obtained during the studies of Lawyer, et al. (1981), direct comparison of their results with those reported here is not possible. Lacking sufficient evidence to the contrary, it is reasonable to hypothesize that the 4fold greater concentrations of glutamine observed in SF calli at 7 days, compared to NSF calli, are required for siacific processes associated with shoot development.

Skokut, et al . (1978) reported that glutamine was the first major organic campound produced during $13 \mathrm{NH}_{4}{ }^{+}$assimilation by tobacco cell suspensions. These workers also showed that glutamine synthesis in these cells was mediated by glutamine synthetase-glutamate synthase, and that glutamine served as a major donor of $\mathrm{NH}_{3}$ for biosynthesis of other amino acids.

The significance of glutamine accumulation to organized development in SF calli is supported by the occurrance of a similar phenomenon in two similar developmental processes. Kamada (1979) noted the accumulation of glutamine during samatic embryogenesis in carrot cell cultures. Capdevila and Dure (1977) also observed increased amounts of glutamine during germination of cotton seea embryos. Glutamine accumulation may provide a diagnostic tool for early detection of the transition from unorganized to organized development in tissue culture systems.

Glutamate concentrations in SF calli were 2-fald greater than those observed in NSF calli 7 days after subculture (Table 12). This difference was due mainly to glutamate accumulation in SF calli; no significant changes were observed in the amounts of this amino acid in NSF calli. No significant differences in glutamate content of NSF and 
SF callus tissues were observed for samples collected 1 - 5 days after subculture.

Koiwai, et al. (1971) reported no change in glutamate concentrations during the first 7 days after inoculation of tobacco cells to fresh medium; these cells showed no signs of differentiation during growth, and are in this respect similar to NSF calli. Almost identical amounts of glutamate to those observed in 7 day SF calli (Table 12) were reported for 8-week-old tobacco callt which had formed shoots (Tabata, et al., 1971). (Calli grown for 8 weeks on four different media which did not induce shoot formation contained quite variable amounts of glutamate, though with the exception of medium containing low concentrations of 2,4-D, undifferentiated calli contained significantly lower concentrations of glutamate than were observed in SF calli). The similarity in amounts of glutamate observed in SF calli sampled 7 days after subculture and SF calli 8 weeks after subculture suggests that the increased amounts of this amino acid reported here for SF calli are characteristic not only of the initiation of shoot formation, but al so of shoots themselves. It is possible that gene expression during the initiation of shoot development is similar to gene expression in young shoots. Butenko (1971) reported detection of antigens specific for shoot meristems soon after subculture of tobacco calli to SF medium. Perhaps synthesis of shoot-like concentrations of metabolites somehow dictates the development of shoots. Further experimentation is certainly required before this hypothesis can be considered anything more than pure speculation.

Lawyer, et al. (1981) observed approximately 2-fold greater 
amounts of glutamate in tobacco calli grown in the light for 2 weeks on medium containing low levels of auxin, compared to calli grown on medium containing high levels of auxin. It remains possible, however, that the increased levels of glutamate reported here for SF calli, compared to NSF calli, are necessary for the induction of processes required for shoot formation, but that other metabolic changes must also occur for the manifestation of this developmental event. Lowering the auxin concentration in the medium 10-fold, as reported by Lawyer, et al. (1981) is not sufficient to induce the "other" metabolic changes. Metabolic consequences of the simultaneous increase in cytokinin levels in the SF medium used for studies reported here may trigger the additional changes required for shoot development. of course, it is also possible that glutamate accumulation is a general consequence of the decreased amounts of auxin in SF medium, and is not a specific requirement of shoot fomation. Further studies are needed to clarify this matter.

Proline concentations were significantly greater in all three types of SF calli 7 days after subculture, compared to corresponding NSF calli (Table 13). As was observed with glutamine, this difference can be attributed to both an increase in proline concentrations in SF calli, and a decrease in the proline content of NSF calli. A similar decrease in proline concentrations was observed between samples of tobacco cell suspension cultures collected 3 and 6 days after inoculation to fresh medium (Koiwai, 1971).

Although glutamate is the metabolic precursor to proline, proline accumulation in 7 day SF cultures can only be partially explained as a direct and non-specific consequence of glutamate accumulation in these 
calli. Whereas glutamate concentrations were approximately 2-fold greater in 7 day SF calli than in 7 day NSF calli, proline levels were 3- to 8-fold greater in the three different types of SF calli, compared to the corresponding types of NSF calli. Proline accumulation in SF calii must therefore be regulated independently of glutamate synthesis.

The concentrations of proline in the 3 types of NSF calli sampled 7 days after subculture varied considerably: calli types $A, B$, and $C$ respectively contained 121,72 , and $357 \mathrm{~mol}$ proline / g fresh weight (Table 13). Even greater variability was observed for SF calli, where proline concentrations in samples of calli types $A, B$, and $C$ were 578 , 249, and $2817 \mathrm{~mol} / \mathrm{g}$ fresh weight, respectively. There was no correlation between the ages of the 3 types of calli and either the amount of proline in NSF and SF call1, or ratios of proline in NSF and SF calli. The absolute amount of proline in a particular line of callus tissue is not characteristic of either its age, or pattern of development. However the relative decrease in proline concentration observed for NSF calli between 3 and 7 days, and the increase observed in SF calli at these times may prove to be diagnostic features of unorganized and organized development. Proline can be readily metabolized to hydroxyproline, an amino acid which is abundant in cell wall proteins. The increased amounts of proline observed in SF calli may be required for increased rates of synthesis of cell wall proteins during cell division associated with "meristemoid" fomation.

Lawyer, et al. (1981) reported 25-fold greater amounts of proline in tobacco calli grown for 2 weeks on medium containing low amounts of auxin, compared to calli grown on medium with 10-fold more auxin. 
Because proline concentrations were not detemined in calli grown for 2 weeks on SF medium, direct comparison with the results of Lawyer, et al. (1981) is not possible.

No significant differences were observed in aspartate contents of SF and NSF calli (Table 14), due to the large amounts of variability observed between replicate samples. Similar concentrations of aspartate were reported by Tabata, et al. (1981) for 8-week-old tobacco SF calli. Undifferentiated calli studied by these workers contained variable amounts of aspartate depending on the amount of 2,4-D supplied in the medium. Lawyer, et al. (1981) repoted 3-fold more aspartate in tobacco callus cultures grown for 2 weeks on medium containing low concentrations of auxin, compared to calli grown on medium containing 10-fold greater concentrations of auxin. Because SF and NSF calli in the study reported here were not sampled at 2 weeks, direct camparison of these results with those of Lawyer, et al. (1981) is not warranted. Aspartate concentrations are apparently not critical for the initation of shoot formation.

No significant changes or differences were observed in amounts of valine + methionine (Table 15), B-alanine (Table 16), or threonine (Table 17) in SF and NSF calli. (Approximately equal amounts of valine and methionine were observed in HPLC chromatograms of SF and NSF calli, using the system described below for detection of ACC). Although not significant at the 0.05 level due to variability between replicate samples, average amounts of valine + methionine and threonine were approximately $1.5-$ fold greater in SF calli than in NSF calli sampled at 7 days. These differences reflect the increased concentrations of many amino acids observed in SF calli, and are 
probably related to increased protein and amino acid synthesis associated with "meristemoid" fomation. Lawyer, et al. (1981) observed similar amounts of these amino acids in tobacco calli cultured on media containing high and low concentrations of auxin. Although average amounts of $\beta$-alanine were consistently 30 \% greater in NSF than in SF calli, this difference was also not judged significant by Student's t-test for differences between mean values. No explanation for this possible difference between NSF and SF calli is available at the present time.

It could be argued that increases in concentrations of arino acids in SF calli at 7 days result from decreases in rates of protein synthesis. However, both the results of sucrose metabolism scudies presented in Chapter 3, Section 5f, and the results of histoct mical studies reported by Thorpe and Murashige (1970) show increased rates of protein synthesis in SF calli, compared to NSF calli $7 \mathrm{c}$.ys after subculture. Perhaps increased amino acid concentration: result in accelerated rates of protein synthesis.

Phenylalanine concentrations were significantly greater in the three types of SF calli than in the corresponding NSF calli 7 days after subculture (Tabie 18). No significant differ nces between SF and NSF calli were detected 1, 2, or 3 days after subculture, though by 5 days SF callus type A contained significantl! more phenylalanine than the corresponding NSF callus samples. Lawyer, et al. (1981) reported no differences in phenylalanine concentiations of calli grown on media containing 10-fold differences in auxin concentrations. The 3-fold differences in phenylalanine concentrations of SF and NSF calli reported here are therefore not a direct consequence of the lowered 
auxin concentrations in SF medium, and may be specific for processes involved in shoot formation.

Maeda and Thorpe (1979) reported increased numbers of tracheary elements in SF calli one week after subculture. Phenylalanine is the precursor for cinnamyl alcohols used in lignin formation, and tracheary elements are characterized by extensive secondary cell wall formation. It is likely that the increased phenylalanine concentrations in SF calli are required for the differentiation of these specialized cells. Although no direct evidence is available on the role of tracheary elements in SF calli, one can postulate that they may be involved in transport of metabolites from storage regions in the callus tissues to sites of active cell division associated with shoot meristem formation.

The large amounts of glutamine observed in tobacco callus cultures interfered with the chramatographic analysis of glycine, serine, alanine, and $\gamma$-aminobutyric acid. There were no apparent differences detected in the incentrations of these amino acids in NSF and SF calli using the high pressure liquid chromatography (HPLC) system described below for the detection of ACC. Results for other neutral amino acids, (tyrosine, tryptophan, leucine, and isoleucine), are not presented because concentrations of these amino acids were below the detection limits of the methods employed. Many samples of SF and NSF calli were screened using the HPLC system described below, however, and no consistent differences in the concentrations of these compounds in NSF and SF calli were observed. 


\section{f. ACC concentrations.}

Though 1-aminocyclopropane-1-carboxylic acid (ACC) is technically a neutral amino acid, concentrations of this compound will be discussed separately. ACC is unlike those amino acids discussed above in that it is a non-protein amino acid, and is the immediate precursor to ethylene, a known plant growth regulator. Concentrations of ACC in NSF and SF calli were quantified in the three types of calli using methods identical to those described for other amino acids.

ACC Concentrations. The amount of ACC in SF tobacco calli was significantly less than that founa in NSF callus tissue (Table 20 and Figure 2). This difference was evident by 1 day after subculture, and was maintained through the first week of growth. Though the differences in ACC concentrations of NSF and SF calli were not constant, NSF calli generally contained approximately 3-fold more ACC than SF calli between 2 and 7 days after subculture. With the exception of the basic amino acid fraction, ACC was the only compound observed to accumulate preferentialiy in the NSF callus.

NSF medium contains $3.0 \mathrm{mg} / 1$ auxin, whereas the SF medium supplies no auxin. The stimulation of ethylene production by auxin is often attributed to an increased activity of ACC synthase (Jones and Kende, 1979, and $\mathrm{Yu}$, et $\mathrm{al} ., 1979)$. In contrast, the enzyme system responsible for the conversion of ACC to ethylene appears to be constitutive in most vegetative plant tissues (Cameron, et al., 1979). (Auxin regulation of ethylene production was recently reviewed by Adams and Yang, 1981). It is therefore reasonable to suggest that the relatively large amounts of ACC found in NSF callus are a response to 
the auxin supplied in the growth medium, and that these levels reflect the relative amounts of ethylene synthesized by the tissues.

Recently Huxter, et al ( (1981) demonstrated a role for ethylene in maintaining tobacco callus in the undifferentiated state. These workers showed that the amount of ethylene evolved from NSF tobacco callus is significantiy greater than that evolved from SF callus tissue. Exogenous ethylene supplied to light-grown SF callus significantly reduced the number of calli which formed shoots, depending on the concentration and time of application. Addition of ACC to SF medium also reduced the formation of shoots. Though it would probably be premature to evoke a cause-and-effect hypothesis concerning ACC levels and shoot-formation, the correlation is striking. This gaseous plant hormone has also been shown to mediate callus formation from cultured citrus buds (Goren, et al., 1979), and to inhibit cytodifferentiation in lettuce pith explants (Zobel and Roberts, 1978).

The concentration of ACC in type A NSF callus increased 3-fold during the first 3 days after subculture (Figure 2). A similar increase in the rate of ethylene production in NSF callus has been reported (Huxter, et al., 1981). The time-course of this response suggests that the increasing concentrations of ACC in NSF tissue are not the result of wound-formation during subculture. The rate of wound ethylene prodjction typically reaches a maximum between 2 and 4 hours after injury (Saltveit and Dilley, 1978, and Yu and Yang, 1979), whereas ACC concentrations in NSF calli increased continuously during the first 5 days after subculture. Possibly subculture of tissue to freshly-prepared NSF medium exposes callus to higher levels of auxin 
than were present after 3 weeks of growth on similar medium, thereby stimulating an increase in ACC concentrations.

It is interesting to note that the 3 different callus lines contained almost identical amounts of ACC at 3 and 7 days after subculture to NSF medium (Table 20). The amount of ACC present in the different SF calli was more variable, though in all cases significantly less than that found in NSF callus of identical origin. This might be related to the sbservation that the absolute timing and number of shoots formed in different lines of callus varies considerably. The unorganized state, however, is quite reproducibly maintained on NSF media.

It is likely that the increased concentrations of ACC observed in NSF calli, compared to SF calli, are indicative of relatively increased rates of ethylene production in NSF tissues. Low corcentrations of ethylene are known to inhibit cell division (Apelbaum and Burg, 1972a, and Lang, et al., 1982). This gaseous plant hormone al so alters patterns of cellulose microfibril deposition from a radial to a longitudinal orientation, resulting in isodiametric rather than rectangular-shaped cells (Apelbaum and Burg, 1972b). Accelerated rates of cell division, specific patterns of cell division, and precise orientation of newly-fomed daughter cells are required for the formation of shoot meristems in callus tissues. Etnylene may prevent the development of organized meristematic activity in NSF calli by directing the formation of large, isodiametric cells.

Al though many of the numerous other metabol ic differences between NSF and SF calli reported throughout this chapter are probably 
required for the expression of the developmental patterns characteristic of NSF and SF calli, it is quite possible that the differences in ACC levels in NSF and SF calli may prove a primary factor regulating the morphology of these tissues. As is discussed in detail in the review article by Green (1980), the most basic requirement for organogenesis is the induction of precise patterns of cell division.

\section{g. Conclusions.}

Differences in metabolite concentrations in NSF and SF calli can be divided into three categories: those which were transient; those for which concentrations were greater in SF calli than in NSF calli; and those for which concentrations were greater in NSF calli than in SF calli. The transient increase in malate concentrations in SF calli at 3 days qualifies for the first category, and probably reflects specific requirements for increased reducing power during the early stages of preparation for organogenesis. This difference between NSF and SF calli precedes any reported differences in callus tissue morphology, and may serve as a valuabie netabolic marker for the induction of shoot formation.

Citrate concentrations were also significantly greater in SF calli than in NSF calli 3 days after subculture. However, unlike malate concentrations, citrate concentrations in SF calli did not decrease significantly between 3 and 7 days. The differences between citrate concentrations in NSF and SF calli reflect the generally increased metabolic activity of SF calli, and correlate with the increased rates of cell division required for "meristemoid" formation. 
Glutamate, glutamine, proline, and phenylalanine concentrations were significantly greater in the 3 types of SF calli than in the corresponding NSF calli 7 days after subculture. Although there is evidence than changes in glutamate concentrations in SF calli may be a nonspecific response to decreased auxin concentrations in SF medium, the changes in concentrations of the other 3 amiro acids may serve as markers for specific processes involved in shoot formation. Increases in glutamine concentrations in SF calli may provide a readily available form of amino groups for use in synthesis of other amino acids during subsequent periods of increased protein synthesis associated with "meristemoid" initiation. Increases in proline concentrations may reflect increased synthesis in cell wall proteins. The greater amounts of phenylalanine in SF calli could be a reflection of the increased rates of lignification associated with tracheary element formation.

ACC concentrations were significantly greater in NSF calli than in SF calli 2 days after subculture. ACC concentrations often reflect rates of ethylene production. Because ethylene may prevent the development of organized tissue by interfering with both cell division, and patterns of cell expansion, ACC concentrations could reflect a mechanism whereby NSF calli are maintained in a unorganized state.

Investigations similar to those reported here should now be conducted using callus from other piant species, and al so mutant lines of callus which have lost the ability to form shoots. These types of studies are needed to determine the significance of observations reported here to the induction of shoot formation. Lacking evidence 
to the contrary, it is reasonable to propose that relative concentrations of malate, citrate, glutamine, proline, phenylalanine, and $A C C$ in unorganized callus tissue subcultured to media which induces the formation of shoots may serve as valuable metabolic markers for this event. 
3. Chapter 4: Tables and Figures. 
Table 1. Uptake and metabolism of $\left[U-{ }^{14} \mathrm{C}\right]$ sucrose to metabolic fractions by tobacco callus cultures after $2,4,6,8,14$, and 21 days of growty on medium containing $[U-14 C]$ sucrose. Callus subdivided into top and bottom regions prior to fractionation. Results presented for top regions represent single measurements and for bottom regions represent average of duplicate samples.

fraction days $\quad$ top botton

(ug-atan C/g fresh weight)

\begin{tabular}{|c|c|c|c|}
\hline $\begin{array}{l}\text { sugars, phosphate } \\
\text { carboxylic acids }\end{array}$ & $\begin{array}{r}2 \\
4 \\
6 \\
8 \\
14 \\
21\end{array}$ & $\begin{array}{r}268 \\
379 \\
626 \\
653 \\
915 \\
1155\end{array}$ & $\begin{array}{r}537 \\
844 \\
649 \\
686 \\
1026 \\
1272\end{array}$ \\
\hline $\begin{array}{l}\text { neutral and acidic } \\
\text { amino acids }\end{array}$ & $\begin{array}{r}2 \\
4 \\
6 \\
8 \\
14 \\
21\end{array}$ & $\begin{array}{r}28 \\
65 \\
148 \\
184 \\
222 \\
114\end{array}$ & $\begin{array}{r}39 \\
81 \\
136 \\
213 \\
136 \\
142\end{array}$ \\
\hline basic amino acids & $\begin{array}{r}2 \\
4 \\
6 \\
8 \\
14 \\
21\end{array}$ & $\begin{array}{r}1 \\
2 \\
5 \\
14 \\
20 \\
15\end{array}$ & $\begin{array}{r}2 \\
5 \\
6 \\
17 \\
15 \\
15\end{array}$ \\
\hline lipids & $\begin{array}{r}2 \\
4 \\
6 \\
8 \\
14 \\
21\end{array}$ & $\begin{array}{r}4 \\
13 \\
17 \\
44 \\
40 \\
40\end{array}$ & $\begin{array}{l}16 \\
38 \\
38 \\
72 \\
62 \\
68\end{array}$ \\
\hline protein & $\begin{array}{r}2 \\
4 \\
6 \\
8 \\
14 \\
21\end{array}$ & $\begin{array}{r}14 \\
60 \\
92 \\
160 \\
182 \\
181\end{array}$ & $\begin{array}{r}49 \\
118 \\
140 \\
232 \\
244 \\
251\end{array}$ \\
\hline
\end{tabular}


Table 1 (continued).

\begin{tabular}{lrrc}
\hline fraction & days & top & botton \\
& & & \\
\hline & & (ug-atom C / & g fresh weight) \\
residue & 2 & 7 & 35 \\
& 4 & 45 & 91 \\
& 6 & 80 & 139 \\
& 8 & 173 & 164 \\
& 14 & 204 & 263 \\
& 21 & 218 & 287 \\
\hline \multirow{2}{*}{ starch } & & & \\
& 2 & 19 & 55 \\
& 4 & 84 & 89 \\
& 6 & 105 & 123 \\
& 8 & 121 & 135 \\
& 14 & 260 & 349 \\
21 & 291 & 436
\end{tabular}


Table 2. Starch concentrations in tobacco callus tissue sampled 2, 4, $6,8,14$, and 21 days after subculture to medium containing [U14C]sucrose. Results presented for top regions represent single measurements and for bottom regions represent average of duplicate samples.

days after subculture top bottom

(mg starch / g fresh weight)

2

$4.1 \quad 4.2$

4

$3.7 \quad 2.5$

6

$2.9 \quad 1.6$

8

$1.1 \quad 1.3$

14

$2.5 \quad 3.4$

21

$2.9 \quad 4.4$


Table 3. Composition of non-shoot-forming (NSF) and shoot-forming (SF) types $A, B$, and $C$ tobacco callus cultures on designated days during the first week after subculture to NSF or SF medium. (Callus types A, $B$, and $C$ differ with respect to the length of time they have been in culture; all formed shoots on SF medium). Results expressed as percentage of total carbon in callus which is present in the various classes of compounds. Total amount of carbon in each type of tissue is expressed as ug-atoms $\mathrm{C} / \mathrm{g}$ fresh weight of callus. Classes of compounds are divided into the following categories: 1 = sugars, phosphate esters, carboxylic acids; 2 = neutral and acidic amino acids; $3=$ basic amino acids; $4=1$ ipids; $5=$ protein; $6=\operatorname{starch} ; 7=$ cell wall debris. For callus type $A$, values represent averages of 3 replicate samples. For callus types $B$ and $C$, values represent averages of duplicate samples on day 3, and of 3 replicate samples on day 7.

\section{metabolite category}

days after

$\begin{array}{llllllll}1 & 2 & 3 & 4 & 5 & 6 & 7 & \text { Total }\end{array}$

subculture

Callus type A

(percent of total carbon)

1 day

$\begin{array}{lllllllll}\text { NSF } & 57.2 & 4.9 & 2.1 & 2.4 & 9.2 & 11.4 & 8.2 & 1840\end{array}$

$\begin{array}{lllllllll}\text { SF } & 50.4 & 6.2 & 0.7 & 2.5 & 9.0 & 12.5 & 11.2 & 1673\end{array}$

2 days

$\begin{array}{lllllllll}\text { NSF } & 52.6 & 5.7 & 1.9 & 2.8 & 11.6 & 13.0 & 11.8 & 1548 \\ \text { SF } & 47.0 & 4.0 & 1.0 & 3.0 & 12.4 & 13.0 & 12.6 & 1699\end{array}$

3 days

$\begin{array}{lllllllll}\text { NSF } & 46.6 & 4.3 & 1.0 & 3.0 & 15.1 & 12.5 & 12.8 & 1774 \\ \text { SF } & 52.1 & 4.3 & 0.9 & 3.0 & 12.5 & 13.4 & 12.7 & 1839\end{array}$

5 days

$\begin{array}{lllllllll}\text { NSF } & 44.8 & 3.2 & 1.3 & 3.5 & 18.5 & 12.9 & 11.1 & 1866\end{array}$

$\begin{array}{lllllllll}\text { SF } & 45.2 & 5.1 & 0.8 & 3.8 & 15.8 & 14.1 & 12.3 & 2039\end{array}$

7 days

$\begin{array}{lllllllll}\text { NSF } & 46.4 & 2.4 & 1.2 & 3.7 & 19.1 & 12.1 & 11.0 & 1718 \\ \text { SF } & 42.9 & 6.7 & 0.9 & 3.5 & 15.3 & 14.5 & 11.3 & 2043\end{array}$


Table 3 (continued).

metabol ite category

days after

$\begin{array}{llllll}3 & 4 & 5 & 6 & 7 & \text { Total }\end{array}$

subcul ture

Callus type B

(percent of total carbon)

3 days

$\begin{array}{lllllllll}\text { NSF } & 50.1 & 3.7 & 1.4 & 3.9 & 19.7 & 8.7 & 11.1 & 1335\end{array}$

$\begin{array}{lllllllll}\text { SF } & 49.9 & 3.3 & 0.9 & 4.4 & 18.1 & 10.1 & 11.3 & 1302\end{array}$

7 days

$\begin{array}{lllllllll}\text { NSF } & 55.1 & 3.0 & 1.1 & 3.5 & 18.7 & 10.4 & 3.1 & 1268\end{array}$

$\begin{array}{lllllllll}\text { SF } & 53.0 & 6.4 & 0.6 & 4.1 & 16.9 & 7.9 & 8.7 & 1527\end{array}$

Callus type $\mathrm{C}$

3 days

$\begin{array}{lllllllll}\text { NSF } & 40.4 & 7.3 & 1.3 & 6.7 & 20.2 & 11.0 & 12.2 & 1754\end{array}$

$\begin{array}{lllllllll}\text { SF } & 43.4 & 6.7 & 0.8 & 5.3 & 19.5 & 10.6 & 11.5 & 1915\end{array}$

7 days

$\begin{array}{lllllllll}\text { NSF } & 48.2 & 5.4 & 1.4 & 3.9 & 19.5 & 11.9 & 5.3 & 1491\end{array}$

$\begin{array}{lllllllll}\text { SF } & 42.3 & 14.6 & 0.8 & 4.4 & 17.7 & 9.0 & 9.1 & 1917\end{array}$ 
Table 4. Changes in the concentration of sucrose in NSF and SF tobacco callus cultures types $A, B$, and $C$ on selected days during the first week after subculture to NSF or SF medium. (Callus types A, B, and $C$ differ with respect to the length of time they have been in culture; all formed shoots on SF medium). Results expressed as unol sucrose / g fresh weight callus tissue. For callus type $A$, values represent averages of 3 replicate samples. For callus types $B$ and $C$, values represent averages of duplicate samples on day 3 , and of 3 replicate samples on day 7 .

\section{days after subculture}

Callus type

1

23

5

7

Type A

(umol sucrose / g fresh weight)

$\begin{array}{llllll}\text { NSF } & 22.8 & 17.0 & 16.1 & 21.7 & 18.8 \\ \text { SF } & 21.8 & 19.2 & 23.1 & 22.8 & 23.4\end{array}$

Type B

$\begin{array}{llllll}\text { NSF } & - & - & 21.3 & - & 27.5 \\ \text { SF } & - & - & 23.0 & - & 27.8\end{array}$

Type C

$\begin{array}{llllll}\text { NSF } & - & - & 23.5 & - & 26.0 \\ \text { SF } & - & - & 32.4 & - & 33.7\end{array}$


Table 5. Changes in the concentration of glucose in NSF and SF tobacco callus cultures types $A, B$, and $C$ on selected days during the first week after subculture to NSF or SF medium. (Callus types A, B, and $C$ differ with respect to the length of time they have been in culture; all formed shoots on SF medium). Results expressed as umol glucose / $g$ fresh weight callus tissue. For callus type $A$, values represent averages of 3 replicate samples. For callus types $B$ and $C$, values represent averages of duplicate samples on day 3 , and of 3 replicate samples on day 7 .

days after subculture

$\begin{array}{llllll}\text { Callus type } & 1 & 2 & 3 & 5 & 7\end{array}$

Type A

(umol glucose / g fresh weight)

$\begin{array}{llllll}\text { NSF } & 54.4 & 41.5 & 39.6 & 36.4 & 35.9 \\ \text { SF } & 41.7 & 41.9 & 45.9 & 40.0 & 39.8\end{array}$

Type B

\begin{tabular}{llllll} 
NSF & - & - & 27.0 & - & 24.8 \\
$\mathrm{SF}$ & - & - & 22.9 & - & 28.0 \\
\hline
\end{tabular}

Type C

$\begin{array}{llllll}\text { NSF } & - & - & 22.2 & - & 23.8 \\ \text { SF } & - & - & 23.5 & - & 26.8\end{array}$


Table 6. Changes in the concentration of fructose in NSF and SF tobacco callus cultures types $A, B$, and $C$ on selected days during the first week after subcul ture to NSF or SF medium. (Callus types $A, \hat{D}$, and $C$ differ with respect to the length of time they have been in culture; all formed shoots on SF medium). Results expressed as umol fructose / $\mathrm{g}$ fresh weight callus tissue. For callus type $\mathrm{A}$, values represent averages of 3 replicate samples. For callus types $B$ and $C$, values represent averages of duplicate samples on day 3 , and of 3 replicate samples on day 7 .

days after subculture

Callus type

$2 \quad 3 \quad 5$

$5 \quad 7$

Typ: A

(umol fructose / $g$ fresh weight)

$\begin{array}{llllll}\text { NSF } & 54.1 & 42.1 & 41.0 & 37.0 & 36.0 \\ \text { SF } & 41.4 & 42.7 & 46.9 & 39.9 & 40.2\end{array}$

Type B

$\begin{array}{llllll}\text { NSF } & - & - & 27.2 & - & 26.4 \\ \text { SF } & - & - & 23.3 & - & 29.3\end{array}$

Type C

$\begin{array}{llllll}\text { NSF } & - & - & 24.1 & - & 24.6 \\ \text { SF } & - & - & 25.1 & - & 29.6\end{array}$


Table 7. Changes in the concentration of uridine diphosphoglucose (UDPG) in NSF and SF tobacco callus cultures types $A, B$, anid $C$ on selected days during the first week after subculture to NSF or SF medium. (Callus types $A, B$, and $C$ differ with respect to the length of time they have been in culture; all formed shoots on SF medium). Results expressed as mol UDPG / $\mathrm{g}$ fresh weight callus tissue. For callus type A, values represent averages of 3 replicate samples. For callus types $B$ and $C$, values represent averages of duplicate samples on day 3 , and of 3 replicate samples on day 7 .

days after subculture

Callus type

$2 \cdot 35$

5

Type A

(nmol UDPG / g fresh weight)

$\begin{array}{lrrrrr}\text { NSF } & 46 & 70 & 79 & 107 & 87 \\ \text { SF } & 44 & 62 & 81 & 87 & 86\end{array}$

Type B

$\begin{array}{llllll}\text { NSF } & - & - & 108 & - & 74\end{array}$

$\begin{array}{llllll}\text { SF } & - & - & 82 & - & 85\end{array}$

Type C

$\begin{array}{lrrrrr}\text { NSF } & - & - & 111 & - & 84 \\ \text { SF } & - & - & 145 & - & 110\end{array}$


Table 8. Changes in the concentration of hexose monophosphates in MSF and SF tobacco callus cultures types $A, B$, and $C$ on selected days during the first week after subculture to NSF or SF mediun. (Callus types $A, B$, and $C$ differ with respect to the length of time they have been in culture; all formed shoots on SF medium). Results expressed as mol hexose monophosphates / $g$ fresh meight callus tissue. For callus type $A$, values represent averages of 3 replicate samples. For callus types $B$ and $C$, values represent averages of duplicate samples on day 3 , and of 3 replicate samples on day 7 .

days after subculture

Callus type

1

2

3

5

7

(nnol hexose monophosphates / g fresh weight)

Type A

NSF 226

358

359

467

456

SF

298

420

510

563

397

Type B

$\begin{array}{llllll}\text { NSF } & - & - & 478 & - & 438 \\ \text { SF } & - & - & 553 & - & 552\end{array}$

Type C

$\begin{array}{llllll}\text { iNSF } & - & - & 550 & - & 583 \\ \mathrm{SF} & - & - & 466 & - & 475\end{array}$


Table 9. Changes in the concentration of malate in NSF and SF tobacco callus cultures types $A, B$, and $C$ an selected days during the first week after subculture to NSF or SF medium. (Callus types $A, B$, and $C$ differ with respect to the length of time they have been in culture; all formed shoots on SF medium). Results expressed as nmol malate / g fresh weight callus tissue. For callus type $A_{2}$ values represent averages of 3 replicate samples. For callus types $B$ and $C$, values represent averages of duplicate samples on day 3 , and of 3 replicate samples on day 7.

days after subculture

Callus type

\begin{tabular}{llllll}
\multicolumn{5}{l}{ days after subculture } \\
1 & 2 & 3 & 5 & 7
\end{tabular}

Type A

(mol malate / g fresh weight)

$\begin{array}{llllll}\text { NSF } & 7,452 & 5,980 & 6,208 & 5,407 & 5,584 \\ \text { SF } & 5,364 & 7,179 & 9,501 & 6,878 & 5,933\end{array}$

Type B

$\begin{array}{llllll}\text { NSF } & - & - & 1,925 & - & 2,307 \\ \text { SF } & - & - & 3,045 & - & 2,710\end{array}$

Type $C$

$\begin{array}{llllll}\text { NSF } & - & - & 2,465 & - & 3,303 \\ \text { SF } & - & - & 4,320 & - & 3,843\end{array}$


Table 10. Changes in the concentration of citrate in NSF and SF tobacco callus cultures types $A, B$, and $C$ on selected days during the first week after subculture to NSF or SF medium. (Callus types A, B, and $C$ differ with respect to the length of time they have been in culture; all formed shoots on SF medium). Results expressed as mol citrate / g fresh wefght callus tissue. For callus type $A$, values represent averages of 3 replicate samples. For callus types $B$ and $C$, values represent averages of duplicate samples on day 3 , and of 3 replicate samples on day 7 .

days after subcul ture

Callus type

1

2

3

5

7

Type A

$$
\text { (mol citrate / } g \text { fresh weight) }
$$

$\begin{array}{rrrrrr}\text { NSF } & 893 & 992 & 1,318 & 1,630 & 935 \\ \text { SF } & 511 & 1,217 & 1,875 & 1,589 & 1,712\end{array}$

Type B

\begin{tabular}{llllll} 
NSF & - & - & 251 & - & 253 \\
SF & - & - & 363 & - & 337 \\
\hline
\end{tabular}

Type C

$\begin{array}{llllll}\text { NSF } & - & - & 387 & - & 281 \\ \text { SF } & - & - & 542 & - & 338\end{array}$


Table 11 Changes in the concentration of glutanine + asparagine in NSF and SF tobacco callus cultures types $A, B$, and $C$ on selected days during the first week after subculture to MSF or SF medium. (Callus types $A, B$, and $C$ differ with respect to the length of time they have been in culture; all formed shoots on SF medium). Results expressed as mol glutamine + asparagine / g fresh weight callus tissue. For callus type $A$, values represent averages of 3 replicate samples. For callus types $B$ and $C$, values represent averages of duplicate samples on day 3 , and of 3 replicate samples on day 7 .

\section{days after slibculture}

Callus type

$\begin{array}{llllll}1 & 2 & 3 & 5 & 7\end{array}$

Type A

(nmol glutamine + asparagine / g fresh weight)

$\begin{array}{lrrrrr}\text { NSF } & 10,613 & 9,514 & 7,692 & 5,008 & 2,986 \\ \text { SF } & 11,190 & 8,665 & 8,764 & 10,104 & 14,507\end{array}$

Type B

\begin{tabular}{cccccc} 
NSF & - & - & 4,055 & - & 2,733 \\
SF & - & - & 3,894 & - & 11,133 \\
\hline Type C & & & & & \\
NSF & - & - & 12,834 & - & 7964 \\
SF & - & - & 13,441 & - & 34,270 \\
\hline
\end{tabular}


Table 12. Changes in the concentration of glutanate in NSF and SF tobacco callus cultures types $A, B$, and $C$ on selected days during the first week after subculture to NSF or SF medium. (Callus types A, B, and $C$ differ with respect to the length of time they have been in culture; all formed shoots on SF medium). Results expressed as mol glutamate / g fresh weight callus tissue. For callus type $A$, values represent averages of 3 replicate samples. For callus types $B$ and $C$, values represent averages of duplicate samples on day 3 , and of 3 replicate samples on day 7 .

days after subculture

Calius type

\begin{tabular}{lllrl}
\multicolumn{5}{c}{ days after subcul ture } \\
& 2 & 3 & 5 & 7
\end{tabular}

Type A

(nmol glutamate / g fresh weight)

$\begin{array}{llllll}\text { NSF } & 1,581 & 1,933 & 1,826 & 1,580 & 1,255 \\ \text { SF } & 1,890 & 1,707 & 1,912 & 2,375 & 2,555\end{array}$

Type B

$\begin{array}{lllllr}\text { NSF } & - & - & 904 & - & 855 \\ \text { SF } & - & - & 846 & - & 1,263\end{array}$

Type C

$\begin{array}{llllll}\text { NSF } & - & - & 1,885 & - & 1,453 \\ \text { SF } & - & - & 1,263 & - & 2,003\end{array}$


Table 13. Changes in the concentration of proline in NSF and SF tobacco callus cultures types $A, B$, and $C$ on selected days during the first week after subculture to NSF or SF medium. (Call us types A, B, and $C$ differ with respect to the length of time they have been in culture; all formed shoots on SF medium). Results expressed as mol proline / g fresh weight callus tissue. For callus type $A$, values represent averages of 3 replicate samples. For callus types $B$ and $C$, values represent averages of duplicate samples on day 3 , and of 3 replicate samples on day 7 .

days after subcul ture

Callus type

\begin{tabular}{llrrrr}
\multicolumn{5}{l}{ days after subcul ture } \\
1 & 2 & 3 & 5 & 7
\end{tabular}

Type A

(nmol proline / g fresh weight)

$\begin{array}{llllll}\text { NSF } & 266 & 261 & 289 & 300 & 121 \\ \text { SF } & 181 & 287 & 197 & 485 & 578\end{array}$

Type B

$\begin{array}{lrrrrr}\text { NSF } & - & - & 124 & - & 72 \\ \text { SF } & - & - & 79 & - & 249\end{array}$

Type C

$\begin{array}{llllll}\text { NSF } & - & - & 2280 & - & 357 \\ \text { SF } & - & - & 1375 & - & 2817\end{array}$


Table 14. Changes in the concentration of aspartate in NSF and SF tobacco callus cultures types $A, B$, and $C$ on selected days during the first week after subcul ture to NSF or SF medium. (Callus types A, B, and $C$ differ with respect to the length of time they have been in culture; all formed shoots on SF medium). Results expressed as nol aspartate / $g$ fresh weight callus tissue. For callus type $A$, values represent averages of 3 replicate samples. For callus types.B and $C$, values represent averages of dupltcate samples on day 3 , and of 3 replicate samples on day 7 .

days after subculture

Callus type

1

2

3

5

7

Type A

(nmol aspartate / $g$ fresh weight)

$\begin{array}{llllll}\text { NSF } & 382 & 584 & 539 & 478 & 400 \\ \text { SF } & 422 & 436 & 521 & 587 & 543\end{array}$

Type 8

\begin{tabular}{cccccc} 
NSF & - & - & 363 & - & 394 \\
SF & - & - & 303 & - & 457 \\
\hline Type C & & & & & \\
NSF & - & - & 697 & - & 594 \\
SF & - & - & 552 & - & 996
\end{tabular}


Table 15. Changes in the concentration of valine + methionine in NSF and SF tobacco callus cultures types A, B, and $C$ on selected days during the first week after subculture to NSF or SF medium. (Callus types $A, B$, and $C$ differ with respect to the length of time they have been in culture; all formed shoots on SF medium). Results expressed as mol valine + methionine / $g$ fresh weight callus tissue. For callus type $A$, values represent everages of 3 replicate samples. For callus types $B$ and $C$, values represent averages of duplicate samples on day 3 , and of 3 replicate samples on day 7 .

days after subculture

$\begin{array}{llllll}\text { Callus type } & 1 & 2 & 3 & 5 & 7\end{array}$

Callus type

Type A

$$
\text { (nmol valine + methionine / g fresh weight) }
$$

NSF

69

64

71

75

61

SF

62

52

66

94

97

Type $B$

$\begin{array}{r}\text { NSF } \\ \text { SF } \\ \hline \text { Type C }\end{array}$

NSF

124

111

SF

110

212 
Table 16. Changes in the concentration of B-alanine in NSF and SF tobacco callus cultures types $A, B$, and $C$ on selected days during the first week after subculture to NSF or SF medium. (Callus types A, B, and $C$ differ with respect to the length of time they have been in culture; all formed shoots on SF medium). Results expressed as mol $B$-alanine $/ g$ fresh weight callus tissue. For callus cype $A$, values represent averages of 3 replicate samples. For callus types $B$ and $C$, values represent averages of duplicate samples on day 3 , and of 3 replicate samples on day 7.

days after subculture

Callus type

\begin{tabular}{llrrr}
\multicolumn{5}{l}{ days after subcul ture } \\
1 & 2 & 3 & 5 & 7
\end{tabular}

(mol B-alanine / g fresh weight)

Type A

$\begin{array}{llllll}\text { NSF } & 172 & 185 & 243 & 270 & 233 \\ \text { SF } & 180 & 172 & 187 & 206 & 176\end{array}$

Type B

NSF

164

234

SF

$\begin{array}{ll}- & 158\end{array}$

168

Type C

$\begin{array}{llllll}\text { NSF } & - & - & 255 & - & 245 \\ \text { SF } & - & - & 166 & - & 183\end{array}$


Table 17. Changes in the concentration of threonine in NSF and SF tobacco callus Cil? tures types $A, B$, and $C$ on selected days during the first week after subcuiture to NSF or SF medium. (Callus types $A, B$, and $C$ differ with respect to the length of time they have been in culture; all formed shoots on $S F$ medium). Results expressed as nol threonine / $g$ fresh weight callus tissue. For callus type $A$, values represent averages of 3 replicite samples. For callus types $B$ and $C$, values represent averages of duplicate samples on day 3 , and of 3 replicate samples on day 7 .

days after subculture

Callus type

1

2

3

5

7

Type A

(nmol threonine / $g$ fresh weight)

$\begin{array}{lrrrrr}\text { NSF } & 99 & 82 & 80 & 102 & 87 \\ \text { SF } & 111 & 79 & 89 & 118 & 122\end{array}$

Type B

NSF

72

82

SF

- $\quad-$

67

101

Type C

$\begin{array}{llllll}\text { NSF } & - & - & 151 & - & 135 \\ \text { SF } & - & - & 133 & - & 243\end{array}$


Table 18. Changes in the concentration of phenylalanine in MSF and SF tobacco callus cultures types $A, B$, and $C$ of selected days during the first week after subculture to NSF or SF medium. (Callus types $A, B$, and $C$ differ with respect to the length of time they have been in culture; all formed shoots on SF medium). Resuits expressed as mol phenylalanine / $g$ fresh weight callus tissue. For callus type $A$, values represent averages of 3 replicate samples. For callus types $B$ and $C$, values represent averages of duplicate samples on day 3 , and of 3 repilicate samples on day 7 .

daye after subculture

$\begin{array}{llllllll}\text { Callus type } & 1 & 2 & 3 & 5 & & 7\end{array}$

Type A

(nol phenylalanine / $g$ fresh weight)

$\begin{array}{llllll}\text { NSF } & 37 & 42 & 39 & 36 & 31 \\ \text { SF } & 44 & 45 & 54 & 68 & 97\end{array}$

Type B

$\begin{array}{llllll}\text { NSF } & - & - & 43 & - & 34 \\ \text { SF } & - & - & 41 & - & 861\end{array}$

Type C

NSF

- $\quad-\quad 57$

57

49

SF

93

188 
Table 19. Typical solvent gradient program used for elution of amino acids from HPLC system described in the text. Solvent $A$ contained $0.125 \%(\mathrm{w} / \mathrm{v})$ SDS and $0.1 \%(\mathrm{v} / \mathrm{v})$ phosphoric acid, $\mathrm{pH}$ 2.45; Solvent B contained $0.125 \%(w / v)$ SDS, $0.1 \%(v / v)$ phosphoric acid, and $50 \%(v / v)$ acetonitrile. Solvent flow rate was $1.0 \mathrm{ml} /$ min.

\begin{tabular}{ccc}
\hline time (min) & Solvent A & Solvent B \\
\hline 0 & $100 \%$ & - \\
20 & $100 \%$ & - \\
25 & $90 \%$ & $10 \%$ \\
95 & $75 \%$ & $25 \%$ \\
120 & $25 \%$ & $75 \%$ \\
125 & - & $100 \%$ \\
\hline
\end{tabular}


Table 20. Changes in the concentration of 1-anino-cyclopropane-1carboxylic acid (ACC) in NSF and SF tobacco callus cultures types A, $B$, and $C$ on selected days during the first week after subculture to NSF or SF medium. (Callus types A, B, and C differ with respect to the length of time they have been in culture; all formed shoots on SF medium). Results expressed as nmol ACC / g fresh weight callus tissue. For callus type A, values represent averages of 3 replicate samples. For callus types $B$ and $C$, values represent averages of duplicate samples on day 3 , and of 3 replicate samples on day 7 .

days after subcul ture

Callus type

$\begin{array}{lllll}2 & 3 & 5 & 7\end{array}$

Type A

(mol ACC / g fresh weight)

$\begin{array}{rrrrrr}\text { NSF } & 98 & 238 & 310 & 360 & 285 \\ \text { SF } & 60 & 63 & 70 & 83 & 105\end{array}$

Type B

$\begin{array}{rrrrrr}\text { NSF } & - & - & 275 & - & 322 \\ \text { SF } & - & - & 37 & - & -\end{array}$

Type C

$\begin{array}{lrrrrr}\text { NSF } & - & - & 293 & - & 321 \\ \text { SF } & - & - & 67 & - & 158\end{array}$


Figure 1. Average ACC concentrations in NSF (open bars) and SF (hatched bars) tobacco callus type $A$ during the first week after subculture to NSF and SF media, respectively. Error bars represent standard error of the mean. Differences between mean values for NSF an SF calli were significant at the $5 \%$ level on day 1 , and at the $1 \%$ level on days $2,3,5$, and 7 according to Student's t-test. 


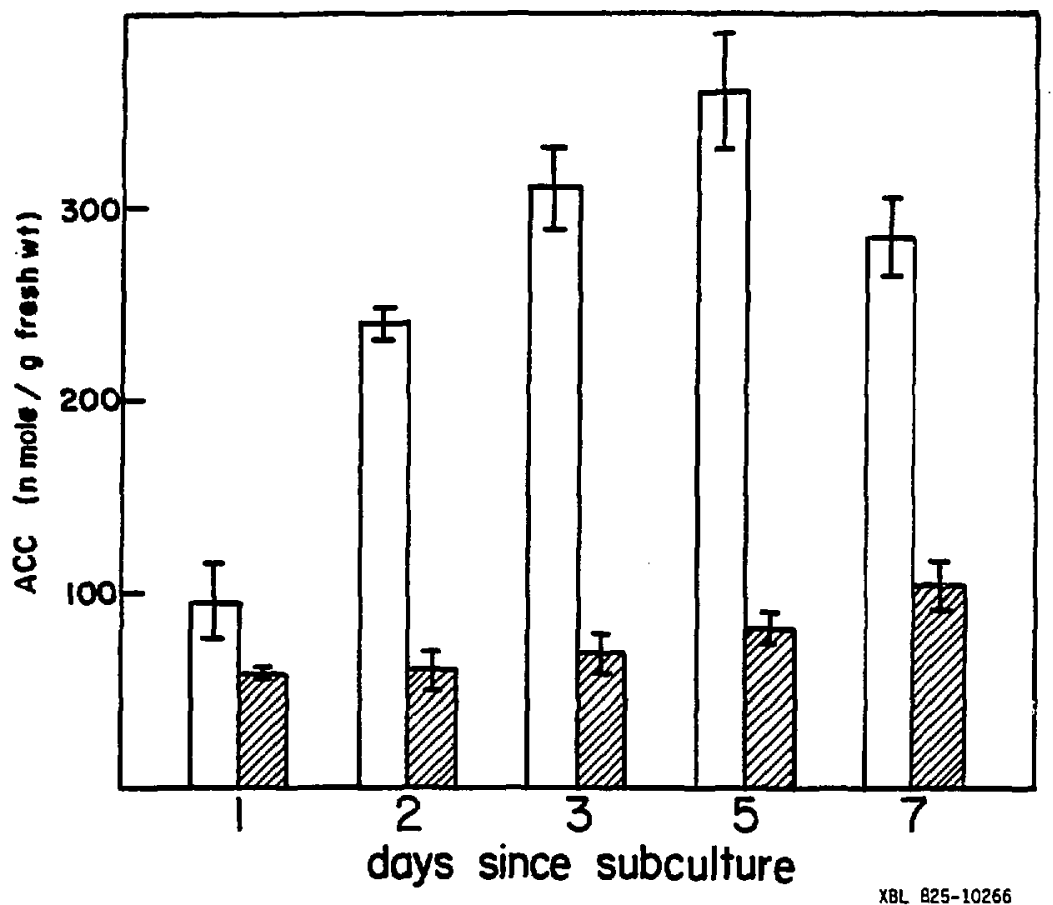


Figure 2. Typical HPLC chramatogram of acidic and neutral amino acids in NSF callus tissue grown for 5 days on NSF medium. See text for details of chromatography. Order of elution of amino acids is designated by abbreviations under individual peaks. Solvent gradient program was identical to that described in Table 19. 
202

Figure I.

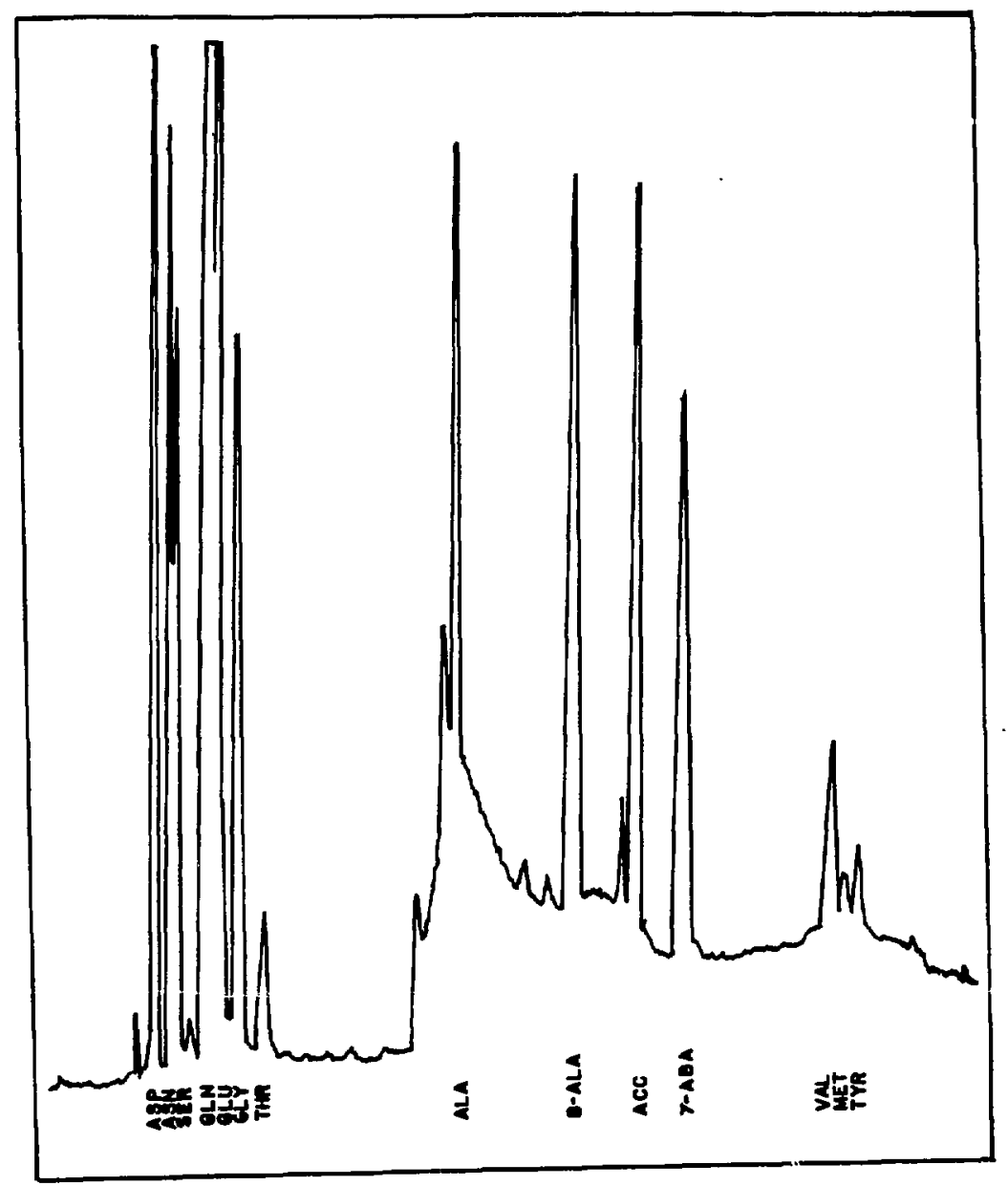

XBL 828-11331 
CHAPTER 5

\section{CONCLUSIONS}

The experiments described in the preceding chapters were conducted to establish metabolic markers for processes characteristic of shoot initiation from callus tissue. Tobacco callus tissue was chosen as a model system because shoot-formation in this species is readlly accomplished by varying the auxin / cytokinin ratio in the tissue culture medium. Many differences in the sucrose metabolism of NSF and SF tobacco calli were apparent within the first week after subculture of undifferentiated callus tissue to NSF and SF media, respectively. These changes in intemediary metabolism were consistent with established patterns of growth and differentiation in the two types of calli.

The chlorophyll content of SF calli was approximately 2-fold greater than that of NSF calli 3 - 12 days after subculture. This difference, however, cannot serve as a reliable marker for shoot induction because unpignented callus tissue from many species will form shoots when cultured on appropriate media. Studies reported here focused on the relative rates of sucrose metabolism in NSF and SF calli, and do not allow assessment of the relative contributions of photosynthetic carion fixation to the nutrition of the two types of calli. It is likely that the greater amounts of chlorophyll in SF calli reflect greater rates of photosynthesis in these calli, relative to NSF calli. Rates of sucrose metabolism in SF calli 
exceeded those in NSF calli during the first two weeks following subculture. Increasing rates of photosynthesis in SF calli would result in even greater differences in the metabolism of the two types of calli than are reported here.

Ho differences were detected in rates of sucrose uptake by NSF and SF calli. Approximately half of the total glucose and fructose associated with NSF calli was loosely-bound, and was removed by gentle rinsing with sucrose and water. It is postulated that invertase enzymes associated with cell walls hydrolyze much of the sucrose metabolized by these calli. The reducing sugars are then incorporated along with sucrose for further metabolism within the cells. This hypothesis is supported by the large intracellular concentrations of glucose and fructose in both NSF and SF calli.

Phosphorylation of hexoses is the primary rate-limiting reaction in sucrose metabolism by tobacco calli. Formation of glucose and fructose from $\left[{ }^{14} \mathrm{C}\right]$ sucrose proceeded at approximately 500 -fold greater rates than those observed for ${ }^{14} \mathrm{C}$-labelling of hexose monophosphates. SF calli metabolized sucrose more rapidly than NSF calli. Though differencos between rates of hexose monophosphates labelling in NSF and SF calli were greatest 7 days after subculture, concentrations of hexose monophosphates were equal in the two types of calli during the first week following subculture. Increased rates of ${ }^{14} \mathrm{C}$-labelling of hexose monophosphates in SF cal1i, compared to NSF calli, are therefore indicative of generally increased rates of metabolism in these tissues. SF calli also released $\mathrm{CO}_{2}$ at greater rates than were observed for NSF calli. Differences between SF and NSF calli in these two general measurements of intermediary carbon metabolism were 
greatest 7 days after subculture, and correlate with the increased rates of localized cell division required for "meristemoid" formation in SF calli. Dry weight / fresh weight ratios for SF calli were al so consistently greater than those for NSF calli by 5 days after subculture. Between the first and second weeks after subculture, growth rates and rates of sucrose metabolism in NSF calli increase significantly. This results in a continuous decrease in the magnitude of differences between rates of sucrose metabolism by NSF and SF calli. Relatively increased rates of carbon metabolism would therefore only be a reliable marker for shoot formation during the first 10 days following subculture.

A transient increase in malate concentrations of SF calli was observed 3 days after subeulture, and may provide a useful marker for shoot induction. The transient increase in malate levels does not reflect increased rates of mitochondrial respiration: a similar pattern was not observed for rates of $\mathrm{CO}_{2}$-release by SF calli, or for citrate concentrations in SF calli. The increase in malate content of SF calli at 3 days may be related to the role of malate as a source of NADPH for use in reductive biosyntheses.

Rates of $\left[{ }^{14} \mathrm{C}\right] \mathrm{glutamine}$ accumulation and concentrations of glutamine were significantly greater in SF calli than in NSF calli one week after subculture. These results are consistent with the role of glutamine as an amino donor in tobacco calli. The accentuated diferences between glutamine metabolism of SF and NSF calli at 7 days correlate with the increased rates of cell division required for "meristemoid" formation. Marked increases in glutamine concentrations have been reported to occur at the onset of organized 
development in unrelated species. These results suggest that glutamine accumulation may provide a useful marker for shoot fomation in callus tissue.

Both increased rates of accumulation and greater concentrations of phenylalanine were observed in SF calli one week after subculture. Phenylalantne accumulation may provide a useful metabolic marker for differentiation in SF calli. Proline concentrations increased dramatically in SF calli between 3 and 7 days after subculture. Relative concentrations of this amino acid in SF and NSF calli may al so provide a marker for shoot induction.

Greater concentrations of glutamate were also observed in SF calli, compared to NSF calli 7 days after subculture. The significance of this observation to shoot initiation is questionable, as a very similar response has been reported for calli subcultured to medium which contains low aux in concentrations but does not induce shoot formation.

Synthesis and concentrations of protein and cell wall materials in NSF and SF calli generally reflected rates of intermediary carbon metabolism and known patterns of callus tissue development. No additional information about events specific for shoot fomation was gained from these results.

Total starch was significantly greater in SF calli than in NSF calli 4 - 21 days after subculture. The transient decrease in starch content of SF callt observed 7 days after subculture corresponds to the greater rates of sucrose metabolism observed in these calli, and reflects the increased rates of cell division required for "meristenoid" production. Starch synthesis provides a reserve form 
of carbohydrate which can be consumed when demands for anergy and carbon skeleton production increase rapidly. In storage tissues, such as the endosperm of seeds, starch is consumed during periods of rapid growth. Starch accumulation in SF calli may represent a basic response of plant tissues to "anticipated" periods of accelerated growth. Because large concentrations of sucrose are supplied to these tissues by the culture medium, net starch degradation is not observed during shoot development, and starch levels decrease only transiently during "meristenoid" formation. Starch accumulation may be a dependable, though dispensible, marker for the induction of shoots.

ACC concentrations were significantly greater in NSF calli than in SF calli $2-7$ days after subculture. ACC concentrations often reflect rates of ethylene biosynthesis. Because ethylene may prevent the development of organized tissue by interfering with both cell division and patterns of Cell expansion, ACC concentrations may reflect a basic mechanism whereby NSF calli are maintained in an unorganized state. Relatively decreased ACC concentrations in SF calli, compared to NSF calli, may be required for the formation of organized centers of cell division, and this feature could provide an easily-assayed marker for the transition from unorganized to organized development.

Large differences in rates of sucrose metabolism were observed for top and bottom halves of both SF and NSF calli. For SF calli, these differences generally reflect the established patterns of shoot formation: shoots are initially formed preferestially in bottom regions of calli, though similar numbers of shoots are ultimately fomed in both regions. Differences between top and bottom halves of 
NSF calli show that it is unrealistic to consider a plece of NSF callus as a cluste, of undifferentiated cells. Cell division activity is more common in peripheral regions of NSF calli, and amino acid synthesis occurs at greaier rates in botton halves of calli. It was postulated that bottom regions of calli may provide metabolites for more actively-growing ragions by both symplastic and apoplastic connections.

These studies on carbon metabolism in NSF and SF tobacco callus cultures show that changes in rates and patterns of sucrose metabolism accompany the development of organized tissue in SF calli. Differences between SF and NSF calli in rates of synthesis and concentration of many intermediary metabolites were reported, and these may serve as useful metabolic markers for various processes that are required for shoot formation. Investigations similar to those reported here should now be conducted using callus derived from different plant species, and ideally also with various mutant lines of callus tissue which will not regenerate shoots in vitro, to establish the significance of the metabolic changes reported during the initial stages of shoot fomation in tobacco cal - Experiments designed to follow the metabolism of glutamate, glutamine, phenylalanine, alanine, and proline would provide valuable information for use in interpreting differences in accumulation of these amino acids in SF and NSF calli in terms of known morphological responses to homonallyinduced shoot formation. 


\section{REFERENCES}

Abo El-Nil, M.M. and F.W. Zettler. 1976. Callus initiation and organ differentiation from shoot tip cultures of Colocasia esculenta. Plant Sci. Lett. 6:401-408.

Adams, D.0. and S.F. Yang. 1981. Ethylene the gaseous plant hormone: mechanism and regulation of biosynthesis. Trends in Blo. Sci. 6:161-164.

Aitchison, P.A., A.J. Macleod, and M.M. Yeoman. 1977. Growth petterns in tissue (callus) cultures. In H.S. Street, Plant Tissue and Cell Culture, 2nd Ed., Univ. of Ca? if. Press, Berkeley. pp. 267-306.

Anderson, R.A., T.R. Kemp, and T.H. Vaughn, 1981. Coniferl alcohol, sinapyl alcohol and scopoletin in tobacco callus tissue during growth of a subculture. Physiol. Plant. 53:89-94.

Apelbaum, A. and S.P. Burg. 1972a. Effect of ethylene on cell division and DNA synthesis in Pisum sativum. Plant Physiol. 50:117124.

Apelbaum, A. and S.P. Burg. 1972b. Effects of ethylene and 2,4dichlorophenoxyacetic acid on cellular expansion in Pisum sativum. Plant Physiol. 50:125-131.

Apelbaum, A., A.C. Burgoon, J.D. Anderson, T. Solomos, and M. Lieberman. 1981. Some characteristics of the system converting 1aminocyclopropane-1-carboxylic acid to ethylene. Plant Pnysiol. 
$17: 80: 84$.

Arnison, P.G. and W.G. Boll. 1974. Isoenzymes in cell cultures of bush bean (Phaseolus vulgaris cr. Contender): isoenzymatic changes during the callus culture cycle and differences between stock cul tures. Can. J. Bot. 52:2621-2629.

Arnon, D.I. 1949. Copper enzymes in isolated chloroplasts. Polyphenyloxidase in Beta vulgaris. Plant Physiol. 24:1-15.

Bajaj, Y.P.S. and M. Bopp. 1972. Growth and organ fomation in Sinapis alba tissue cultures. 2. Pflanzenphysiol . 77:378-381.

Bandiera, M. and G. Morpugo. 1970. Kinetin / auxin ratio and development of chloroplasts in tissue cultures of Daucus carota. Experientia 26:558-559.

Barba, R. and L.G. Nicke11. 1969. Nutrition and organ differentiation in tissue cultures of sugarcane, a monocotyledon. Planta 89:299-302.

busicambe, D., J. Giorgini, and J.L. Key. 1980. The effect of auxin on the polyadenylated RNA of soybean hypocotyls. In C.J. Leaver, ed., Genome Organization and expression in Plants, Plenum Press, New York. pp. 175-186.

Baul combe, D.C. and J.L. Key. 1980. Polyadenylated RNA sequences which are reduced in concentration following auxin-treatment of soybean hypocotyls. J. Biol. Chem. 255:8907-8913.

Bayliss, M.H. 1980. Chromosomal variation in plant tissues in 
culture. In I.K. Vasil, ed., Perspectives in Plant Cell and Tissue Culture, Internat. Rev. Cytology, Supp. 11A, Academic Press, New York. pp. 113-144.

Bergmann, L., W. Grosse, and P. Koth. 1976. Influences of ammonium and nitrate on $\mathrm{N}$-metabolism, malate accumulation and malic enzyme activity in suspension cultures of Nicotiana tabacum var. ."Samsun". Z. Pflanzenphysiol . 80:60-70.

Bessemer, J., U. Harden, and J. Reinert. 1969. Der Einfluss von Kinetin and Gibberellinsaure auf die Oganbildung an in vitro Kultivierten Blattern von Chichorium intybus L. Z. Pflanzenphysiol. $60: 123-134$.

Bevin, M. and D.H. Northcote. 1981a. Subculture-induced protein synthesis in tissue cultures of Glycine max and Phaseolus vulgaris. Planta 152:24-31.

Bevin, M. and D.H. Northcote. 1981b. Some rapid effects of synthetic auxins on mRNA levels in cultured plant cells. Planta $152: 32-35$.

Bick, M.D., H. Liebke, J.H. Cherry, and B.L. Strehler. 1970. Changes in leucyl- and tyrosyl-tRNA of soybean cotyldons during plant growth. Biochim. Biophys. Acta 204:175-182.

Binding, H., R. Nehls, R. Kock, J. Finger, and G. Mordhorst. 1981. Comparative studies on protoplast regeneration in herbaceous species of the Dicotyledonae class. Z. Pflanzenphysiol. 101:119-130. 
Bourgin, J.P., Y. Chupeau, and C. Missonier. 1979. Plant regeneration from mesophyll protoplasts of several Nicotiana species. Physio1. Plant. 45:288-292.

Brown, D.C., D.W.M. Leung, and T.A. Thorpe. 1979. 0smotic requirement for shoot fomation in tobacco callus. Physiol. Plant. $30: 36-41$.

Brown, D.C.W. and T.A. Thorpe. 1980. Adenosine phosphate and nicotianamide adenine dinucleotide pool sizes during shoot initiation in tobacco callus. Plant Physiol. 65:587-590.

Bruinsma, J. 1963. The quantitative analysis of chlorophylls a and $b$ in plant extracts. Photochem. Photobiol 2:241-249.

Bui Dang Ha, D., B. Norreel; and A. Masset. 1975. Regeneration of Asparagus officinalis $L$. through callus cultures derived fram protoplasts. J. Exp. Bot. 26:263-270.

Butenko, R.G. 1971. Cell differentiation in tobacco tissue culture. Coll. internat. C.N.R.S. 193:155-161.

Cameron, A.C., C.A.L. Fenton, Y.Yu, D.0. Adams, and S.F. Yang. 1979. Stimulation of ethylene production in plant tissues by 1 aminocyclopropane-1-carboxyl ic acid. Hort. Science 14:178:180.

Capdevila, A.M. and Dure III, L. 1977. Developmental biochemistry of cottonseed embryogenesis and gemination. VI11. Free amino acid pool composition during cotyledon development. Plant Physiol. $59: 268-273$. 
Carpenter, W.J.G. and J.H. Cherry. 1966. Effects of benzyladenine on accumulation of ${ }^{32} p$ into nucleic acids of peanut cotyledons. Biochim. Biophys. Acta 114:640-662.

Carter, 0., Y. Yamada, and E. Takahashi. 1967. Tissue culture of oats. Nature 214:1029-1030.

Chand, S. and S.C. Roy. 1981. Induction of organcgenesis in callus cultures of Nigella sativa. Ann. Bot, 48:1-4.

Chang, W. and Y Hsing. 1978. Callus formation and regeneration of frond-like structures in Lemna perpusilla 6746 on a defined medium. Plant Sci. Lett. 13:133-136.

Chaturvedi, H.C., A.R. Chowdhury, and G.C. Mitra. 1974a. Morphoenesis in stem-callus tissue of Citrus grandis in long-term cultures- a biochenical analysis. Current Sci. 43:139-142.

Chaturvedi, H.C., A.R. Chowdhury, and G. C. Mitra. 1974b. Shootbud differentiation in stem callus tissue of Citrus grandis and correlated changes in its free amino acid content. Current Sci. $43: 536-537$.

Chen, Y-M, C-Y Lin, H. Chang, T.J. Guilfoyle, and J.L. Key. 1975. Isolation and purification of nuclei from control and auxin-treated soybean hypocotyls. Plant Physiol. 56:78-82.

Cheng, T-Y and H.H. Smith, 1975. Organogenesis from callus cultures of Hordeum vulgare. Planta 123:307-310. 
Cheung, G.P., Y. Rosenblum, and H.J. Sallach. 1968. Comparative studies of enzymes related to serine metabolism in higher plants. Plant Physiol . 43:1813-1820.

D'Amato, F. 1977. Cytogenetics of differentiation in tissue and cell cultures. In J. Reinert and Y.P.S. Bajaj, eds., Plant Cell, Tissue, and Organ Culture, Springer-Verlag, New York. Pp. 343-357.

de la Burde, R., E. H. Poindexter, and J.P. Bell. 1964. The distribution of amino acids in tobaccos from different stalk regions. Tobacco Sci. 8:26-32.

Dickson, R.E. 1979. Analytical procedures for the sequential extraction of ${ }^{14} \mathrm{C}$-labeled constituents from leaves, bark, and wood of cottonwood plants. Physiol. Plant. 45:480-488.

Engvild, K.C. 1973. Shoot differentiation in callus cultures of Datura inoxia. Physiol. Plant. 28:155-159.

Earle, E.D. and R.W. Langhaus. 1974. Propagation of Chrysanthemum in vitro: Multiple plantlets from shoot tips and establishment of tissue cultures. J. Am. Soc. Hort. Sci. 99:128-132.

Earle, E.D. and J.G. Torrey. 1965. Morphogenesis in cell colonies grown from Convovulus cell suspensions plated on synthetic media. Am. J. Bot. 53:850-859.

Effer, W.R. and S. L. Ranson. 1967. Respiratory metabolism in buckwheat seedlings. Plant Physiol . 42:1042-1052.

Erner, Y., O. Reuveni, and E.E. Goldschmidt, 1975. Partial 
purification of a growth factor from orange juice which affects citrus tissue culture and its reflacement by citric acid. Plant Physiol. $56: 279-282$.

Fosket, D.E., and D.A. Tepfer. 1978. Homonal regulation of growth in cultured plant cells. In Vitro $14: 63-75$.

Fosket, D.E., M.J. Volk, and M. Goldsmith. 1977. Polyribosome fomation in relation to cytokinin-induced cell division in suspension cultures of Glycine max. Plant Physiol . 60:554-562.

Fridborg, G. 1971. Growth and organogenesis in tissue cultures of Allium cepa var. proliferum. Physiol. Plant. 25:436-440.

Galston, A.W., J. Bonner, and R.S. Baker. 1953. Flavoprotein and peroxidase as components of the indoleacetic acid oxidase system of peas. Arch. Biochem. Biophys. 42:456-470.

Gamborg, 0.L., F. Constabel, and J.P. Shyluk, 1974. Organogenesis in callus from shoot apices of Pisum sativum. Physiol. Plant. 30:125128.

Gautheret, R.J. 1955. The nutrition of plant tissue cultures. Ann. Rev. Plant Physiol. 6:433-484.

Goldberg, R.A. 1980. Structural gene expression in tobacco. In C.J. Leaver, ed., Gename Organization and Expression in Plants, Plenum Press, New York. pp. 117-126.

Goodwin, P.G. 1978. Phytohomones and growth and development uf organs of the vegetative plant. In D.S. Letham, P.G. Goodwin, and 
T.J.V. Higgins, eds., Phytohomones and Related Compounds- A Comprehensive Treatise, Vol. 2, Elsevier North-Holland, Inc., New York. pp. 31-173.

Goren, R., A. Altman, and I. Giladi. 1979. Role of ethylene in abscisic-acid-induced callus formation from citrus bud cultures. Plant Physiol 63:280-282.

Green, C.E. and R.L. Phillips. 1975. Plant regeneration from tissue cultures of maize. Crop'Sci. 15:417-421.

Green, P.B. 1980. Organoenesis- a biophystcal view. Ann. Rev. Plant Physiol. 31:51-82.

Gresshoff, P.M. 1978. Phytohomones and growth and differentiation of cells and tissues cultured in vitro. In D.S. Letham, P.G. Goodwin, and T.J.V. Higgins, eds., Phytohomones and Related Compounds- A Comprehensive Treatise, Vol. 2, El sevier NorthHoll and, Inc. New York. Pp. 1-29.

Hahlbrock, K. and H. Griesbach, 1979. Enzymic controls in the biosynthesis of lignins and flavonoids. Ann. Rev. Plant Physiol. $30: 105-130$.

Hanes, C.S. and F.A. Isherwood. 1959. Separation of phosphoric esters on the filter paper chromatograms. Nature 164:1107-1112.

Hanson, A.D. and W.D. Hitz. 1982. Metabolic responses of mesophytes to plant water deficits. Arn. Rev. Plant Physiol. 33:163203. 
Hasegawa, P.M., T. Murashige, and J.B. Mudd. 1977. The fate of Ltyrosine-UL- ${ }^{14} \mathrm{C}$ in shoot-forming tobacco callus. Physiol. Plant $41: 223-230$.

Hassig, B.E. and R.E. Dickson. 1979. Starch measurement in plant tissue using enzymatic hydrolysis. Physiol. Plant. 47:151-157.

Heinz, D.J., G.W.P. Gee, and L.G. Nickell. 1969. Chromosome numbers of some saccharum species hybrids and their cell suspension cultures. Am. J. Bot. 56:450-456.

Henke, R.R., M.A. Mansur, and J. Constantin. 1978. Organogenesis and plantlet formation from organ- and seedling-derived callus of rice (Oryza sativa). Physiol. Plant. 44:11-14.

Hi11, G.P. 1967. Morphogenesis in stem-callus of Convolvulus arvensis L. Ann. Bot. 31:437-446.

Hi11, G.P. 1968. Shuot formation in tissue cultures of Chrysanthemum Bronze Prie. Physiol. Plant. 21386-389.

Hussey, G. 1980. In vitro propagation. In O.S. Ingram and J.P. Helgeson, eds, Tissue Culture Methods for Plant Pathologists, Blackwell Scientific Publications, Boston, Mass. pp. 51-61.

Huxter, T.J., T.A. Thorpe, and D.M. Reid. 1981. Shoot initiation in light-and dark-grown tobacco callus: the role of ethylene. Physiol. Plant. 53:319-326.

Jacobsen, U.V. 1977. Regulation of ribonucleic acid metabolism by plant hormones. Annu. Rev. Plant Physiol 28:537-564. 
Kahl, G. 1974. Metabolism is plant storage tissue slices. Bot. Rev. 40:263-314.

Kamada. H. 1979. Effects of exogenously applied growth regulacors and amino acids on the organogenesis in higher plant tissue cultures. Pho Thesis. The University of Tsukuba, Ibaraki, Japan. As cited in Tanimoto and Harada, 1982.

Kaul, K. and P.S. Sarharwa1. 1971. Effects of sucrose and kinetin on growth and chlorophyll synthesis in tobacco tissue cultures. Plant Physiol . 47:6910695.

Kaul, K. and P.S. Sabharwal. 1972. Morphogenetic studies on Haworthia: establishment of tissue cultures and control of differentiation. Am. J. Bot. 59:377-384, 52-58.

Keys, A.J. 1980. Synthesis and interconversion of glycine and serine. In B.J. Miflin, ed., The Biochemistry of Plants, Vol. 5, Academic Press, Inc., New York. pp. 359-374.

Kishinami, I. and K. 0jima. 1980. Accumulation of -aminobutyric acid due to adding ammonium or glutamine to cultured rice cells. Plant Cell Physiol. 21:581-590.

Kochhar, T.S., P.R. Bhalla, and P.S.Sabharwal. 1971. Effect of tobacco smoke components on organogenesis in tissue culture. Plant Ce11 Physiol. 12:603-608.

Koiwai, A., M. Noguchi, and E. Tamaki. 1971. Changes in the amino 
acid composition of tobacco cells in suspension culture. Phytochem. $10: 561-566$.

Lang, J.M., W.R. Eisinger, and P.B. Green. 1982. Effects of ethylene on the orientation of microtubules and cellulose microfibrils of Pea epicotyl cells with polylamellate cell walls. Protoplasma

Laties, G.G. 1978. The development and control of respiratory pathways in slices of plant storage organs. In G. Kahl, ed., Biochemistry of wounded plant tissues, Walter de Gruyter, Co., New York. pp. 421-465.

Lance, B., D.M. Reid, and T.A. Thorpe. 1976. Endogenous gibberellins and growth of tobacco callus cultures. Physiol Plant $36: 28-292$.

Larsen, P.O., K.L. Cornwell, S.L. Gee, and J.A. Bassham, 1981. Amino acid synthesis in photosynthesizing spinach cells. Plant Physiol. 68:292-299.

Lawyer, A.L., K.L. Grady, and J.A. Bassham. 1981. Intracellular concentrations and metabolism of carbon compounds in tobaccc callus cultures: effects of light and auxin. Plant Physiol. 68:857-864.

Lee, T.H., W.B. McGlasson, and R.A. Edwards. 1970. Physiology of disks of irradiated tomato fruits. 1. Influence of cutting and infiltration on respiration, ethylene praduction, and ripening. Rad. Bot. 10:521-529. 
Lee, T.T. 1971. Cytokinin-controlled indoleacetic acid oxidase isoenzymes in tobacco callus cultures. Plant Physiol 47:181-185.

Lee, T.T. and F. Skoog. 1965a. Effects of substituted phenols on bud formation and growth of tobacco tissue cultures. Physiol. Plant. $18: 388-402$.

Lee, T.T. and F. Skoog. 1965b. Effects of hydroxybenzoic acids on indoleacetic acid inactivation by tobacco callus extracts. Physiol. Plant. 18:577-585.

Lehninger, A.L. 1975. Biochenistry, 2nd Ed. Worth Publishers, Inc. New York.

Letham, D.S. 1974. Regulators of cell division in plant tissues. $\mathrm{XX}$. The cytokinins of coconut milk. Physiol. Plant. 32:66-70.

Linsmaier, E.M. and F. Skoog. 1965. Organic growth factor requirements of tobacco tissue cultures. Physiol. Plant. 18:100-127.

Lisada, C.C. and S.F. Yang. 1979. A simple and sensitive assay for 1-aminocyclopropane-1-carboxylic acid. Anal. Biochen. 100:140-145.

Loewenberg, J.R. 1965. Promotion of indoleacetic acid destruction by citric acid and L-alanine. Physiol. Plant. 18:31-40.

Lu, C. and I.K. Vasil. 1982. Somatic embryogenesis and plant regeneration in tissue cultures of Panicum maximum Jacq. Am. J. Bot. $69: 77-81$. 
Maass, H. and D. Klambt. 1977. Cytokinin effect on protein synthesis in vivo in higher plants. Planta 133:117-120.

Mader, M., P. Munch, and M. Bopp. 1975. Regulation und Bedeutung der Peroxidase-Musteranderungen in Sprosdifferenzierendum Kalluskul turen von Nicotiana tabacum L. Planta 123:257-265.

Maeda, E. and T.A. Thorpe. 1979. Shoot histogenesis in tobacco callus cultures. In Vitro 15:415-424.

Marcelle, R. 1970. Effets de l'gibberelline et des frei nants, phosphon $D$ et CCC, sur la bougeonnement ephiphylle chez Bryophyllum tubiflorum Harv. Physiol. Veg. 8:125-133.

Masteller, V.J. and D.J. Holden. 1970. The growth of and organ formation from callus tissue of sorghum. Plant Physiol. 45:362-364.

McCoy, T.J., R.L. Phillips, and H.W. Rines, 1982. Cytogenetic analysis of plants regenerated from oat (Avena sativa) tissue cultures; high frequency of partial chramosame 10ss. Can. J. Genet. Cytol . 24:37-50.

Meijer, E.G.M. and W.J. Broughton. 1981. Regenerationn of whole plants from hypocotyl-, root-, and leaf-derived tissue cultures of the pasture legume Stylosanthes guyanesis. Plant Physiol. 52:280-284.

Miller, C.O. and F. Skoog. 1953. Chemical control of bud formation in tobacco sten segments. Am. J. Bot. 40:768-773.

Miller, C.O., F. Skoog, F.S. Okumura, M.H. vonSaltza, and F.M. Strong. 1955a. Structure and synthesis of kinetin. J. Am. Chem. Soc. 
$77: 2262-2263$.

Miller, C.0., F. Skoog, F.S. Okumura, M.H. vonSaltza, and F.M. Strong. 1955b. Isolation, structure, and synthesis of kinetin, a substance promoting cell division. J. Am. Chem. Soc. 78:1375-1380.

Miller, C.0., F. Skoog, M.H. vonSaltza, and F.M. Strong. 1955. Kinetin, a cell division factor from deoxyribonuclefc acid. J. Am. Chem. Soc. 77: 1392.

Moiseeva, N.A., A.D.Volodarsski, and R.G. Butenko. 19?9. Clarification of tobacco stem meristem marker antigens. Sov. Plant Physiol. 26:381 -386.

Montague, M.J., J.W. Koppenbrink, and E.G. Jaworski. 1978. Polyamine metabolism in embryogenic cells of Daucus carota. I. Changes in intracellular content and rates of synthesis. Plant Physiol. 62:430-433.

Montague, M.J., T.A. Armstrong, and E.G. Jaworski. 1979. Polyamine metabolism in embryogenic cells of Daucus carota. II. Changes in arginine decarboxylase activity. Plant Physiol. 63:341345.

Muir, W.H. 1963. Influence of variation in chromosome number on differentiation in plant tissue cultures. In $R$. White and $A, R$. Grove, eds., Proc. of an International Conference on Plant Tissi- Culture, McCutchan Pub. Corp., Berkeley, CA. pp. 485-492.

Murashige, T. 1964. Analysis of the inhibition of organ formation 
in tobacco tissue culture by gibberellin. Physiol. Plant. 17:636-643.

Murashige, T. 1974. Plant propagation through tissue culture. Annu. Rev. Pl. Physiol . 25:135-166.

Murashige, T. and R. Nakano. 1967. Chromosome complement as a determinant of the morpphogenic potential of tobacco cells. Am. $\mathrm{J}$. Bot. 54:963-970.

Murashige, T. and F. Skoog. 1972. A revised medium for rapid growth and bio assays with tobacco tissue cultures. Physiol. Plant. $15: 473-497$.

Murashige, T. and D.F.4. Tucker. 1969. Growth factor requirements of citrus tissie culture. Proc. First Int. Citrus Symp. 3:1155-1161. Cited in Erner, et.al. (1975).

Nakano, H. and E. Maeda. 1979. Shoot differentiation in callus of Orzya sativa L. Z. Pflanzenphysiol. 93:449-458.

Narayanaswamy, S. 1977. Regeneration of plants from tissue cultures. In J. Keinert and Y.P.S. Bajaj, eds., Plant Cell, Tissue and Organ Culture, Springer-Verlag, New York. pp. 179-248.

Negruti, I., M. Jacobs, and D. Bachita. 1978. Some factors controlling in vitro morphogenesis of Arabidopsis thaliana. $Z$. Pflanzenphysiol. 86:113-124.

Nehls, R. 1978. Isolation and regeneration of protoplasts from Solanum nigrum. Plant Sci. Lett. 12:183-187. 
Nishi, T., Y. Yamada, and E. Takahashi. 1968. Organ redifferentiation and plant restoration in rice callus. Nature 219:508-509.

Nitsch, C. and J.P. Nitsch. 1967. The induction of flowering in vitro in stem segments of Plumbago indica L. I. The production of vegetative buds. Planta $72: 355-370$.

Noguchi, M., K. Yamanoto, and E. Tamaki. 1961. Studies on the nitrogen metabolism in tobacco plants. A. Nitrogenous compounds in the tobacco sap. Agric. Biol. Chem. 25:626-631.

Oswald, T.H., A.E. Smith, and D.V. Phillips. 1977. Callus and plantlet regeneration from cell cultures of ladino clover and soybean. Physiol. Plant. 39:129-134.

Palmer, C.E. 1976. ACP-glucose pyrophosphorlase and UDP-glucose pyrophosphorylase activity in callus tissue during shoot initiation and callus growth. Z. Pflanzenphysiol . 77:345-349.

Patterson, B.D. and A.J. Trewayas. 1967. Changes in the pattern of protein synthesis induced by 3-indoleacetic acid. Plant Physiol. $42: 1081-1086$.

Paulet, P. and J.P. Nitsch. 1959. Stimulation chimique de bourgeonnement chez Cardamine pratensis L. Bull. Soc. Bot. Fr. 106:425-441. Cited in K.C. Engvild (1973).

Pedersen, T.A., M. Kirk, and J.A. Bassham. 1966. Light-dark transients in levels of intermediate compounds during photosynthesis 
in air-adapted Chlorella. Physiol. P1ant. 19:219-231.

Perdrizet, E. and J. Prevost. 1981. Al iphatic and aromatic amines during development of tobacco. Phytochem. 20:2131-2134.

Pillai, A.S. and A.C. Hildebrandt. 1969. Induced differentiation of geranium plants from undifferentiated callus in vitro. Am. J. Bot. 56:

Plumb-Dhindsa, P.L., R.S. Dhindsa, and T.A. Thorpe. 1979. Nonautotrophic $\mathrm{CO}_{2}$ fixation during shoot formation in tobacco callus. 1 . Exp. Bot. 30:759-767.

Radjai, M.K. and R.T. Hatch, 1980. Fast determination of amino acids by ion-pair high-performance liquid chromatography using online post-column detivitization. J. Chromatog. 197:319-322.

Raff, J.H., J.F. Hutchinson, R.B. Knox, and A.E. Clark. 1979. Cell recognition: antigenic deteminants of plant organs and their cultured callus cells. Differentiation 12:179-186.

Rangan, T.S. 1974. Morphogenic investigations on tissue cultures of Panicum miliaceum. Z. Pflanzenphysiol. 72:456-459.

Rao, P.S. and S. Narayanaswami. 1968. Induced morphogenesis in tissue cultures of Solanum xanthocarpum. Planta 81:372-375.

Raschke, K. 1975. Stomatal action. Ann. Rev. Plant Physiol. $26: 309-340$.

Reinert, J. and Y.P.S. Bajaj. 1977, Aspects of organization- 
organogenesis, embryogenesis, and cytodifferentiation. In H.S. Street, Plant Tissue and Cell Culture. 2nd Ed., Univ. of Calif. Press, Berkeley. pp. 389-427.

Ross, M.K. and T.A. Thorpe, 1973. Physiological gradients and shoot initation in tobacco callus cultures. Plant Cell Physiol. 14:473-480.

Ross, M.K., T.A. Thorpe, and J.W. Costerton. 1973. U1trastructural aspects of shoot-initiation in tobacco callus cultures. An. J. Bot. 60:788-795.

Roth, M. 1971. Fluoresence reaction for amino acids. Anal. Chem. 43:880-882.

Sacristan, M.D. and G. Melchers. 1969. The caryological analysis of plants regenerated from tumorous and other callus cultures of tobacco. Mol. Gen. Genet. 105:317-333.

Saltviet, M.E. and D.R. Dflley. 1978. Rapidly induced wound ethylene from excized segments of etiolated pisum sativum L., cV. Alaska. 1. Characterization of the response. Plant Physiol. 61:447450.

Sargent, J.A. and F. Skoog. 1960. Effects of indoleacetic acid and kinetin as scopoletin-scopolin levels in relation to growth of tobacco tissues in vitro. Plant Physiol. 35:934-941.

Saunders, J.W. and E.T. Bingham. 1975. Growth regulator effects on bud initiation in callus cultures of Medicago sativa. Am. J. Bot. 
62:654-659.

Schneider, M.J., J.C.J. Lin, and F. Skoog. 1969. Nucleic acid metabolism during cytokinin-induced cellular differentiation. Plant Physiol . 44:1207-1210.

Schraudol $\tilde{F}, \mathrm{H}$. and J. Reinert. 1959. Interaction of plant growth regulators in regeneration processes. Nature 184:465-466.

Scott, K.J., ¿. Daly, and H.H. Smith. 1964. Effects of indoleacetic acid and kinetin on activities of enzymes of the hexose monophosphate shunt in tissue cultures of tobacco. Plant Phystol. 39:709-711.

Seeni. S. and A. Gnanam. 1981. Isozymes of glucose-6-phosphate dehydrogense and $\mathrm{NAO}^{+}$-malate dehydrogenase in shoot-foming foliar discs of tobacco. P1ant Ce11 Physiol. 22:969-977.

Sekiya, J. and Y. Yamada. 1978. DNA-dependent RNA polymerase II from 3 types of tobacco cells cultured in vitro. Agric. Biol. Chem. 42: 485-486.

Sen, K., M.M. Choundhuri, and B. Ghosh. 1981. Changes in polyamine contents during development and gemination of rice seeds. Phytochen. 20:631-633.

Shantz, E.M. and F.C. Steward, 1955. The identification of compound A from coconut milk as 1,3-diphenylurea. J. Am. Chem. Soc. $77: 6351-6353$.

Sharp, W.R., L.S. Caldas, 0. Crocomo, L. Monaco, and A. Carvalho. 
1973. Production of Coffee arabica callus of three ploidy Tevels and subsequent morphogenesis. Phyton 31:67-74.

Shepard, J.F. and R.E. Totten. 1977. Mesophyll cell protoplasts of potato. Isolation, proliferation, and plant regeneration. Plant Physiol. 60:313-316.

Short, K.C., D.A. Tepfler, and D.E. Fosket. 1974. Regulation of polyribosome fomation and cell division in cultured soybean cells by cytokinin. J. Cell Sci. 15:75-87.

Skokut, T.A., C.P. Wolk, J. Thomas, J.C. Meeks, and P.W. Shaffer. 1978. Initial organic products of assimilation of $\left[{ }^{13} \mathrm{~N}\right]$ ammonium and $\left[{ }^{13} \mathrm{~N}\right]$ nitrate by tobacco cells cultured on different sources of nitrogen. Plant Physiol. 62:?99:304.

Skoog, F. 1944. Growth and organ formation in tobacco tissue cultures. Am. J. Bot. 31:19-24.

Skoog, F. and C.0. Miller. 1957. Chemical regulation of ogan formation in plant tissues cultured in vitro. Symp. Soc. Exptl. Biol. 11:118-131. Reprinted in W.M. Laetsch and R.E. Cleland. 1967. Papars on Plant Growth and Development, Little Brown and Co., Boston.

Skoog, F. and E. Montaldi. 1961. Auxin-kinetin interactions regulating the scopoletin-scopolin levels in relation to growth of tobacco tisues in vitro. Plant Physiol. 35:934-941.

Skoog, F., F.M. Strong, and C.0. Miller. Cytokinins. Science 148:5 32 . 
Skoog, F. and C. Tsui. 1948. Chemical control of growth and bud formation in tobacco stem segments and callus cultured in vitro. Am. J. Bot. 35: 782-787.

Skoog, F. and C. Tsui. 1951. Growth substances and the formation of buds in plant tissues. In F. Skoog, ed, Plant Growth Substances. Univ. of Wisc. Press, Madison. pp. 263-285.

Springer, W.D., C.E. Green, and K.A. Kohn. 1979. A histological examination of tissue culture initiation from immature embryos of maize. Protoplasma 101:269-281.

Stetler, D.A. and W.M. Laetsch. 1965. Kinetin-induced chloroplast maturation in cultures of tobacco tissue. Science 149:1387-1388.

Stewart, G.R. and F. Lahrer. 1980. Accumulation of amino acids and related compounds in relation to environmental stress. In B.J. Miflin, ed., The Biochemistry of Plants, Vol. 5, Acadenic Press, Inc., New York. pp. 609-935.

Straus, J. 1962. Invertase in cell walls of plant tissue cultures. Plant Physiol. 37:342-348.

Streeter, J.G. and J.F. Thompson. 1972. Anaerobic accumulation of $\gamma$-aminobltyric acid and alanine in radish leaves (Raphanus sativus) $L$. Plant Physiol. 49:572-578.

Sunderland, N. and B. Wells. 1978. Plastid structure and development in green callus tissues of 0xalis dispar. Ann. Bot. $32: 327-346$. 
Syono, K. 1965. Physiological and biochemical changes of carrot root callus during successive cultures. Plant Cell Physiol . 6:371-392.

Tabata, M., H. Yamamota, H. Hiraoka, Y. Marumoto and M. Konoshima. 1971. Regulation of nicotine production in tobacco tissue cultures by plant growth regulators. Phytochem. 10:723-729.

Tanimoto, S. and H. Harada. 1982. Studies on the initial process of adventitious bud differentiation in Torenia stem segments cultured in vitro. 1. Effects of Cytokinin. Biochem. Physiol. Pflanzen 177:222-228.

Tepfer, D.A. and D.E. Fosket. 1978. Hormone-mediated translational control of protein synthesis in cultured cells of Glycine max. Dev. Bior. 62:486-497.

Thorpe, T.A. 1974. Carbohydrate availability and shoot formation in tobacco callus cultures. Physiol. Plant. 30:77-81.

Thorpe, T.A. 1980. Organogenesis in vitro: structural, physiologicail, and biochemical aspects. In I.K. Vasil, ed., Perspectives in 'llant Cell and Tissue Culture, Internat. Rev. of Cytology, Supplement 11A, Academic Press, New York. pp.71-111.

Thorpe, T.A. and T. Gaspar. 1978. Changes in isoperoxidases during shoot formation in tobacco cells. In Vitro. 14:522-526.

Thorpe, T.A. and E.J. Laishey. 1973. Glucose oxidation during shoot initiation in tobacco callus cultures. J. Exp. Bot. 24:10821089. 
Thorpe, T.A. and D.D. Meier. 1972a. Starch metabolism, respiration and shoot-fomation in tobacco callus cultures. Physiol. Plant. 27:365-369.

Thorpe, T.A. and D.D. Meier. 1972b. Sucrose metabolism during tobacco callus growth. Physiol. Plant. 27:365-369.

Thorpe, T.A. and D.D. Meier. 1973. Effect of gibberellic acid and abscisic acid on shoot formation in tobacco callus cultures. Physiol. Plant. 29:121-124.

Thorpe, T.A. and T. Muraśhige. 1968. Starch accumulation in shoot-forming tobacco call us cultures. Science 160:421-422.

Thorpe, T.A. and T. Murashige, 1970. Some histochemical changes underlying shoot initiation in tobacco callus cultures. Can. J. Bot. $48: 277-285$.

Torrey, J.G. 1966. The initiation of organized development in plants. Adv. Morpho. 5:39-91.

Torrey, J.G. 1967. Morphogenesis in relation to chromosomal constitution in long-term plant tissue cultures. Physiol. Plant. $20: 265-275$.

Tran Thanh Van, K.M. 1981. Contral of morphogenesis in in vitro cultures. Annu. Rev. P1 ant Physiol. 32:291-311.

Tyron, $K$. 1955. Scopoletin in diferentiating and nondifferentiating cultured tobacco tissue. Science 123:590. 
van Staden, J. and S.E. Drewes. 1975. Identification of zeatin and zeatin riboside in coconut milk. Physiol. Plant. 36:106-109.

Vasil, I.K. 1981. Plant cell culture and somatic cell genetics of cereals and grasses. Plant Molecular Biology Newsletter 2:9-23.

Vasil, I.K. and A.C. Hildebrandt. 1966. Variattons of morphogenetic behavior in plant tissue cultures. I. Cichorium endiva. Amer. J. Bot. 53:860-869.

Vasil, V. and I.K. Vasil. 1981. Somatic enbryogenesis and plant regeneration from tissue cultures ofpennisetum americanum and $\underline{P}$. americanum $\times$. purpureum hybrid. Am, J. Bot. 68:864-872.

Walker, K.A., P.C. Yu, S.J. Sato, and E.G. Jaworski. 1978. The hormonal control of organ formation in callus of Medicago sative L. cultured in yitro. Am. J. Bot. 62:654-659.

Waller, G.R. and E.K. Nowacki. 1978. Alkaloid biology and metabolism in plants. Chapter 4. Plenum Press, New York. pp. 121-141.

White, P.R. 1939. Controlled differentiation in a plant tissue culture. Bul1. Torrey Bot. Club 66:507-513. Cited tn P.R. White. 1943. Handbook cf Plant Tissue Culture. Jaques Cattell Press, Lancaster, PA. pp. 209-226.

Wolter, K.E. 1968. Root and shoot initiation in aspen callus cultures. Nature 219:509-510.

Wolter, K.E. and J.C. Gorden. 1975. Peroxidases as indicators of growth and differentiation in aspen callus cultures. Physiol. Plant. 
J.S. Wrench, L.C. Brady, and R.K. Hinde. 1980. Interaction of slicing and osmotic stress on proline metabolism in jerusalem artichoke tuber tissue. Aust. J. Plant Physiol. 7:149-157.

Yeoman, M.M. and A.J. Macleod. 1977. Tissue (callus) culturestechniques. In H.S. Street, ed., Plant Tissue and Cell Culture, 2nd Ed., Univ. of Calif. Press, Berkeley. pp. 31-59.

Yie, S-T., and S.I. Liaw. 1977. Plant regeneration from shoot tips and callus of papaya. In Vitro 12:473-478.

Yu, Y., D.O. Adam5, and S.F. Yang. 1979. Regulation of auxininduced ethylene production in mung bean hypocotyls. Flant Physiol. $63: 589-590$.

Yu, Y. and S.F. Yang. 1979. Biosynthesis of wuund ethylene. Plant Physiol. 66:281-285.

Zobel, R.W., and L. W. Roberts. 1978. Effects of low concentrations of ethylene on cell division and cytodifferentiation of lettuce pith explants. Can. J. Bot. 56:987-990.

Zurfluh, L.L. and T.J. Guilfoyle. 1980. Auxin-induced changes in the patterns of protein synthesis in soybean hypocotyls. Proc. Nat. Acad. Sci, USA. 77:357-361.

Zurfluh, L.L. and T.J. Guilfoyle. 1982a. Auxin-induced changes in the population of translatable messenger RNA in elongating sections of soybean hypocotyl. Plant Physiol. 69:332-337. 
Zurfluh, L.L. and T.J. Guil foyle. 1982b. Aux in- and ethyleneinduced changes in the population of translatable messenger RNA in basal sections and intact soybean hypocotyl. Plant Physiol. 69:338340 . 